Universidade de São Paulo

Instituto de Física

\title{
Estudo de propriedades de nuvens no contexto de sensoriamento remoto com satélites usando códigos de transferência radiativa
}

\author{
Marina Monteiro Mendonça
}

Orientador: Prof. Dr. Alexandre Lima Correia

Dissertação de mestrado apresentada ao Instituto de Física como requisito parcial para a obtenção do título de Mestre em Ciências.

Banca Examinadora:

Prof. Dr. Alexandre Lima Correia (IF/USP)

Dra. Elisa Thomé Sena (IAG/USP)

Prof. Dr. Theotonio Mendes Pauliquevis Júnior (ICAQF/UNIFESP)

São Paulo

2017 


\section{FICHA CATALOGRÁFICA}

Preparada pelo Serviço de Biblioteca e Informação do Instituto de Física da Universidade de São Paulo

Mendonça, Marina Monteiro

Estudo de propriedades de nuvens no contexto de sensoriamento remoto por satélites usando códigos de transferência radiativa.

São Paulo, 2017.

Dissertação (Mestrado) - Universidade de São Paulo. Instituto de Física. Depto. de Física Aplicada.

Orientador: Prof. Dr. Alexandre Lima Correia

Área de Concentração: Física Atmosférica.

Unitermos: 1. Códigos de transferência radiativa; 2. Sensoriamento remoto; 3. Nuvens; 4. Atmosfera.

USP/IF/SBI-089/2017 


\title{
University of São Paulo \\ Physics Institute
}

\section{Study of properties of clouds in the context of remote sensing using radiative transfer codes}

\author{
Marina Monteiro Mendonça
}

Advisor: Prof. Dr. Alexandre Lima Correia

Dissertation submitted to the Physics Institute of the University of São Paulo in partial fulfillment of the requirements for the degree of Master of Science.

Examining Committee:

Prof. Dr. Alexandre Lima Correia (IF/USP)

Dr. Elisa Thomé Sena (IAG/USP)

Prof. Dr. Theotonio Mendes Pauliquevis Júnior (ICAQF/UNIFESP) 
Aos Monteiro Mendonça 


\section{Agradecimentos}

Sou uma pessoa de muita sorte e a lista de pessoas a quem sou grata é extremamente extensa, mas tento resumir nas linhas a seguir.

Agradeço à todos os ocupantes da sala 102, Alex, André e, especialmente, a Clarice que puxou minha orelha sempre que necessário (muitas vezes) e foi a melhor companhia nos dias de trabalho e fabricação de placas para as salas. À Elisa, pelos chás, conversas e ajudas com um SBDART temperamental. Mas principalmente pelos chás, claro.

À Márcia Yamasoe, pelas aulas de Radiação, pelos seminários informais e pela ajuda direta (quando travamos um pouquinho) e indireta (quando eu estava escrevendo essa dissertação, especialmente a fundamentação teórica.)

Aos amigos queridos que esse IFUSP me deu. Com destaque especial pro Thales, pra Natasha e pro Kadu, que foram companhias maravilhosas em momentos muito importantes que eles nem sabem.

Aos amigos que torceram para um fim cheio de sucesso desse mestrado para que, assim, eu pudesse marcar uma data para a Paçoca Fest. À Juliana pela ajuda na revisãorelâmpago e pelas sobremesas. Ao Mario Japs Kajiya por toda paciência para me ouvir reclamando e falando empolgadamente sem parar sobre coisas que não são da área dele. À Fefa por me animar com planos pro futuro, por não me deixar desistir e pela promessa de Irish Car Bomb Cupcakes. À Thaís por ser a amiga mais incrível que uma pessoa pode ter e, consequentemente, sendo extremamente compreensiva, paciente e animadora.

Ao Purê, à Canela, à Charlotte, à Nina e à Polenta, ao ar condicionado portátil do quarto e ao Beethoven's Last Night da Trans-siberian Orchestra, que tornam minha vida

algo que vale a pena ser vivido. À Alexandra Elbakyan, fundadora do sci-hub. Ao sci-hub, claro.

Ao Marcelo X-Fernando Alves que emprestou tempo e equipamento para rodar todos os inúmeros scripts que eu precisei rodar e construiu, um tanto mais que indiretamente, para a atração principal deste trabalho, a look-up table. E, além disso, é um amigo maravilhoso e incentivou demais que esse trabalho ficasse bonitinho.

Ao Alexandre, por toda paciência e calma para orientar esse trabalho. Por me explicar tantas coisas e dividir seu conhecimento comigo de uma forma absurdamente generosa, humana, didática e humilde. Por ser um modelo de pessoa que gostaria de ser na 
carreira acadêmica. Por estar sempre disponível, sem me pressionar com exigências que eu não poderia cumprir. Por ter me ensinado durante todo a trajetória deste trabalho e seus muitos títulos. E por ter arriscado voltar ao LaTeX só um pouquinho para comentar este trabalho. Quem sabe logo ele dá ao braço a torcer que as coisas com LaTeX ficam lindas. Ao Diego por todo amor, companheirismo, paciência e inteligência. Por ter me visto nos piores dias e ter me ajudado a enfrentar todos os meus monstrinhos e focar no que realmente precisava de mim. Por ter me visto nos melhores dias e ter me aguentado empolgadíssima mostrando gráficos, escolhendo cores para as séries, explicando diagramas Nakajima-King ou apenas tagarelando sobre nuvens, física, aulas e tudo isso que me faz feliz. Por ter sido o melhor apoio que eu poderia ter tido. Por ter me ajudado a deixar meus códigos mais apresentáveis e eficientes.

Ao Du, por ser um irmão e uma pessoa tão incrível que eu mal tenho palavras pra agradecer. Aos meus pais, por serem os maiores incentivadores de todas as minhas loucuras e tagarelices. Por terem feito o possível e o impossível para que eu estivesse onde estou hoje. Por terem me ensinado a ser a pessoa que sou hoje. Por todas as discussões acaloradas sobre a envergadura terrestre, a borda, terapias quânticas e fabricação de nuvens. Por todas as conversas enriquecedoras sobre todos os assuntos sérios e nem tanto, e por ouvirem extensas explicações sobre nuvem, sobre o sol, sobre gráficos, análises e códigos. Não consigo colocar em palavras o quanto sou agradecida por tudo. (minha família é tão incrível que eu fico mesmo sem palavras)

À CAPES pelo apoio financeiro durante o período de desenvolvimento desta pesquisa (que foi essencial).

E, sem medo de agradecer demais e ser repetitiva: à Clarice Miranda Fiorese Furtado, à Natasha Fioretto Aguero, ao Diego Ernesto Pereyra, ao Mario Hissashi Kajiya e ao Marcelo Barbosa Alves, gostaria de agradecer a força, ajuda, revisão e suporte incríveis durante a reta final. Vocês foram maravilhosos. 


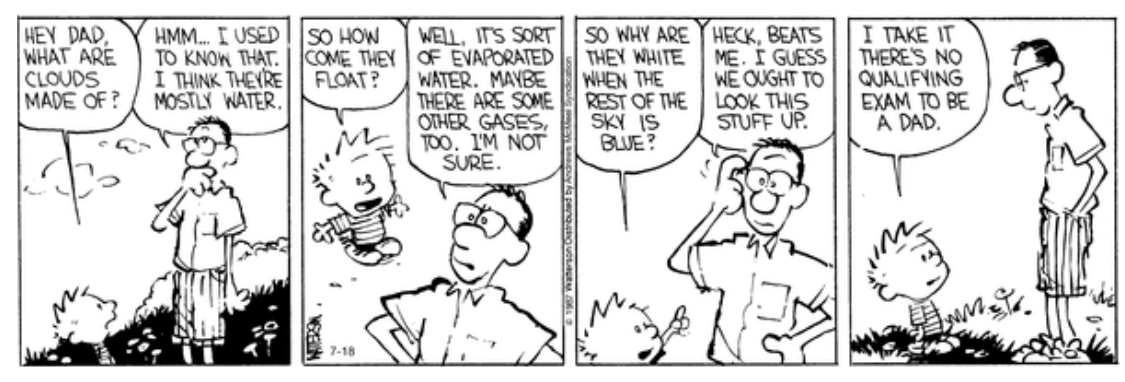





\section{Resumo}

Nuvens desempenham papel fundamental no balanço radiativo terrestre, e o conhecimento de suas propriedades micro e macrofísicas é importante para o estudo do clima global. O desenvolvimento de nuvens está ligado à dinâmica da atmosfera, fluxos de energia térmica e radiativa à superfície, e também depende crucialmente do tamanho de seus hidrometeoros. Uma ferramenta importante para o estudo de hidrometeoros em nuvens de grande escala é o sensoriamento remoto por satélite, que representa uma alternativa para se estudar propriedades de nuvens em grandes escalas espaciais. No entanto, atualmente não há estudos para subsidiar análises de propriedades microfísicas de nuvens a partir de plataformas geoestacionárias. Neste trabalho foram comparados dois códigos de transferência radiativa amplamente utilizados pela comunidade científica, SBDART e libRadtran, em simulações considerando variações de propriedades atmosféricas, de superfície, macro e microfísicas de nuvens. Em seguida estudou-se a transferência radiativa em nuvens de água e gelo determinando o impacto simulado de diversas geometrias de iluminação e observação nas radiâncias medidas por sensoriamento remoto. Finalmente, foram desenvolvidas tabelas de referência para a determinação de tamanho de hidrometeoros em nuvens, para fases líquida e sólida, a partir de radiâncias medidas por um sensor em satélite geoestacionário. As comparações entre SBDART e libRadtran mostram resultados sistematicamente subestimados pelo libRadtran. Em um céu sem nuvens a diferença entre as refletâncias calculadas em ambos os modelos é inferior a $4 \%$ quando consideradas variações em albedo de superfície e coluna de ozônio. Em um céu com nuvens a diferença entre os resultados dos modelos para comprimento de onda de $630 \mathrm{~nm}$ e intervalo visível (590 a $660 \mathrm{~nm}$ ) pode chegar até $18 \%$ para variações de profundidade óptica entre 0 e 20. Para profundidade óptica maior que 20 essas diferenças variam entre 4 e $9 \%$, além de refletâncias constantes para o intervalo entre 3850 e $4000 \mathrm{~nm}$ e para comprimento de onda de $3900 \mathrm{~nm}$. A divergência de resultados obtidos pelos dois modelos é atribuída a diferenças estruturais entre os códigos, uma vez que atualmente apenas o libRadtran apresenta atualizações periódicas pela comunidade científica. Assim, este modelo foi utilizado para a construção da tabela de referência simulando medidas de radiâncias em plataforma geoestacionária. A tabela construída compreende 86 valores de raios efetivos de hidrometeoros, variando entre 2 e $59 \mu \mathrm{m}$, com fases termodinâmicas de água e gelo, 16 valores de geometria de observação solar, 3 valores de ângulos de observação, 2 valores de azimute relativo, e condições fixas de profundidade óptica de nuvem de 50, conteúdo integrado de ozônio de 255 DU e $60 M M$ de vapor d'água. Essas condições foram escolhidas como representativas para a região Amazônica. Em um teste de aplicação direta da tabela de referência a medidas de radiância realizadas com satélite geoestacionário foram obtidos raios efetivos entre 2 e $30 \mu \mathrm{m}$ para gotículas de água e até $24 \mu \mathrm{m}$ para cristais de gelo. Os resultados obtidos neste trabalho poderão ser aplicados futuramente a medidas obtidas por plataformas geoestacionárias em estudos de tamanhos de hidrometeoros, tornando possível a análise de sua evolução temporal.

Palavras-chave: códigos de transferência radiativa; sensoriamento remoto; nuvens; atmosfera; 



\begin{abstract}
Clouds play a fundamental role in the terrestrial radiative balance, and knowledge of its micro and macrophysical properties is important for the study of global climate. Cloud development is linked to the dynamics of the atmosphere, thermal and radiative energy flows to the surface, and also depends crucially on the size of its hydrometeors. An important tool for the study of large-scale cloud hydrometeors is satellite remote sensing, which represents an alternative to study cloud properties at large spatial scales. However, there are currently no studies to support analyzes of microphysical properties of clouds from geostationary platforms. In this work, two radiative transfer codes widely used by the scientific community, SBDART and libRadtran, were compared in simulations considering variations of atmospheric, surface, macro and microphysical properties of clouds. Next, radiative transference was studied in water and ice clouds, determining the simulated impact of various lighting and observation geometries on radiances measured by remote sensing. Finally, look-up tables were developed for the determination of the size of hydrometeors in clouds, for liquid and solid phases, from radiances measured by a geostationary satellite sensor. The comparisons between SBDART and libRadtran show results systematically underestimated by the libRadtran. In a cloudless sky the difference between the reflectances calculated in both models is less than $4 \%$ when considering variations in surface albedo and ozone. In a clouded sky the difference between the model results for wavelengths of $630 \mathrm{~nm}$ and the visible range (590 to $660 \mathrm{~nm}$ ) can reach up to $18 \%$ for optical depth variations between 0 and 20. For optical depths greater than 20, these differences range from 4 to $9 \%$, in addition to constant reflections for the range of 3850 to $4000 \mathrm{~nm}$ and for a wavelength of $3900 \mathrm{~nm}$. The divergence of results obtained by the two models is attributed to structural differences between the codes, since currently only the libRadtran presents periodic updates by the scientific community. Thus, this model was used for the construction of the reference table simulating measurements of radiances in geostationary platform. The constructed table comprises 86 values of effective radii of hydrometeors, ranging from 2 to $59 \mu \mathrm{m}$, with thermodynamic phases of water and ice, 14 values of geometry of solar observation, 3 values of angles of observation, 2 relative azimuth values, and fixed cloud optical depth conditions of 50, integrated ozone content of $255 \mathrm{DU}$ and $60 \mathrm{~mm}$ of water vapor. These conditions were chosen as representative for the Amazon region. In a test of direct application of the look-up table to measurements of radiance obtained with geostationary satelite we obtained effective radius up to between 2 and 30 for water droplets and up to 24 for ice crystals. The results obtained in this work can be applied in the future to measurements obtained by geostationary platforms in studies of sizes of hydrometeors, making possible the analysis of their temporal evolution.
\end{abstract}

Keywords: radiative transfer codes; remote sensing; clouds; astmosphere; 



\section{Lista de figuras}

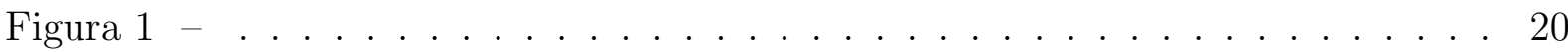

Figura 2 - Irradiância espectral referente à emissão solar, em amarelo, emissão de um corpo negro com $\mathrm{T}=5778 \mathrm{~K}$, na linha preta e irradiância solar à superfície, em vermelho, com as indicações de bandas de absorção gasosa. Traduzido de Beckmann and Spizzichino (1987). . . . . . . . . 21

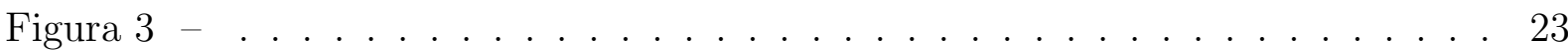

Figura 4 - Diagrama conceitual, de Rosenfeld et al. (2014), descrevendo cinco estágios microfísicos comuns a nuvens convectivas. A curva mais clara representa um ambiente marítimo com baixa concentração de CCN. As curvas intermediária e mais escura (ao topo) indicam, respectivamente, nuvem em ambiente de poluição moderada e extrema. . . . . . . . . . . 24

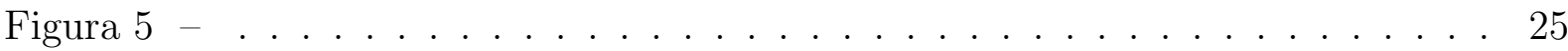

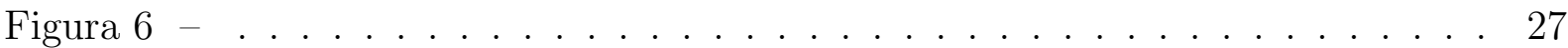

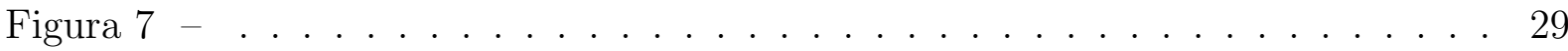

Figura 8 - Ilustração da geometria envolvida na definição de radiância: com visão tridimensional (a) e em um plano vertical (b). (Yamasoe and Corrêa,

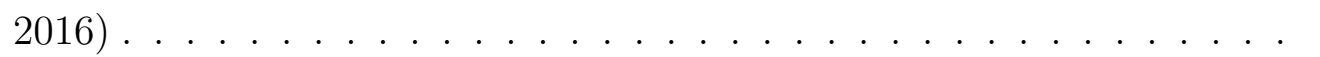

Figura 9 - Espectro de emissão solar em linha cheia, espectro de emissão de um corpo negro com temperatura de 5777K em linha tracejada. (Iqbal, 2012) 35

Figura 10 - Irradiância espectral para um corpo negro de temperatura comparável com a superfície Solar $(6000 \mathrm{~K})$ em preto e com temperatura próxima a terrestre $(350 \mathrm{~K})$ em vermelho. (Sena, 2013) . . . . . . . . . . 36

Figura 11 - Regiões de regime de espalhamento em função do raio da partícula e comprimento de onda. $($ Sena, 2013) . . . . . . . . . . . . 37

Figura 12 - Tipos de espalhamento para (a) partículas de até 1/10 do comprimento de onda incidente, (b) partículas com cerca de 1/4 do comprimento de onda, (c) partículas maiores que o comprimento de onda incidente.

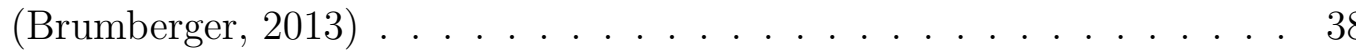


Figura 13 - Função de fase para $\mathrm{m}=1,33+\mathrm{i} 0$; Na linha tracejada $x=0,01$, a linha sólida na parte inferior apresenta $x=1$ e a curva sólida na parte superior $x=50$. (Zdunkowski et al., 2007) . . . . . . . . . . 42

Figura 14 - Representação gráfica para Lei de Beer. (Sena, 2013) . . . . . . . . . . 43

Figura 15 - Representação para interação entre radiação eletromagnética incidente na atmosfera. Adaptado de (Sena, 2013). . . . . . . . . . . . . . . 44

Figura 16 - Fluxograma do algoritmo DISORT, traduzido de (Stamnes et al., 2000). 48

Figura 17 - Diagrama Nakajima-King apresentado em (Nakajima and King, 1990). Refletâncias calculadas para diferentes valores de COD em 0,75 $\mu \mathrm{m}$ e diferentes raios efetivos nos comprimentos de onda $0,75 \mu \mathrm{m}$ e $2,16 \mu \mathrm{m}$. Alguns dados medidos sobre stratocumulus estão sobrepostos ao diagrama.

Figura 18 - Diagrama Nakajima-King apresentado em (Kaufman and Nakajima, 1993). Refletância nos comprimentos de onda $0,64 \mu \mathrm{m}$ e $3,75 \mu \mathrm{m}$ para nuvens em diferentes combinações de profundidade óptica e raio efetivo com ângulo solar zenital de $60^{\circ}$ e ângulo zenital de observação médio de $10^{\circ} \ldots \ldots \ldots \ldots \ldots \ldots$

Figura $19-\ldots \ldots \ldots \ldots \ldots \ldots \ldots \ldots$

Figura 20 - Refletâncias calculadas pelo libRadtran e SBDART para comprimentos de onda de $630 \mathrm{~nm}$ e intervalo VIS (590 - $660 \mathrm{~nm}$ ), à esquerda, e para $3900 \mathrm{~nm}$ e IR (3850 - $4000 \mathrm{~nm})$, à direita, para diferentes valores de albedo de superfície.

Figura 21 - Refletâncias calculadas pelo libRadtran em função das refletâncias pelo SBDART para diferentes valores de albedo de superfície comprimentos de onda de $630 \mathrm{~nm}$ e intervalo VIS (590 - $660 \mathrm{~nm}$ ), à esquerda, e para $3900 \mathrm{~nm}$ e IR (3850 - $4000 \mathrm{~nm})$, à direita.

Figura 22 - Refletâncias calculadas pelo libRadtran e SBDART para comprimento de onda de $630 \mathrm{~nm}$ e intervalo VIS (590 - $660 \mathrm{~nm}$ ), à esquerda, e para $3900 \mathrm{~nm}$ e IR (3850 - $4000 \mathrm{~nm})$, à direita, com diferentes valores para coluna de ozônio. 
Figura 23 - Refletâncias calculadas pelo libRadtran e SBDART para comprimento de onda de $630 \mathrm{~nm}$ e intervalo VIS, com diferentes valores para coluna de ozônio, com ajuste de função $\rho_{l r t}=a \rho_{s b d}+b$ para cada conjunto de dados. $R^{2}>0.99999$ para os dois ajustes. . . . . . . . . . . 66

Figura 24 - Refletâncias calculadas pelo libRadtran e SBDART para diferentes valores de $\mathrm{H}_{2} \mathrm{O}$ na atmosfera: à esquerda, comprimento de onda único de 630nm e intervalo VIS (590 - $660 \mathrm{~nm})$; à direita, comprimento de onda único de 3900nm e IR $(3850-4000 \mathrm{~nm})$. . . . . . . . . . . . . .

Figura 25 - Refletâncias calculadas pelo libRadtran e SBDART com diferentes valores para vapor d'água para comprimentos de onda de $630 \mathrm{~nm}$ e intervalo VIS, à esquerda, e para 3900 $\mathrm{nm}$ e intervalo IR, à direita, com ajuste de função $\rho_{l r t}=a \rho_{s b d}+b$ para cada conjunto de dados. $R^{2}=0.99993$ para todos os ajustes, exceto utilizando o conjunto relativo à $630 n m \ldots \ldots \ldots \ldots$. . . . . . . . . . . . . . . . . . . .

Figura 26 - Refletâncias para 630nm (à esquerda) e no intervalo VIS (590nm a $660 \mathrm{~nm}$ ) (à direita) calculadas pelo SBDART e libRadtran para atmosfera com nuvem, entre 2 e 3km da superfície, considerando diferentes profundidades ópticas (COD) para dois raios efetivos $(5 \mu m$ e $25 \mu m)$.

Figura 27 - Refletâncias, considerando dois raios efetivos $(5 \mu m$ e $25 \mu m)$, pelo SBDART e libRadtran para atmosfera com nuvem, entre 2 e $3 \mathrm{~km}$ da superfície, considerando diferentes profundidades ópticas (COD) para dois comprimentos de onda: $3900 \mathrm{~nm}$, à esquerda, e intervalo IR (3850 $\mathrm{nm}$ a $4000 n m) 5 \mu m$, à direita. . . . . . . . . . . . . . . . .

Figura 28 - Refletâncias calculadas pelo libRadtran e SBDART para comprimentos de onda de $630 \mathrm{~nm}$ e intervalo VIS, calculados para diferentes CODs considerando dois raios efetivos, com ajuste de função $\rho_{l r t}=a \rho_{s b d}+b$ para cada conjunto de dados. $R^{2}>0.99998$ para todos os ajustes . . .

Figura 29 - Refletâncias calculadas pelo libRadtran e SBDART para comprimentos de onda de 3900 $\mathrm{nm}$ e intervalo IR, calculados para diferentes CODs, com ajuste de função $\rho_{l r t}=a \rho_{s b d}+b$ para cada conjunto de dados. À esquerda resultados considerando $r_{e f f}=5 \mu \mathrm{m}$, à direita $r_{e f f}=25 \mu \mathrm{m}$. $R^{2}>0,9999$ para todos ajustes. . . . . . . . . . . . 
Figura 30 - Refletâncias calculadas pelo libRadtran e SBDART para comprimento de onda de 630nm e intervalo VIS, calculados para diferentes albedos de superfície em atmosfera com nuvem de $\mathrm{COD}=50$, com ajuste de função $\rho_{l r t}=a \rho_{s b d}+b$ para cada conjunto de dados. À esquerda resultados considerando $r_{\text {eff }}=5 \mu \mathrm{m}$, à direita $r_{\text {eff }}=25 \mu \mathrm{m} . R^{2}>0,9999$ para todos ajustes. . . . . . . . . . . . . . . . . . 73

Figura 31 - Diagrama Nakajima-King com valores de referência, retirados de Kaufman and Nakajima (1993), em preto, com valores obtidos através do SBDART em azul e do libRadtran em verde. . . . . . . . . . . . . . 74

Figura 32 - Refletâncias no topo da atmosfera, para o canal 1, em função do raio efetivo em nuvens de água com espessuras de 2,3 e $4 \mathrm{~km}$. . . . . . . 78

Figura 33 - Refletâncias no topo da atmosfera, para o canal 1, em função do raio efetivo em nuvens de água com topos em 3, 4, 5 e $6 \mathrm{~km}$. . . . . . . . 79

Figura 34 - Correção a ser aplicada na refletância de referência em função do topo de nuvem de água . . . . . . . . . . . . . . . . . 8 80

Figura 35 - Refletâncias, para o canal 2, no topo da atmosfera em função do raio efetivo em nuvens de água com topos em $3,4,5$ e $6 \mathrm{~km}$. . . . . . . . 80

Figura 36 - Refletâncias calculadas para o canal 1 no topo da atmosfera em função do raio efetivo em nuvens de gelo com topos em $6,7,8$ e $9 \mathrm{~km}$. . . . . . 81

Figura 37 - Correção a ser aplicada na refletância de referência em função do topo de nuvem de gelo. . . . . . . . . . . . . . . . . . . . . 82

Figura 38 - Raio efetivo em função de refletância no canal 2 para $S Z A=0^{\circ}, 30^{\circ} \mathrm{e}$ $60^{\circ}$ com $V Z A=20$ para $P H I=30^{\circ}$ à esquerda e $P H I=150^{\circ}$ à direita. 83

Figura 39 - Raio efetivo em função de refletância no canal 2 para $S Z A=0^{\circ}, 30^{\circ} \mathrm{e}$ $60^{\circ} \operatorname{com} V Z A=30$ para $P H I=30^{\circ}$ à esquerda e $P H I=150^{\circ}$ à direita. 84

Figura 40 - Refletância obtida para diferentes SZA versus refletância obtida para $\theta_{0}=0^{\circ}$, com $\theta=30^{\circ}$. Cada ponto representa um raio efetivo calculado. 84

Figura 41 - Refletância obtida para diferentes SZA versus refletância obtida para $\theta_{0}=0^{\circ}, \operatorname{com} \theta=20^{\circ}$. Cada ponto representa um raio efetivo calculado. 85

Figura 42 - Refletância obtida para diferentes SZA versus refletância obtida para $\theta_{0}=0^{\circ}, \operatorname{com} \theta=10^{\circ}$. Cada ponto representa um raio efetivo calculado. 
Figura 43 - Refletância obtida para diferentes raios efetivos em função de $\theta_{0}$, com $\theta=10^{\circ}$ e $\phi=30^{\circ}$ à esquerda, e $\phi=150^{\circ}$ à direita. Os valores para os raios efetivos apresentados são (em $\mu m): 2,5,10,20,30,40$ e 50 . O tom mais escuro inicia em 2 , clareando conforme aumenta $r_{\text {eff }}$. . . . 86

Figura 44 - Refletância obtida para diferentes raios efetivos em função de $\theta_{0}$, com $\theta=20^{\circ}$ e $\phi=30^{\circ}$ à esquerda, e $\phi=150^{\circ}$ à direita. Os valores para os raios efetivos apresentados são (em $\mu m): 2,5,10,20,30,40$ e 50 . O tom mais escuro inicia em 2 , clareando conforme aumenta $r_{\text {eff }} . \ldots 86$

Figura 45 - Refletância obtida para diferentes raios efetivos em função de $\theta_{0}$, com $\theta=30^{\circ}$ e $\phi=30^{\circ}$ à esquerda, e $\phi=150^{\circ}$ à direita. Os valores para os raios efetivos apresentados são (em $\mu m): 2,5,10,20,30,40$ e 50 . O tom mais escuro inicia em 2 , clareando conforme aumenta $r_{\text {eff }} . \ldots 8$

Figura 46 - Raio efetivo em função de refletância no canal 2, para nuvens de gelo, $\operatorname{com} \theta_{0}=0^{\circ}, 30^{\circ}$ e $60^{\circ} \operatorname{com} \theta=10^{\circ}$ para $\phi=30^{\circ}$ à esquerda e $\phi=150^{\circ}$ à direita. . . . . . . . . . . . . . . . . . . . . .

Figura 47 - Raio efetivo em função de refletância no canal 2, para nuvens de gelo, $\operatorname{com} \theta_{0}=0^{\circ}, 30^{\circ}$ e $60^{\circ} \operatorname{com} \theta=20^{\circ}$ para $\phi=30^{\circ}$ à esquerda e $\phi=150^{\circ}$ à direita. . . . . . . . . . . . . . . . . . . . 88

Figura 48 - Raio efetivo em função de refletância no canal 2, para nuvens de gelo, $\operatorname{com} \theta_{0}=0^{\circ}, 30^{\circ}$ e $60^{\circ} \operatorname{com} \theta=30^{\circ}$ para $\phi=30^{\circ}$ à esquerda e $\phi=150^{\circ}$ à direita. . . . . . . . . . . . . . . . . . . . .

Figura 49 - Refletância obtida para diferentes raios efetivos em função de $\theta_{0}$, com $\theta=30^{\circ}$ e $\phi=30^{\circ}$ à esquerda, e $\phi=150^{\circ}$ à direita. Os valores para os raios efetivos apresentados são (em $\mu m): 5,10,20,30,40$ e 50. O tom mais escuro inicia em 2 , clareando conforme aumenta $r_{e f f} . \ldots$.

Figura 50 - Refletância obtida para diferentes raios efetivos em função de $\theta_{0}$, com $\theta=20^{\circ}$ e $\phi=30^{\circ}$ à esquerda, e $\phi=150^{\circ}$ à direita. Os valores para os raios efetivos apresentados são (em $\mu m): 5,10,20,30,40$ e 50. O tom mais escuro inicia em 2 , clareando conforme aumenta $r_{\text {eff }} \ldots$. . . . . 
Figura 51 - Refletância obtida para diferentes raios efetivos em função de $\theta_{0}$, com $\theta=10^{\circ}$ e $\phi=30^{\circ}$ à esquerda, e $\phi=150^{\circ}$ à direita. Os valores para os raios efetivos apresentados são $(\mathrm{em} \mu m): 5,10,20,30,40$ e 50. O tom mais escuro inicia em 2 , clareando conforme aumenta $r_{\text {eff }} \ldots \ldots$. . . . . 90

Figura 52 - Refletâncias em comprimento de onda central em função de refletância em canal, para nuvem de água. À esquerda relação para o intervalo visível e à direita para o infravermelho . . . . . . . . . . . . . . . . . . 92

Figura 53 - Refletâncias em comprimento de onda central em função de refletância em canal, para nuvem de gelo. À esquerda relação para o intervalo visível e à direita para o infravermelho . . . . . . . . . . . . . . . . . . 92

Figura 54 - Diagrama tipo Nakajimka-King para nuvens de água com uso de comprimentos de onda centrais $630 \mathrm{~nm}$ e $3900 \mathrm{~nm} \ldots . . \ldots 93$

Figura 55 - Diagrama tipo Nakajimka-King para nuvens de gelo com uso de com-

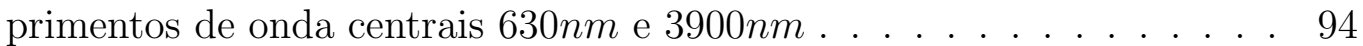

Figura 56 - Região de interesse para determinação de raio efetivo através de dados obtidos pelo GOES-13. O quadrado menor indica a área que possui apenas floresta que foi utilizada. (PugliesiSilva et al., 2017) . . . . . . . 95

Figura 57 - Exemplos de diagramas produzidos por Pugliese Silva et al. (2017). Temperaturas de topo de nuvem em função dos raios efetivos, às 16:00 (horário local), para as três estações determinadas. As curvas nos gráficos representam os três quartis das distribuições de tamanho. (Pugliese Silva et al., 2017) . . . . . . . . . . . . . . . . . 997 


\section{Lista de tabelas}

Tabela 1 - Principais gases presentes na atmosfera seca, sem vapor d'água. Fonte:

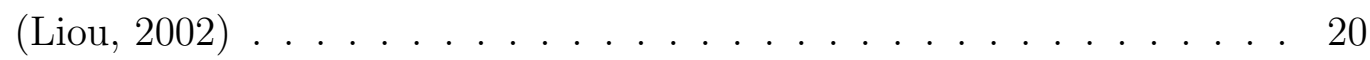

Tabela 2 - Parâmetros usados na comparação entre libRadtran e SBDART (atmosfera sem nuvem) . . . . . . . . . . . . . . . . 62

Tabela 3 - Irradiância direta descendente $\left(W / m^{2}\right)$ para cada intervalo espectral nos modelos testados, com coluna de ozônio 250DU e sem água precipitável 63

Tabela 4 - Coeficientes angular e linear para os ajustes de função $\rho_{l r t}=a \cdot \rho_{s b d}+b$ para os intervalos e comprimentos de onda utilizados. $R^{2}>0,99998$ para todos os ajustes . . . . . . . . . . . . . . . 65

Tabela 5 - Parâmetros usados na comparação entre libRadtran e SBDART (atmosfera com nuvem de água) . . . . . . . . . . . . . . . . . 69

Tabela 6 - Refletâncias calculadas pelo SBDART e libRadtran para o intervalo IR (3850 a $4000 \mathrm{~nm}$ ) e para o comprimento de onda de $3900 \mathrm{~nm}$. . . . . 72 



\section{Sumário}

Introdução . . . . . . . . . . . . . . . . . 19

$1.1 \quad$ Constituintes Atmosféricos . . . . . . . . . . . . . 19

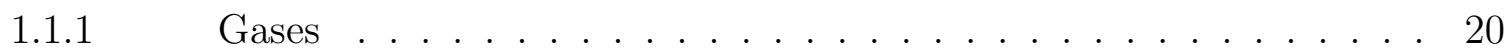

1.1.2 Aerossóis . . . . . . . . . . . . . . . . 22

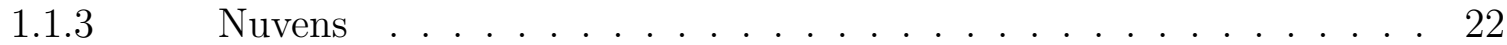

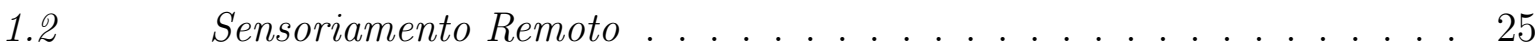

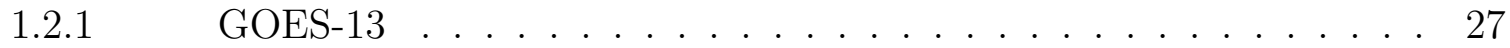

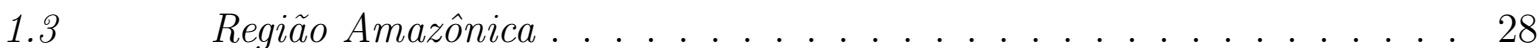

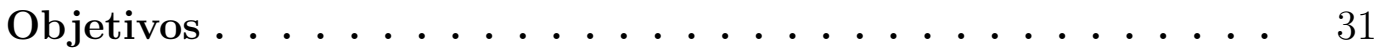

3.1 Radiação de corpo negro e grandezas radiométricas . . . . . . . . . . . 33

3.2 Espectro Solar e Terrestre .................. 35

3.3 Interação Radiação-Atmosfera . . . . . . . . . . . 36

3.3.1 Espalhamento . . . . . . . . . . . . . . 36

3.3.2 Lei de Beer-Lambert-Bouguer e Absorção . . . . . . . . . . . . . . 43

3.3.3 Espessura e Profundidade Óptica . . . . . . . . . . . . . . . . . 43

3.3.4 A Equação de Transferência Radiativa (ETR) para atmosfera planoparalela ........................... 44

3.4 Método numérico de solução da ETR . . . . . . . . . . . 45

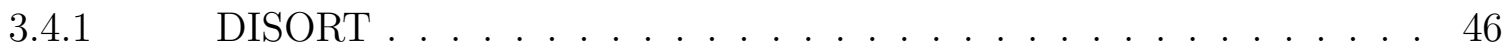

3.5 Propriedades de nuvens no contexto de simulações de transferência radiativa .......................... 47

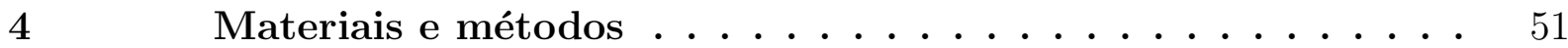

4.1 Modelos de Transferência Radiativa . . . . . . . . . . . . . 51

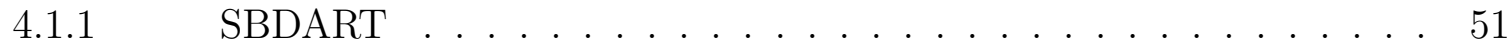

4.1.2 libRadtran . . . . . . . . . . . . . . . . 52

4.2 Diagrama de Nakajima-King . . . . . . . . . . . . 55

$4.3 \quad G O E S-13 \ldots \ldots \ldots \ldots \ldots \ldots \ldots \ldots$ 
Análises propostas neste trabalho . . . . . . . . . . . . . 58

4.4.1 Análise comparativa e validação do libRadtran . . . . . . . . . 58

$4.4 .2 \quad$ Estudo do libRadtran . . . . . . . . . . . . . . 58

4.4.3 Tabela de referência $\ldots \ldots \ldots \ldots$

Resultados ...................... 6 61

Superfície e gases . . . . . . . . . . . . . . . 63

5.1.3 Comparação com Kaufman-Nakajima . . . . . . . . . . . . . . 74

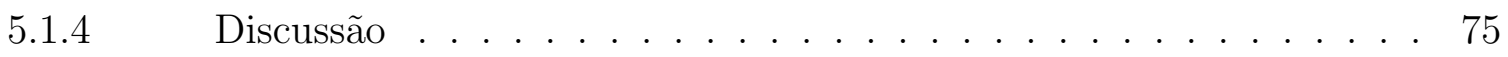

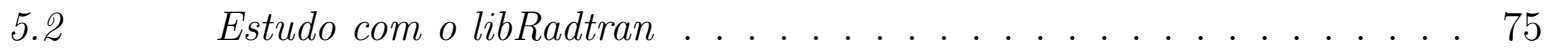

5.2 .1 Absorção molecular . . . . . . . . . . . . . . . . 75

5.2.2 Parametrizações de propriedades ópticas para nuvens $\ldots \ldots \ldots 76$

5.2 .3 Configuração física da nuvem . . . . . . . . . . . . . . 77

5.3 Look-up table para determinação de raio efetivo . . . . . . . . . . 82

$5.3 .1 \quad$ Nuvens de água . . . . . . . . . . . . . . 83

$5.3 .2 \quad$ Nuvens de gelo $\ldots \ldots \ldots \ldots$. . . . . . . . . 87

5.3 .3 Relação entre refletâncias . . . . . . . . . . . . . . . . 91

5.3 .4 Diagrama Nakajima-King . . . . . . . . . . . . . . 93

$5.4 \quad$ Aplicação da LUT . . . . . . . . . . . . . . . . 94

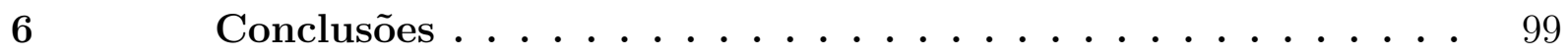

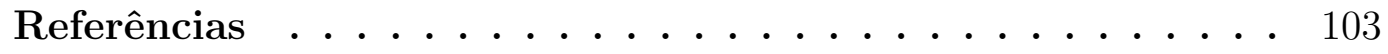

$\begin{array}{ll}\text { APÊNDICES } & 111\end{array}$ 


\section{Introdução}

A radiação eletromagnética emitida pelo Sol tem papel vital para o sistema terrestre. Interações entre a radiação incidente, atmosfera e superfície estão intimamente relacionadas a efeitos dinâmicos, químicos e biológicos no planeta. Variações na radiação solar incidente podem estar associadas às alterações de temperatura, modificações em fluxos atmosféricos, eventos meteorológicos e climáticos (Mayer and Kylling, 2005).

A interação radiação-atmosfera é tópico de extensos estudos e base para o desenvolvimento de técnicas de sensoriamento remoto da atmosfera, como em radiômetros a bordo de satélites, aviões ou em superfície. Sensores em satélites fornecem informações para o retrieval de características relacionadas à superfície e à atmosfera e seus constituintes (gases, aerossóis e nuvens).

\subsection{Constituintes Atmosféricos}

A maior parte das interações do feixe de radiação solar que chega à superfície terrestre ocorrem na atmosfera terrestre. Dessa forma, é importante que sejam conhecidos seus constituintes principais. A atmosfera pode ser dividida em quatro camadas, como ilustrado na figura 1.1: troposfera, estratosfera, mesosfera e termosfera.

A camada mais externa, a termosfera, apresenta temperaturas entre $500^{\circ} \mathrm{C}$ e $2000^{\circ} \mathrm{C}$ e tem início em aproximadamente $90 \mathrm{~km}$ em relação ao solo. A partir de $50 \mathrm{~km}$, abaixo da termosfera, localiza-se a mesosfera, com temperaturas decrescentes conforme a altura, tendo mínimos de até $-90^{\circ} \mathrm{C}$ no seu topo. A pressão atmosférica na base da mesosfera é cerca de $1 \%$ da pressão atmosférica na superfície. Entre $50 \mathrm{~km}$ e aproximadamente $12 \mathrm{~km}$ localiza-se a estratosfera, onde pode ser encontrada a camada de ozônio, que absorve radiação UV.

A troposfera, camada mais próxima da superfície, concentra $80 \%$ de toda a massa da atmosfera, além de ser a camada onde ocorrem os principais fenômenos meteorológicos.

É, portanto, o principal foco de estudo neste trabalho. 


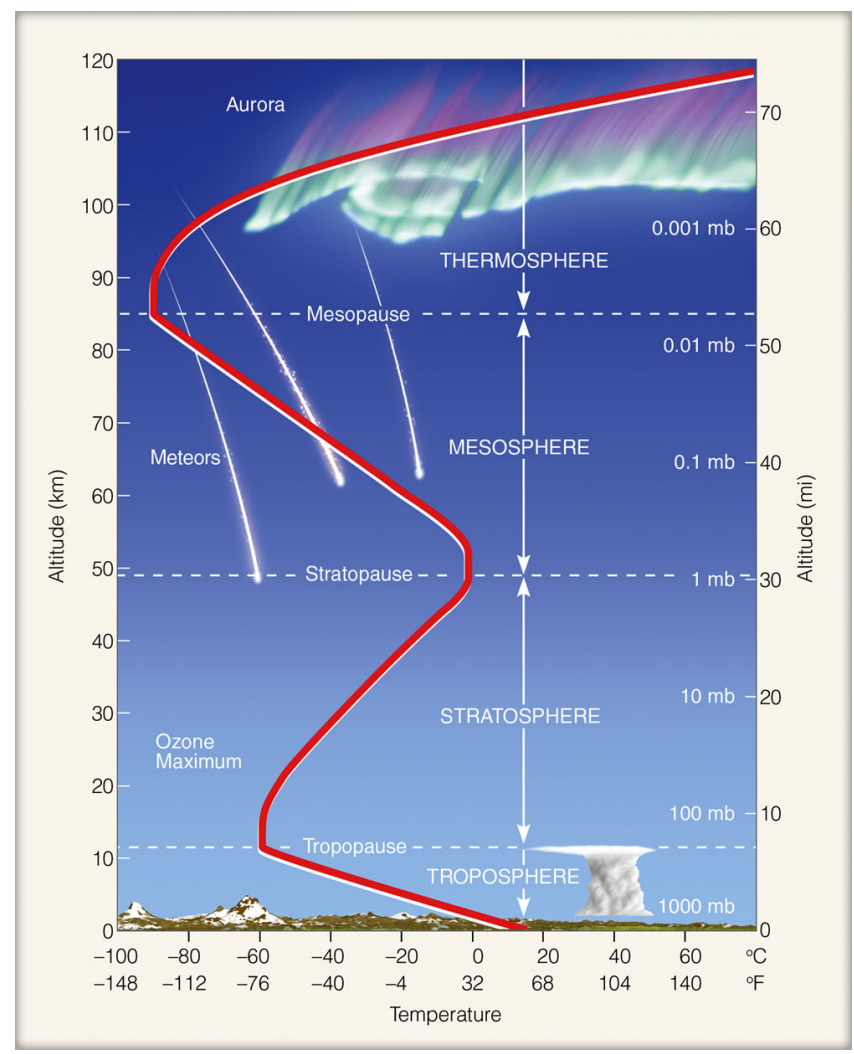

Figura 1 - Camadas da atmosfera e indicação de temperatura em cada altura. ${ }^{1}$

\subsubsection{Gases}

A atmosfera terrestre é composta principalmente dos gases nitrogênio, oxigênio e argônio. Em menor concentração são encontrados os chamados gases traço, conforme pode ser visto na tabela 1 , como neon, metano e dióxido de carbono.

Tabela 1 - Principais gases presentes na atmosfera seca, sem vapor d'água. Fonte: (Liou, 2002)

\begin{tabular}{llc}
\hline \multicolumn{1}{c}{ Gás } & & Proporção na atmosfera (\%) \\
\hline Nitrogênio & $\mathrm{N}_{2}$ & 78,084 \\
Oxigênio & $\mathrm{O}_{2}$ & 20,946 \\
Argônio & $\mathrm{Ar}$ & 0,9340 \\
Dióxido de carbono & $\mathrm{CO}_{2}$ & 0,04 \\
Neon & $\mathrm{Ne}$ & 0,001818 \\
Metano & $\mathrm{CH}_{4}$ & 0,000179 \\
\hline
\end{tabular}

O vapor d'água é um importante composto gasoso da atmosfera e sua concentração é fortemente dependente da localização e variável no tempo, podendo chegar a $5 \%$ em es-4-1-layers-of-the-atmosphere, acesso em 18/02/2017 
determinadas regiões (Wallace and Hobbs, 2006) enquanto representa 0,25\% de toda a massa da atmosfera.

Os compostos gasosos citados e outros, assim como o ozônio, podem interagir com a radiação incidente no topo da atmosfera atenuando-a por absorção e espalhamento, diminuindo a intensidade do feixe que incidirá na superfície. Essas interações se dão em diferentes comprimentos de onda para os diferentes gases. Detalhes sobre as interações são apresentados no capítulo 3.

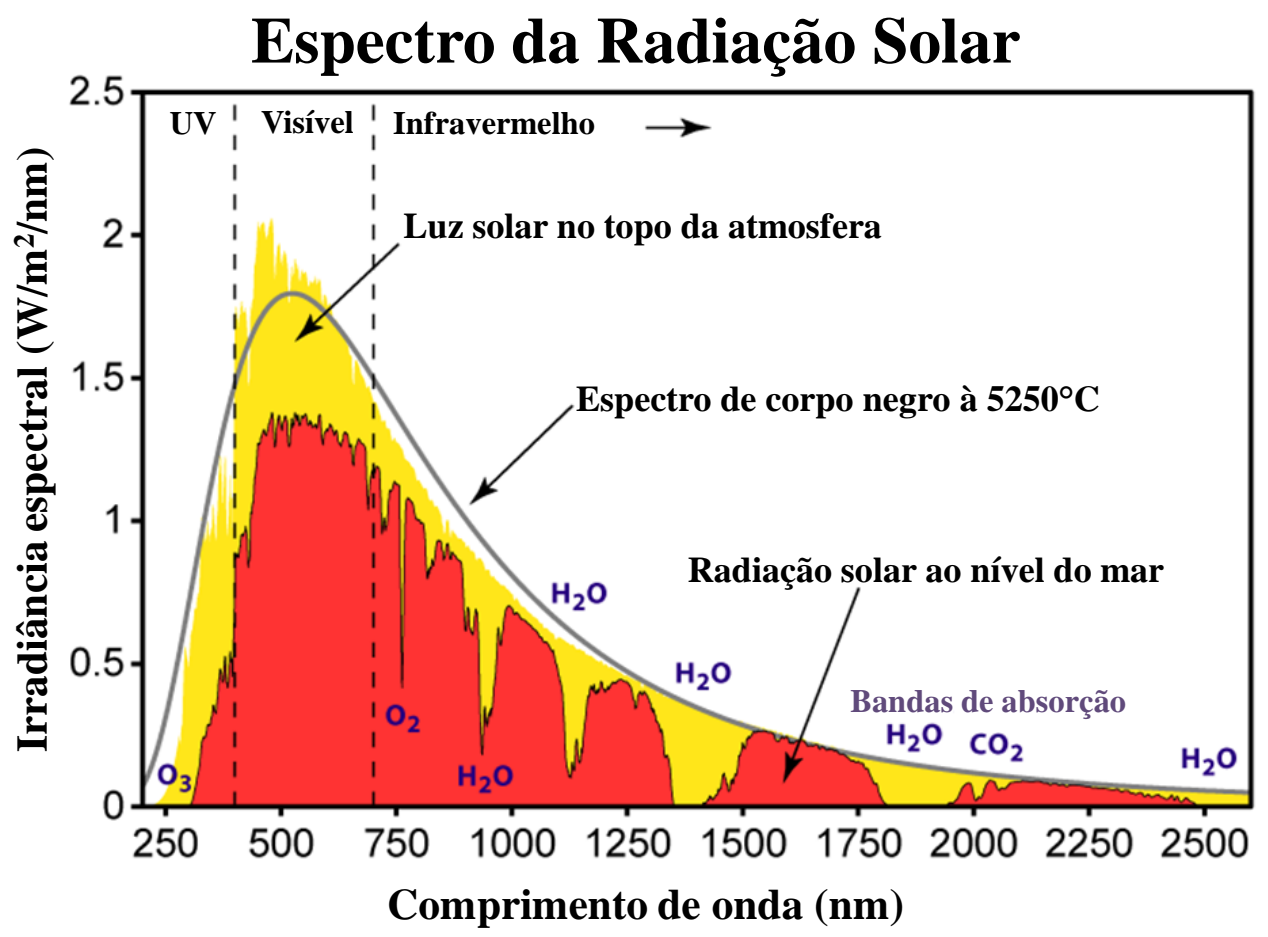

Figura 2 - Irradiância espectral referente à emissão solar, em amarelo, emissão de um corpo negro com $\mathrm{T}=5778 \mathrm{~K}$, na linha preta e irradiância solar à superfície, em vermelho, com as indicações de bandas de absorção gasosa. Traduzido de Beckmann and Spizzichino (1987).

Conhecendo essas faixas de absorção gasosa, o sensoriamento remoto através de satélites pode ser utilizado para determinação de concentração gasosa na atmosfera, utilizando radiômetros com bandas em comprimentos de ondas estratégicos. O OMI (do inglês Ozone Monitoring Instrument), instrumento de monitoramento de ozônio a bordo do satélite Aura da NASA, possui espectrômetros no intervalo de 270 a 314 nm (UV-1) e 306 a 380 nm (UV-2), regiões de absorção do ozônio, conforme visto na figura 2. Mede-se a coluna total de ozônio que é o valor de todo ozônio integrado da superfície ao topo da atmosfera. Cerca de $90 \%$ do ozônio atmosférico se encontra na estratosfera, enquanto o restante está na troposfera. 


\subsubsection{Aerossóis}

Aerossóis atmosféricos são partículas sólidas ou líquidas suspensas na atmosfera, com diâmetros entre $0,002 \mu m$ e $100 \mu m$, que tem um ciclo de vida da ordem de dias, no máximo semanas, na atmosfera (Seinfeld and Pandis, 1998). A distribuição de tamanho, composição química, formato e concentrações é bastante variada dependendo da localização geográfica e temporal.

Tais partículas podem advir de fontes naturais, como poeira de solo, aerossóis marinhos, emissões vulcânicas, etc, ou de fontes antrópicas. Aerossóis de fontes antrópicas podem ser os emitidos em queimadas (como no cinturão agrícola da Amazônia), ou emissões urbanas, veiculares e industriais (Costa et al., 2015). Também devem ser considerados aerossóis de fontes biogênicas, tendo a região amazônica como uma das principais fontes diretas de aerossóis orgânicos.

Aerossóis estão direta e indiretamente relacionados ao balanço radiativo terrestre. Diretamente, eles interagem com a radiação incidente por absorção ou espalhamento, atenuando a radiação incidente no topo da troposfera em seu caminho até a superfície. Indiretamente, servem com núcleos de condensação de nuvem (CCN - do inglês Cloud Condensation Nuclei). Um aumento na quantidade de aerossol na atmosfera implica em um aumento proporcional do albedo da nuvem e de seu tempo de vida (Twomey, 1977). Isso porque com maiores quantidades de $\mathrm{CCN}$ ativados, a nuvem terá maior número de gotículas, de raios menores.

\subsubsection{Nuvens}

Nuvens são conjuntos visíveis de partículas de água líquida e/ou cristais de gelo, oriundas da condensação de vapor de água disponível na atmosfera, em suspensão e recobrem cerca de $60 \%$ da superfície terrestre ${ }^{2}$. As nuvens desempenham papel fundamental no balanço radiativo terrestre e na dinâmica hidrológica do planeta

As nuvens podem ser classificadas quanto a sua distribuição espacial, seu desenvolvimento vertical e seu posicionamento conforme ilustrado na figura 3. Essas características, assim como o raio efetivo dos hidrometeoros e a fase termodinâmica, determinam se a

2 WMO. International Cloud Atlas, 2017. URL https://www.wmocloudatlas.org/, acesso em $17 / 06 / 2017$ 
nuvem terá efeito de aquecimento ou resfriamento da atmosfera. Nuvens frias e finas, como as Cirrus, transmitem grande parte da radiação solar incidente no TOA e absorvem parte da radiação emitida pela terra, e a reemite em comprimentos de onda referentes à sua temperatua, tendo um efeito de aquecimento da superfície terrestre (Gouveia, 2014). Por outro lado, nuvens baixas e espessas, como a Stratocumulus, refletem grande parte da radição solar e atuam como resfriadoras da superfície.

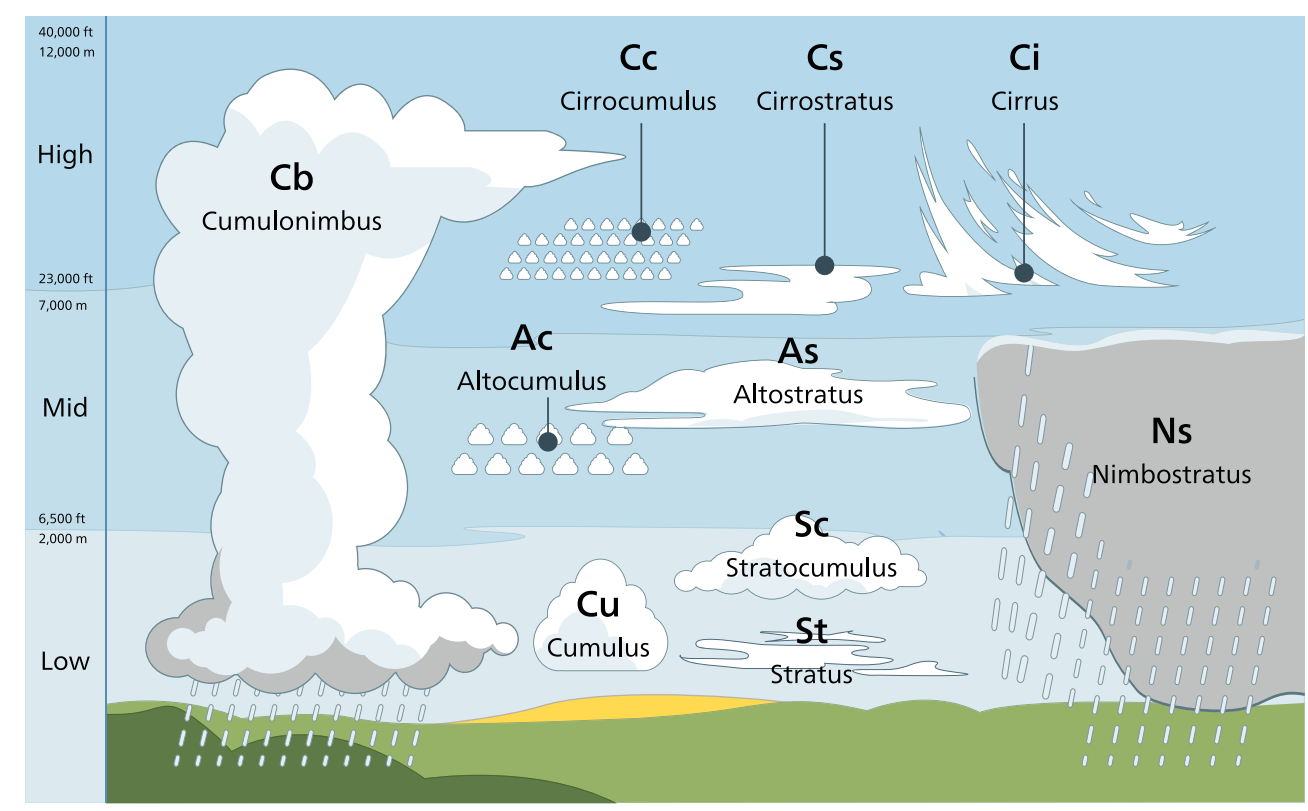

Figura 3 - Classificação de nuvens quanto ao seu posicionamento na atmosfera e seu desenvolvimento vertical ${ }^{3}$.

De forma resumida, a formação de nuvens ocorre através da condensação de vapor de água em CCN, sendo possível quando há supersaturação de vapor d'água. É dito ativado o CCN onde há condensação de água e crescimento de gotas por difusão, e o número de ativações na base de nuvens convectivas depende da quantidade de CCN disponível e da velocidade da corrente ascendente. Os núcleos de condensação são partículas de aerossol compostas principalmente de sulfatos, nitratos, sal marinho e, em alguns casos, compostos com carbono (Twomey, 1971). A alteração na disponibilidade média de aerossol na atmosfera resulta na variação de núcleos disponíveis para ativação.

Inicialmente, assim que há ativação de um CCN através da condensação, o processo de crescimento da gotícula se dá por difusão de moléculas de vapor até que atinjam um

3 V. de Bruyn, 2015. URL https://commons.wikimedia.org/w/index.php?title=File:Cloud_ types_en.svg, acesso em 07/06/2017 
raio de aproximadamente $14 \mu m$, quando esse processo se torna muito lento e ineficiente, ainda que não cesse (Rosenfeld and Gutman, 1994). A partir de $14 \mu m$, o raio da gotícula cresce principalmente devido à colisão e coalescência, ou seja, a junção de gotículas após choque entre elas. Esse processo acontece dentro de uma nuvem graças a repetição de um ciclo de ascensão e queda provocado por correntes ascendentes que a eleva até determinada altura de onde passa a cair novamente.

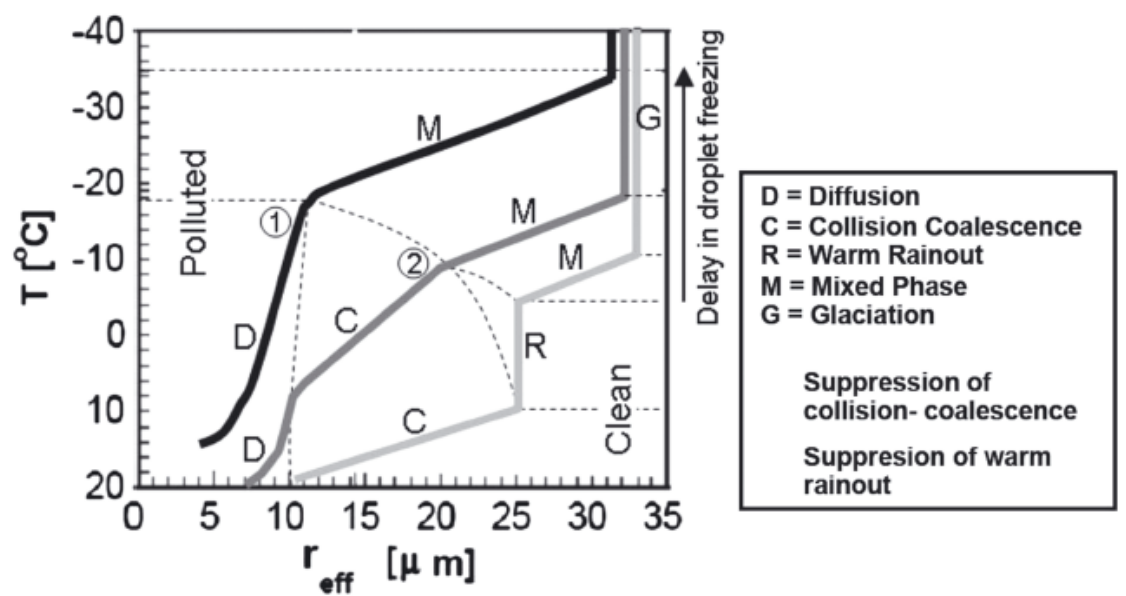

Figura 4 - Diagrama conceitual, de Rosenfeld et al. (2014), descrevendo cinco estágios microfísicos comuns a nuvens convectivas. A curva mais clara representa um ambiente marítimo com baixa concentração de CCN. As curvas intermediária e mais escura (ao topo) indicam, respectivamente, nuvem em ambiente de poluição moderada e extrema.

Rosenfeld and Lensky (1998) determinam cinco zonas microfísicas na extensão vertical de uma nuvem através de uma relação entre temperatura e raio efetivo (a ser definido no capítulo 3). Essas zonas, ilustradas na figura 4, indicam o processo dominante na região. As zonas de difusão (D) e coalescência (C) mantém esses principais processos e podem ser seguidas pela zona de rainout $(\mathrm{R})$, onde as maiores gotículas caem do topo da nuvem, equilibrando àquela altura o crescimento adicional pelo processo de colisão e coalescência. Na fase mista (M) tem-se o início da formação de cristais de gelo a partir das gotículas que serão congeladas em sua quase totalidade ou totalidade na zona de glaciação $(\mathrm{G})$.

Através da figura 4 é possível notar que o aumento na concentração de CCN suprime a fase de rainout e prolonga o processo de difusão, diminuindo ou até eliminando 
a fase de coalescência. Também percebe-se que o processo de glaciação tende a ocorrer em temperaturas cada vez mais baixas com o aumento de núcleos disponíveis.

Partículas de nuvem de água podem ser consideradas esferas perfeitas, porém para nuvens de gelo é necessário considerar os formatos dos cristais, também chamados hábitos. O tipo de cristal formado dependerá de diversas condições, como saturação e temperatura, como pode ser visto na figura 5. Neste trabalho, para o estudo de transferência radiativa em nuvens contendo cristais de gelo, considera-se uma mistura de diferentes tipos de hábitos utilizada por Baum et al. (2005).

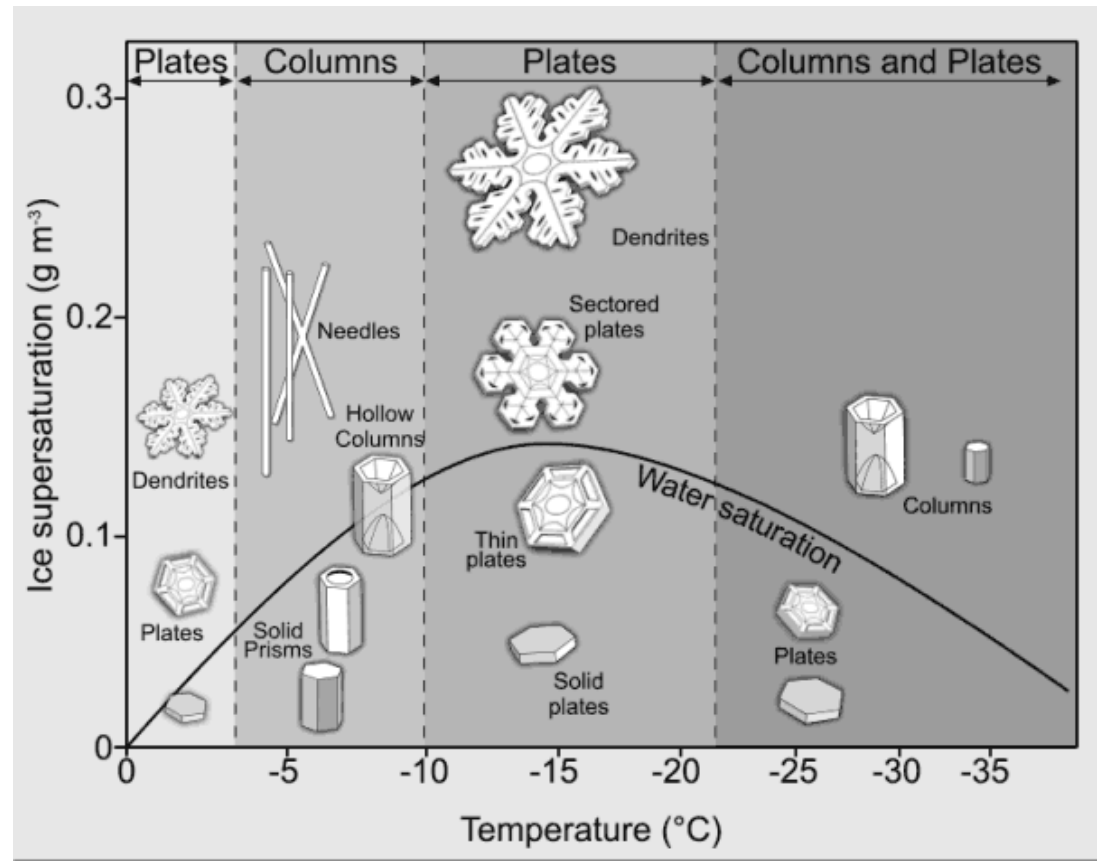

Figura 5 - Diagrama Nakaya de morfologia de cristais de gelo. Cristais com hábitos diferentes sao formados dependendo das condições atmosféricas de saturação de vapor d'água com relação a uma superfície de gelo e da temperatura de formação do cristal $^{4}$.

\subsection{Sensoriamento Remoto}

Nos esforços de monitorar a atmosfera terrestre diversos sensores, a bordo de satélites em órbita, realizam medidas de radiâncias no topo da atmosfera. Essas medidas podem ser utilizadas para obter características de nuvens, os chamados produtos de nuvem, tais como raio efetivo, fase termodinâmica e profundidade óptica (Cloud Optical Depth, COD).

4 C. Emersic, Ice crystal morphology diagram illustrating the shapes, habit, of ice crystals as a function of both ambient temperature and ice supersaturation, 2015. URL http://www. cas . manchester .ac . uk/images/photos/themes/600x400/cp_scatt_Fig2_hr.png, acesso em 17/06/2017 
Dentre os sensores que produzem algum produto de nuvem podemos citar alguns:

- Advanced Very High Resolution Radiometer (AVHRR/4), a bordo do satélite NOAA16 (Holben, 1986);

- Clouds and the Earth's Radiant Energy System (CERES), a bordo dos satélites Terra, Aqua e Suomi National Polar-orbiting Partnership (S-NPP) (Wielicki et al., 1996);

- Moderate-Resolution Imaging Spectroradiometer (MODIS), a bordo dos satélites Terra e Aqua (King et al., 1992b);

- CloudSat, satélite polar com órbita aproximada de 1,5 hora, com radar de $94 \mathrm{GHz}$ (Stephens et al., 2002);

- Cloud-Aerosol Lidar with Orthogonal Polarization (CALIOP), a bordo do satélite CALIPSO (Liu et al., 2009);

- Visible Infrared Imaging Radiometer Suite (VIIRS), a bordo do S-NPP (Cao et al., 2013).

Esses satélites possuem órbita heliossíncrona, caso particular de órbita polar, ou seja, o satélite transita entre pólos porém sua órbita permanece em um mesmo plano para observador localizado no Sol. Apesar de obterem uma cobertura global, imagens de uma mesma região podem levar até 12 horas para serem obtidas novamente. Dessa forma, análises de nuvens considerando dados obtidos por satélites geoestacionários passam a ser relevantes.

Satélites de órbita geoestacionária apresentam período de translação coincidente com a rotação terreste, mantendo-se a uma mesma distância da superfície da Terra. Assim, informações de uma mesma região podem ser obtidas com maior frequência temporal comparados a satélites de órbitas heliossíncronas.

Produtos para climatologia atmosférica, de nuvens e de superfície, podem ser obtidos através do projeto International Satellite Cloud Climatology Project (ISCCP) (Schiffer and Rossow, 1983; Rossow, 2011). O projeto utiliza dados obtidos por diversos satélites geoestacionários, como os das séries Meteosat e GOES, para conseguir informações como COD, temperatura de topo de nuvem, CWP, pressão de topo de nuvem. Esses produtos estão disponíveis para o período entre 1983 e 2009 e possuem cobertura global com resolução de $280 \mathrm{Km}$, a cada 3 horas, considerando a atmosfera com 7 camadas 
verticais. No entanto, não há produto para avaliação de microfísica de nuvens, como a determinação do raio efetivo de gotas de água e cristais de gelo.

\subsubsection{GOES-13}

O satélite GOES-13 faz parte do Sistema de Satélites Geoestacionários (Geostationary Operational Environmental Satellites, GOES), um esforço do governo americano para o monitoramento ambiental terrestre ${ }^{5}$ sob comando da National Oceanic and Atmospheric Administration (NOAA) .

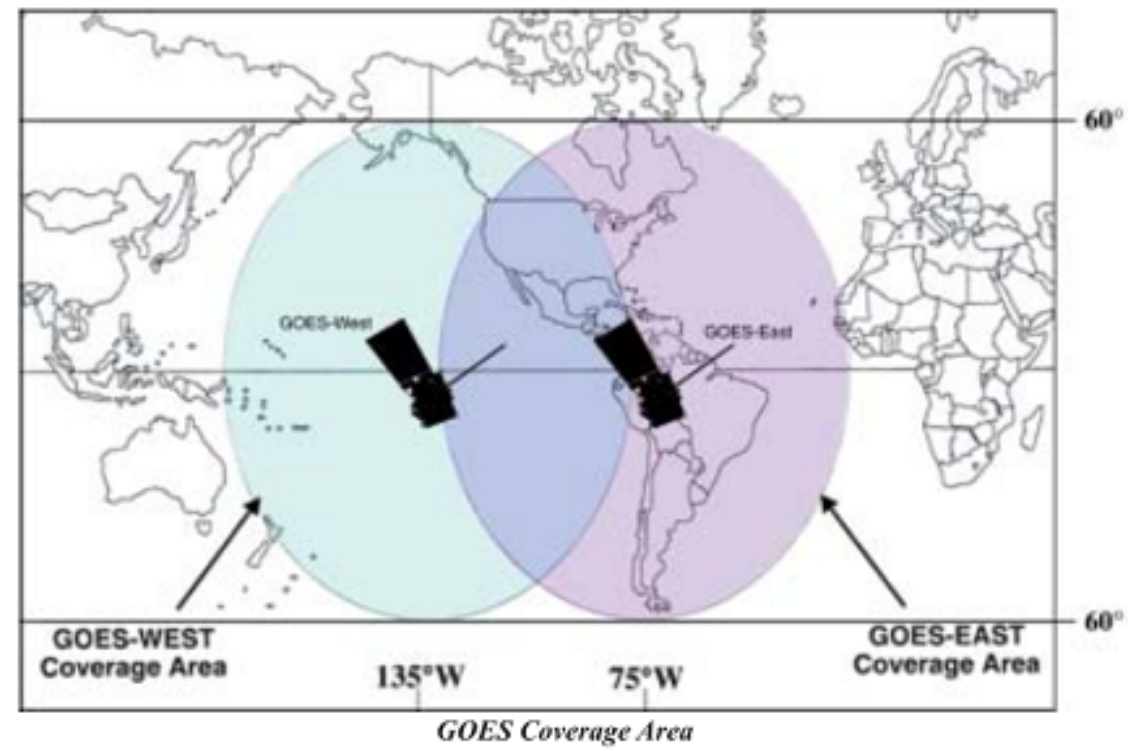

Figura 6 - Área de cobertura dos satélites designados para posições Leste e Oeste. O GOES-13 é o satélite chamado de GOES-East. ${ }^{6}$

Lançado em 2006, o satélite está localizado a $75^{\circ}$ Oeste (posição designada como "GOES-East" na figura 6), a uma altitude média de 35.800 km, e obtém imagens a cada 30 minutos. Alterações na programação de realização de medidas do satélite podem ser realizadas para monitorar eventos atmosféricos de interesse, como furacões ativos na costa americana. Nota-se na figura 6 que a área de cobertura do GOES-East é vantajosa para estudos atmosféricos na região amazônica.

5 GOES I-M Data Book. NASA DLR 101-08, 1996. URL https://goes.gsfc.nasa.gov/text/GOES-N_ Databook, acesso em 17/06/2017

6 NOAA GOES-N, O, P - The Next Generation. URL https://www.nasa.gov/pdf/112855main_ GOESNOPWeb1.pdf, acesso em 17/06/2017 


\subsection{Região Amazônica}

Com extensão aproximada de 7 milhões de $\mathrm{km}^{2}$, a Bacia Amazônica representa cerca de 33\% da América do Sul e tem $80 \%$ de sua superfície recoberta por floresta tropical. Cerca de $70 \%$ da bacia está contida em território brasileiro, o restante pertencendo a Bolívia, Colômbia, Peru, Guiana, Guiana Francesa, Suriname e Venezuela (Goulding et al., 2003).

O bioma da Amazônia é formado por três tipos de vegetação, de terra firme, de várzea e de igapó, além de regiões de cerrado e campinas. As florestas de várzea e de igapó são localizadas em áreas frequentemente alagadas por rios, respectivamente, de água branca e de água preta, enquanto as florestas de terra firme são estabelecidas distantes dos rios (Ferreira et al., 2005). Esse bioma é extremamente rico em espécies e possui atividade intensa que impacta diretamente e indiretamente o clima regional e global (Nobre et al., 2005; Salazar et al., 2007).

No Brasil, a Amazônia Legal, apresentado na figura 7 é o território compreendido pelos estados do Amapá, Amazonas, Roraima, Rondônia, Pará, Tocantins, Mato Grosso, Maranhão a oeste de $44^{\circ} \mathrm{W}$ e Goiás a norte de $13^{\circ} \mathrm{S}$ e representa aproximadamente $60 \%$ de todo o país. O estabelecimento da região Amazônia Legal, que é conceito político administrativo, se deu pela Lei 1.806, de 6 de janeiro de 1953, que cria bases para ocupação e exploração posterior dos recursos naturais da região. A exploração territorial recebera incentivo nas décadas de 70 e 80 através de políticas públicas e subsídios estatais, criando condições crescentes para o desmatamento e ocupação de sua extensão (Artaxo et al., 2013).

A Amazônia é situada na região equatorial e possui clima quente e úmido, caracterizado por altos índices pluviométricos (em média cerca de $2300 \mathrm{~mm} / \mathrm{ano}$ ). Essa precipitação tem variabilidade bem definida, em estações chuvosa e seca. Durante a estação chuvosa, entre dezembro e junho, a região possui atmosfera com concentrações de partículas consideravalemente baixas, da ordem de 300 partículas por $\mathrm{cm}^{3}$. Na estação seca, de julho a outubro, a atmosfera apresenta concentração de partículas bastante elevada $(\approx 20.000$ partículas por $\mathrm{cm}^{3}$ ) resultado de grande atividade antropogênica na região e queima de biomassa (Andreae et al., 2015; Artaxo et al., 2006). 
A região conhecida como "arco do desmatamento", que se estende ao longo das bordas leste e sul da floresta e compreende 256 municípios, é a extensão com maior incidência de desmatamento. Gases e partículas inseridas na atmosfera por queima de biomassa estão sujeitos a transportes em larga escala, afetando não só a atmosfera local como em toda a extensão amazônica (Pauliquevis et al., 2007; Cirino et al., 2014).

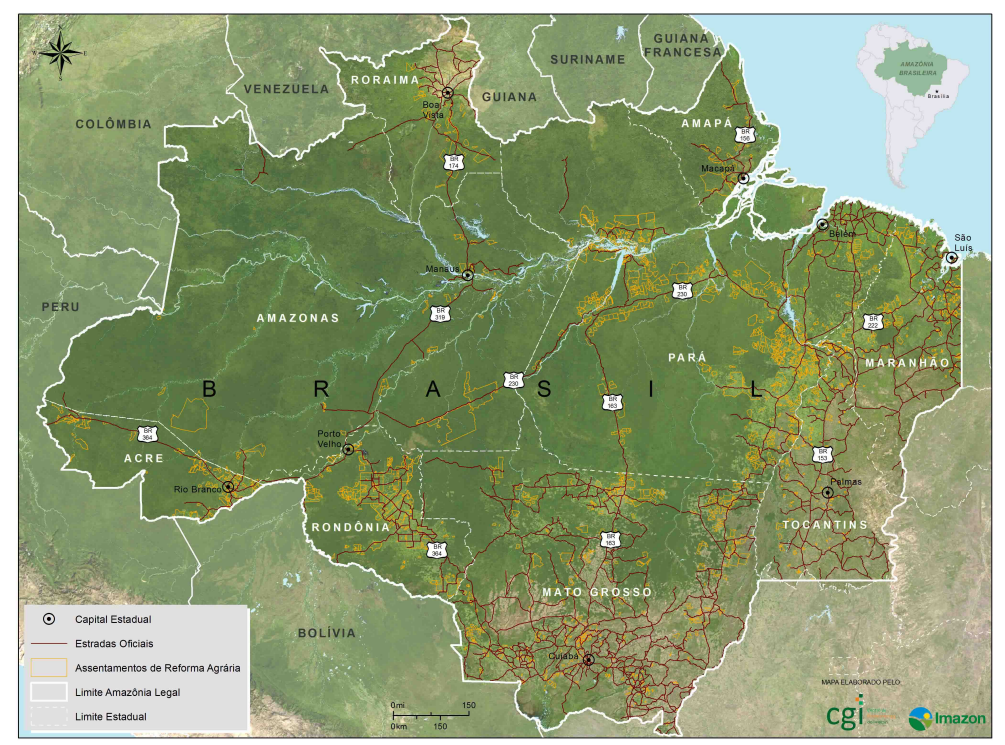

Figura 7 - Mapa, elaborado por Imazon ${ }^{7}$, da Amazônia Legal delimitada por linhas brancas, com indicação de território coberto por floresta, em verde escuro.

A Amazônia apresenta intensa atividade convectiva e o material disperso na atmosfera através de atividades do bioma amazônico (inclusive por atividades antrópicas) é fonte da maior parte das partículas que atuam como núcleo de condensação de nuvem (CCN). As atividades antrópicas, como o desmatamento, tem impactos em todo ecossistema da região, assim como o sistema atmosférico. De fato, influenciam a dinâmica hidrológica em micro, meso e grande escala (Wang et al., 2009).

Considerando as diferenças na dinâmica e na composição atmosférica entre as estações seca e chuvosa é possível utilizar a Amazônia como laboratório para pesquisas que relacionam o aerossol atmosférico e seu impacto sobre propriedades macro e microfísicas de nuvens. Com efeito, foram observadas evidências de que o aumento no aerossol atmosférico tem papel na inibição de chuva quente e na concentração de gotículas (Costa et al., 2015). A alteração nas características de nuvens pode afetar diretamente o balanço radiativo da região e, consequentemente, ter impacto no clima global.

7 Imazon, Assentamentos da Amazônia Legal, 2013. URL http://www.imazongeo.org.br/doc/ galeriaMapas.php, acesso em 17/06/2017 



\section{Objetivos}

Este trabalho se situa no contexto de desenvolvimento de pesquisas para melhoria na obtenção de informações sobre a atmosfera na região amazônica, a partir de sensores em satélites. O objetivo principal deste trabalho é estudar ferramentas de solução da equação de transferência radiativa e aplicá-las de modo a obter propriedades ópticas e microfísicas de nuvens de água e de gelo sobre a Amazônia. Esse objetivo pode, portanto, ser dividido em objetivos menores e complementares:

- Comparar resultados de cálculos de transferência radiativa utilizando-se os códigos libRadtran e SBDART;

- Estudar características do libRadtran assim como as refletâncias de nuvens de água e gelo em relação às características microfísicas de nuvens, ângulo de iluminação solar e de visada, composição do perfil atmosférico em termos de ozônio e vapor d'água e posições físicas das nuvens.

- Desenvolver tabelas de referência (look-up tables - LUT) que permitam a determinação de raio efetivo de nuvem de água e gelo em diferentes geometrias através de reflectâncias calculadas por medidas de sensor à bordo do satélite geoestacionário GOES-13.

No capítulo 3 são apresentados os conceitos físicos que fundamentam esse trabalho. No capítulo 4 são expostos os modelos utilizados, assim como as técnicas e análises propostas. O capítulo 5 apresenta os resultados obtidos ao longo desta pesquisa, além de discussões para cada análise, seguido das conclusões que encerram este trabalho, no capítulo 6 . 



\section{Fundamentação Teórica}

O desenvolvimento deste trabalho foi possível através de um estudo prévio dos princípios relacionados à interação entre radiação eletromagnética e os constituintes atmosféricos. Os principais conceitos empregados nesta dissertação são apresentados neste capítulo.

\subsection{Radiação de corpo negro e grandezas radiométricas}

Um corpo negro é definido como um corpo que absorve toda a radiação eletromagnética incidente e, para se manter em equilíbrio térmico, reemite-a com a mesma taxa de absorção. A radiação reemitida é característica do corpo negro que a emitiu, independente da radiação incidente nele. A emissão em um determinado comprimento de onda (espectral) pode ser calculada através da Lei de Planck (equação (1)).

$$
B(\lambda, T)=\frac{2 h c^{2}}{\lambda^{5}} \frac{1}{e^{\frac{h c}{k_{B} T}-1}}
$$

em que $h$ é a constante de Planck, $c$ a velocidade da luz no vácuo, $k_{B}$ a constante de Boltzmann, $T$ é a temperatura absoluta do corpo emitindo radiação, com $B(\lambda, T)$ em $W m^{-2} s r^{-1}$ no SI.

A radiância $(L)$ é definida como o quociente da intensidade de radiação, em determinado comprimento de onda, de um elemento de superfície, em uma determinada direção, e a área da projeção ortogonal deste elemento em um plano perpendicular à essa direção (equação (2)) (Liou, 2002). A geometria está representada na figura 8.

$$
L=\frac{I}{\cos \theta \times d t d \Omega d A}
$$

A radiância espectral $\left(L_{\lambda}\right)$, definida conforme a equação (3), representa a radiância em um intervalo infinitesimal de comprimento de onda, enquanto $L$ diz respeito à radiância em todo o espectro eletromagnético. Frequentemente $L_{\lambda}$ é utilizada com unidades de $W m^{-2} s r^{-1} n m^{-1}$.

$$
L_{\lambda}=\frac{d L}{d \lambda}
$$




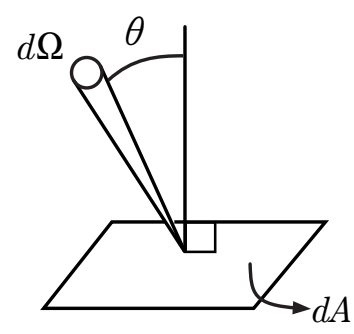

a)

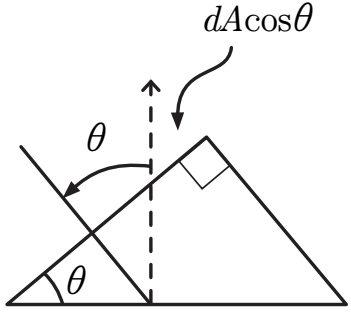

$d A$

Figura 8 - Ilustração da geometria envolvida na definição de radiância: com visão tridimensional (a) e em um plano vertical (b). (Yamasoe and Corrêa, 2016)

Fica evidente, então, que a radiância tem uma dependência direcional, que é relevante ao avaliar o fluxo de energia radiativa em um contexto de sensoriamento remoto da atmosfera. Porém, é possível considerar o fluxo radiativo sem a dependência direcional através do conceito de irradiância espectral incidente em um hemisfério, dada pela equação (4), desde que sejam conhecidas as radiâncias em todas as direções deste hemisfério.

$$
F_{0}=\int_{0}^{2 \pi} \int_{0}^{\frac{\pi}{2}} L(\theta, \varphi) \cos \theta \sin \theta d \theta d \varphi
$$

A irradiância pode ser entendida, então, como o fluxo de energia que atravessa um elemento de área, com unidades em $W m^{-2}$, vindo de todas as direções em um hemisfério.

Considerando o escopo deste trabalho, é importante apresentar outras grandezas: albedo e refletância $(\rho)$. O albedo é a grandeza definida como a razão entre a radiação refletida pela superfície e a radiação incidente na mesma.

A refletância representa o albedo de uma superfície Lambertiana, superfície de reflexão difusa homogênea tem todas as direções, considerando a radiância em determinada direção e o fluxo incidente. A refletância pode ser obtida através da equação (5), definida em Nakajima and King (1990). Neste estudo, a refletância de nuvens é calculada utilizando a radiância medida pelo GOES. Esta refletância é maior que a de um céu limpo, considerando superfície e atmosfera apenas.

$$
\rho=\frac{\pi L}{\mu_{0} F_{0}}
$$


em que $\mu_{0}$ é o cosseno do ângulo zenital solar, $L$ a radiância medida pelo sensor e $F_{0}$ a irradiância solar no topo da atmosfera (TOA - do inglês Top of Atmosphere).

\subsection{Espectro Solar e Terrestre}

O espectro solar médio possui um pico em emissão na região do espectro visível, limitado entre 400 e $700 \mathrm{~nm}$. Apesar da lei de Planck ser definida para um corpo negro, pode-se notar que é uma boa aproximação para determinar o espectro de emissão do Sol, considerando a temperatura de sua superfície entre $5750 \mathrm{~K}$ e $6000 \mathrm{~K}$.

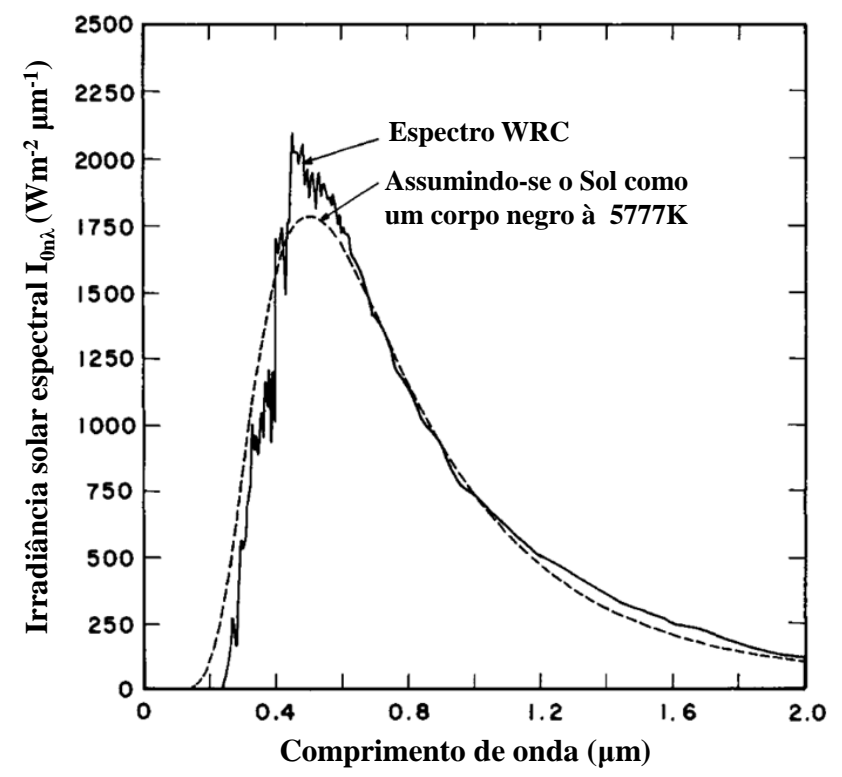

Figura 9 - Espectro de emissão solar em linha cheia, espectro de emissão de um corpo negro com temperatura de $5777 \mathrm{~K}$ em linha tracejada. (Iqbal, 2012)

Utilizando a mesma aproximação, ou seja, a lei de Planck, pode-se determinar o espectro de emissão terrestre, dada sua temperatura aproximada de $350 \mathrm{~K}$, para efeito de comparação, o que pode ser visto na figura 10.

Conforme comparativo apresentado na figura 10, para os comprimentos de onda a serem utilizados deste trabalho é possível considerar desprezível a contribuição devido às emissões terrestres e das camadas atmosféricas e seus constituintes para os comprimentos de onda visíveis utilizados neste trabalho. 


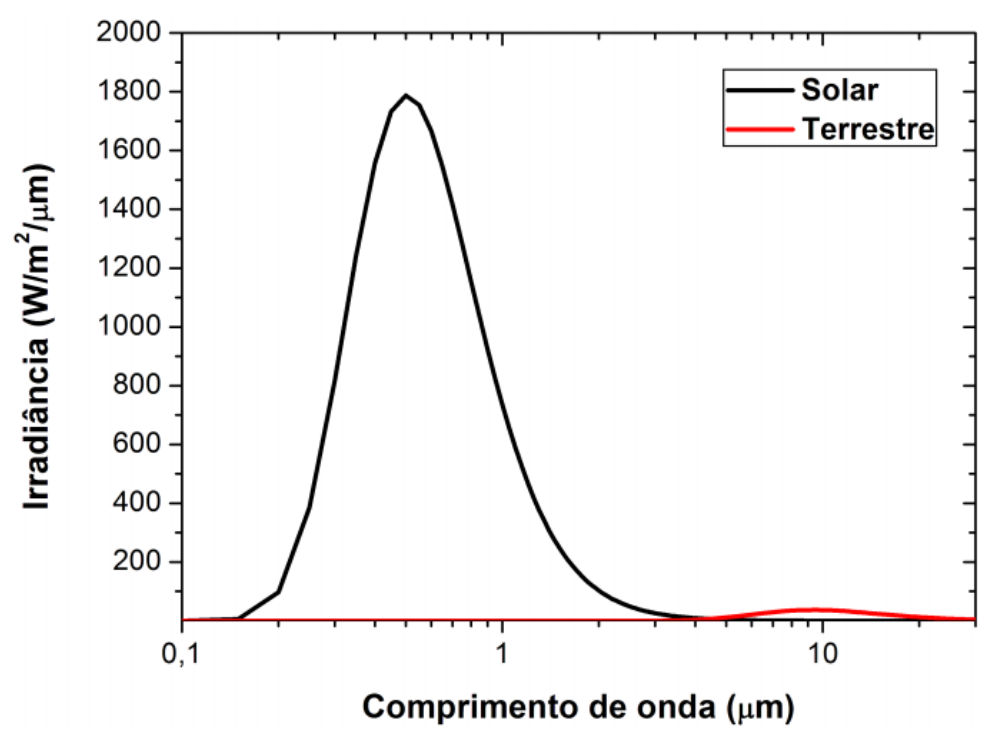

Figura 10 - Irradiância espectral para um corpo negro de temperatura comparável com a superfície Solar $(6000 \mathrm{~K})$ em preto e com temperatura próxima a terrestre (350K) em vermelho. (Sena, 2013)

\subsection{Interação Radiação-Atmosfera}

Ao incidir na atmosfera terrestre, a radiação solar pode interagir com os constituintes opticamente ativos da atmosfera sendo espalhada para outras direções ou atenuada por absorção antes de chegar à superfície. No processo de absorção, a energia do feixe incidente é transformada em outras formas de energia, frequentemente em energia térmica, enquanto no processo de espalhamento, a radiação incidente em uma direção é espalhada ou desviada para outras direções, havendo produção de energia difusa (Liou, 2002). Esses processos serão brevemente explicados a seguir.

\subsubsection{Espalhamento}

Ao sofrer espalhamento, um feixe é desviado da sua orientação incidente para outras orientações, sendo a distribuição angular deste desvio dependente do tamanho da partícula espalhadora e do comprimento de onda do feixe.

É possível determinar uma relação entre o parâmetro de tamanho de uma partícula espalhadora de raio a recebendo um feixe de comprimento de onda $\lambda$ e o tipo de espalhamento sofrido pela radiação através da equação (6). Para $x \ll 1$ tem-se regime de 
espalhamento Rayleigh e para $x \geq 1$ o espalhamento é chamado Mie, já que a teoria Mie se apresenta como boa aproximação para o espalhamento verificado.

$$
x=\frac{2 a \pi}{\lambda}
$$

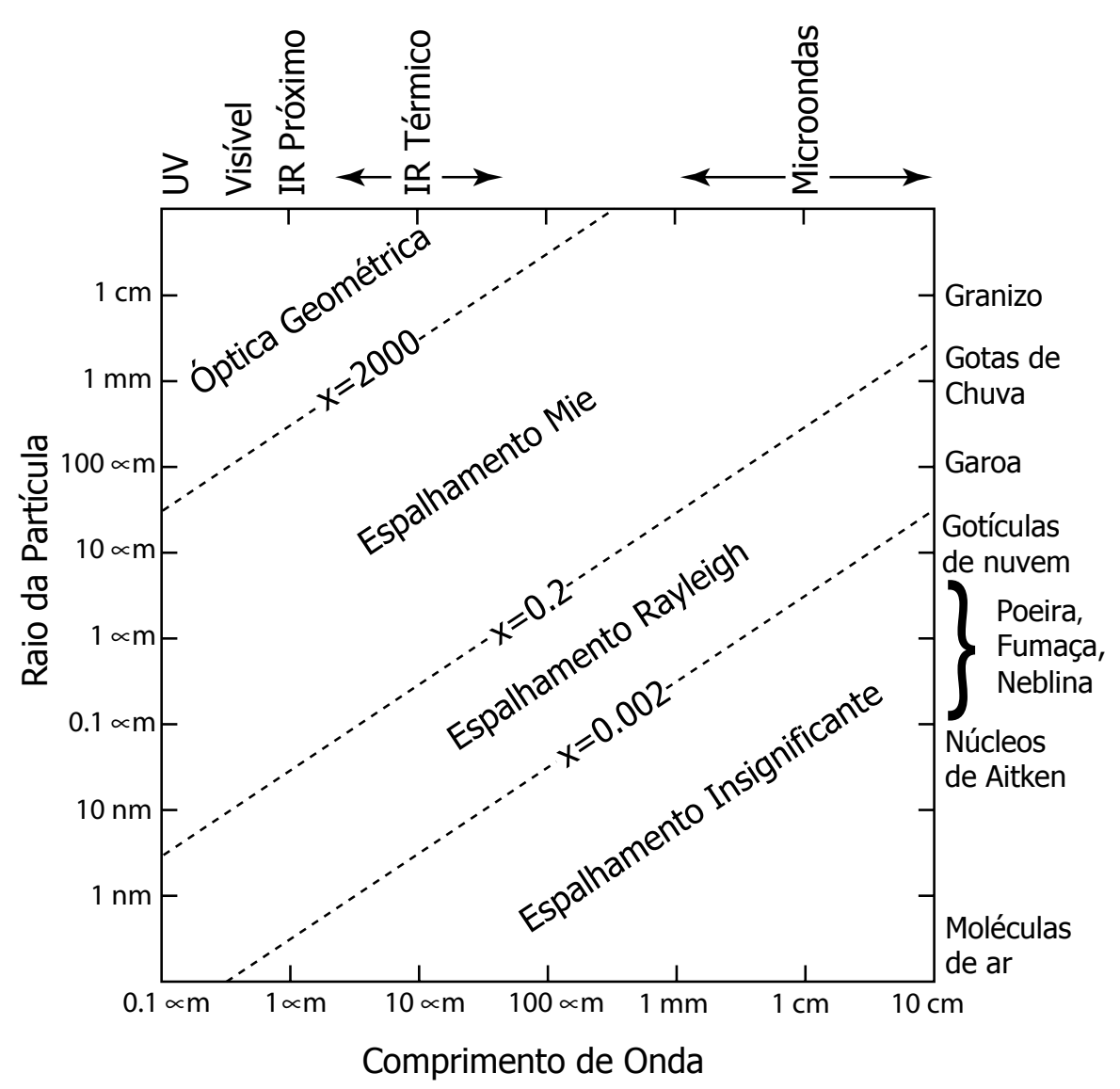

Figura 11 - Regiões de regime de espalhamento em função do raio da partícula e comprimento de onda. (Sena, 2013)

O espalhamento não é necessariamente isotrópico em todas as direções, conforme figura 12. De fato, diferentes valores para o parâmetro de tamanho implicam em diferentes funções de fase, função matemática que descreve o padrão angular de espalhamento de um feixe de comprimento de onda $\lambda$ para uma certo ângulo de espalhamento $\Theta$ (ângulo entre direção incidente e espalhada).

Define-se também a seção de choque de espalhamento $\left(\sigma_{s}\right)$, que representa a área de espalhamento efetiva de um elemento de massa em dada posição; o coeficiente linear de espalhamento $\left(\beta_{s}\right)$, que determina a distância característica na qual a radiação é espalhada; 


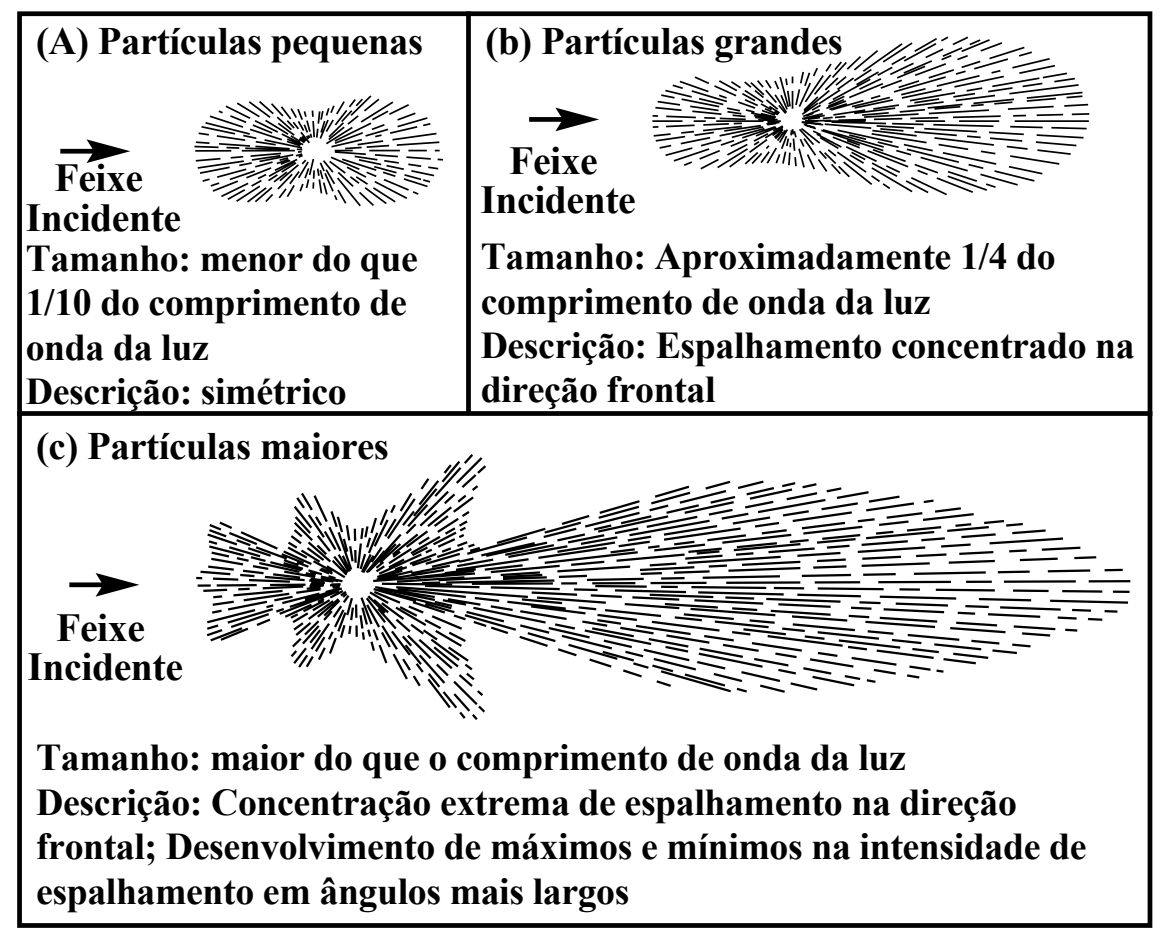

Figura 12 - Tipos de espalhamento para (a) partículas de até 1/10 do comprimento de onda incidente, (b) partículas com cerca de 1/4 do comprimento de onda, (c) partículas maiores que o comprimento de onda incidente. (Brumberger, 2013)

e a espessura óptica de espalhamento $\left(\tau_{s}\right)$. Essas grandezas são definidas conforme o tipo de espalhamento.

\subsubsection{Espalhamento Rayleigh}

Enunciado em 1871, o espalhamento Rayleigh é a formulação mais simples de espalhamento (Liou, 2002) e descreve a interação da radiação solar com moléculas e partículas com raio menor que $0,1 \lambda$, aproximadamente. Isso significa que esse tipo de interação é predominante ao tratar dos componentes moleculares da atmosfera terrestre.

Conforme apresentado na figura 12, este tipo de espalhamento não é caracterizado por uma grande diferença angular no espalhamento, porém não se trata de um efeito isotrópico. A função de fase, que descreve o espalhamento pode ser descrita conforme a equação (7):

$$
P_{R}(\cos (\Theta))=\frac{3}{4}\left(1+\cos ^{2}(\Theta)\right)
$$


A seção de choque de espalhamento de uma partícula é dada pela equação (8), em que $N_{0}$ é a concentração de moléculas por $m^{3}$ e $n$ é o índice de refração do ar.

$$
\sigma_{R}=\frac{24 \pi^{3}}{\lambda^{4} N_{0}^{2}} \frac{\left(n^{2}-1\right)^{2}}{\left(n^{2}+2\right)^{2}}
$$

A espessura óptica, portanto, será dada por:

$$
\tau_{R}=\int_{\infty}^{z} \beta_{R} d z
$$

em que $\beta_{R}$ é o coeficiente linear de espalhamento: $\beta_{R}=\sigma_{R} N\left(z^{\prime}\right)$, com $N\left(z^{\prime}\right)$ sendo a concentração de partículas na posição $z^{\prime}$.

\subsubsection{Espalhamento Mie}

Desenvolvida em 1908 pelo físico alemão Gustav Mie, a teoria Mie utiliza as equações de Maxwell para descrever a radiação espalhada na interação entre luz e partículas esféricas na forma de séries infinitas (Wriedt, 2012). O desenvolvimento pode ser visto em detalhes em Hulst and van de Hulst (1957), em Hergert and Wriedt (2012) ou em Liou (2002). São apresentados a seguir os principais pontos da teoria Mie para o espalhamento.

Resolvendo as equações de Maxwell em coordenadas esféricas atendendo as condições de contorno adequadas, tem-se que as componentes do campo elétrico espalhado são:

$$
\left[\begin{array}{c}
E_{/ /}^{S} \\
E_{\perp}^{S}
\end{array}\right]=\frac{e^{-i k r+i k x}}{i k r}\left[\begin{array}{cc}
S_{1}(\theta) & 0 \\
0 & S_{2}(\theta)
\end{array}\right]\left[\begin{array}{c}
E_{/ /}^{i} \\
E_{\perp}^{i}
\end{array}\right]
$$

com $S_{1}$ e $S_{2}$ sendo funções de espalhamento que indicam a distribuição de energia espalhada para dado ângulo $\theta$ de espalhamento, ou seja, o ângulo entre o feixe incidente e o feixe 
espalhado. As funções $S_{1}$ e $S_{2}$ são descritas como séries infinitas conforme apresentado a seguir:

$$
\begin{aligned}
& S_{1}(\theta)=\sum_{n=1}^{\infty} \frac{2 n+1}{n(n+1)}\left(a_{n} \tau_{n}\left(\cos (\theta)+b_{n} \pi_{n}(\cos (\theta))\right)\right) \\
& S_{2}(\theta)=\sum_{n=1}^{\infty} \frac{2 n+1}{n(n+1)}\left(a_{n} \pi_{n}\left(\cos (\theta)+b_{n} \tau_{n}(\cos (\theta))\right)\right)
\end{aligned}
$$

As funções $\pi_{n}$ e $\tau_{n}$ são:

$$
\begin{aligned}
\pi_{n}(\cos (\theta)) & =\frac{1}{\sin (\theta)} P_{n}^{1}(\cos (\theta)) \\
\tau_{n}(\cos (\theta)) & =\frac{d}{d \theta} P_{n}^{1}(\cos (\theta))
\end{aligned}
$$

$\operatorname{com} P_{n}^{\prime}(\cos (\theta))$ o polinômio de Legendre de primeira ordem associado. $a_{n}$ e $b_{n}$ são definidas como:

$$
\begin{aligned}
a_{n} & =\frac{\psi_{n}(m x) \psi_{n}(x)-m \psi_{n}(m x) \psi_{n}^{\prime}(x)}{\psi_{n}^{\prime}(m x) \xi_{n}(x)-m \psi_{n}^{\prime}(m x) \xi_{n}(x)} \\
b_{n} & =\frac{m \psi_{n}(m x) \psi_{n}(x)-\psi_{n}(m x) \psi_{n}^{\prime}(x)}{m \psi_{n}^{\prime}(m x) \xi_{n}(x)-\psi_{n}^{\prime}(m x) \xi_{n}(x)}
\end{aligned}
$$

sendo $x$ o parâmetro de tamanho, $m$ o índice de refração complexo e $\psi_{n}$ e $\xi_{n}$ são funções relacionadas às funções de Bessel e Hankel, respectivamente.

A matriz de espalhamento Mie que apresenta a função de fase pode ser descrita como:

$$
P(\theta)=\left[\begin{array}{cccc}
P_{11}(\theta) & P_{12}(\theta) & 0 & 0 \\
P_{21}(\theta) & P_{22}(\theta) & 0 & 0 \\
0 & 0 & P_{33}(\theta) & P_{34}(\theta) \\
0 & 0 & P_{43}(\theta) & P_{44}(\theta)
\end{array}\right]
$$

Para esferas, tem-se que $P_{11}=P_{22}$ e $P_{33}=P_{44}$. Os termos da primeira linha da matriz estão relacionados à intensidade e, como os termos não diagonais são muito menores que os 
termos da diagonal principal, a intensidade da função de fase pode ser escrita considerando $I=P_{11}(\theta)$, ou seja:

$$
P(\theta)=\frac{2}{k^{2} r^{2} Q_{e s p}}\left|S_{1}\right|^{2}+\left|S_{2}\right|^{2}
$$

sendo $Q_{e s p}$ o fator de eficiência de espalhamento definido pela equação (16).

$$
Q_{e s p}=\frac{2}{x^{2}} \sum_{n=1}^{\infty}(2 n+1)\left(\left|a_{n}\right|^{2}+\left|b_{n}\right|^{2}\right)
$$

O fator de eficiência de extinção é definido pela equação (17):

$$
Q_{e x t}=\frac{2}{x^{2}} \sum_{n=1}^{\infty}(2 n+1) \operatorname{Re}\left(a_{n}+b_{n}\right)
$$

Adequando essas definições a um sistema de muitas partículas, com concentração $\mathrm{N}$ e distribuição de tamanho $n(r)$, tem-se descrições para a função de fase (equação (18)), coeficientes de extinção (equação (19)) e de espalhamento (equação (20)), e albedo simples (equação (21)).

$$
\begin{gathered}
P(\theta)=\frac{2 \pi N}{k^{2} \alpha_{e s p}} \int_{0}^{\infty}\left(\left|S_{1}\right|^{2}+\left|S_{2}\right|^{2}\right) n(r) d r \\
\alpha_{e x t}=N \int_{0}^{\infty} \pi r^{2} Q_{e x t} n(r) d r \\
\alpha_{e s p}=N \int_{0}^{\infty} \pi r^{2} Q_{e s p} n(r) d r \\
\omega_{0}=\frac{\alpha_{e s p}}{\alpha_{e x t}}
\end{gathered}
$$

Define-se também o parâmetro de assimetria, que representa o grau de assimetria do espalhamento, conforme a equação (22). Seu valor varia entre 1 e -1 , de forma que $g=0$ indica espalhamento simétrico, $g=-1$ retroespalhamento e $g=1$ espalhamento frontal.

$$
g=\frac{1}{2} \int_{0}^{\pi} P(\theta) \cos \theta \sin \theta d \theta
$$


A função de fase é frequentemente escrita a partir dos polinômios de Legendre:

$$
P(\theta)=\sum_{j=0}^{N} \chi_{j} P_{j}(\theta)
$$

Os $\chi_{j}$ presentes na equação anterior são os coeficientes da expansão (equação $(24)$ ) e $P_{j}$ os polinômios de Legendre de grau $j$.

$$
\chi_{j}=\frac{2 j+1}{2} \int_{-1}^{1} P(\cos (\theta)) P_{j}(\cos (\theta)) d \cos (\theta)
$$

Esta aproximação é extensamente utilizada em códigos de transferência radiativa, com melhores resultados a medida que mais polinômios são considerados. Quanto maiores as partículas, maior deve ser o número de termos para a obtenção de um resultado de qualidade. Isto acontece porque a complexidade da função de fase é aumentada conforme o parâmetro de tamanho $x$, como ilustrado na figura 13.

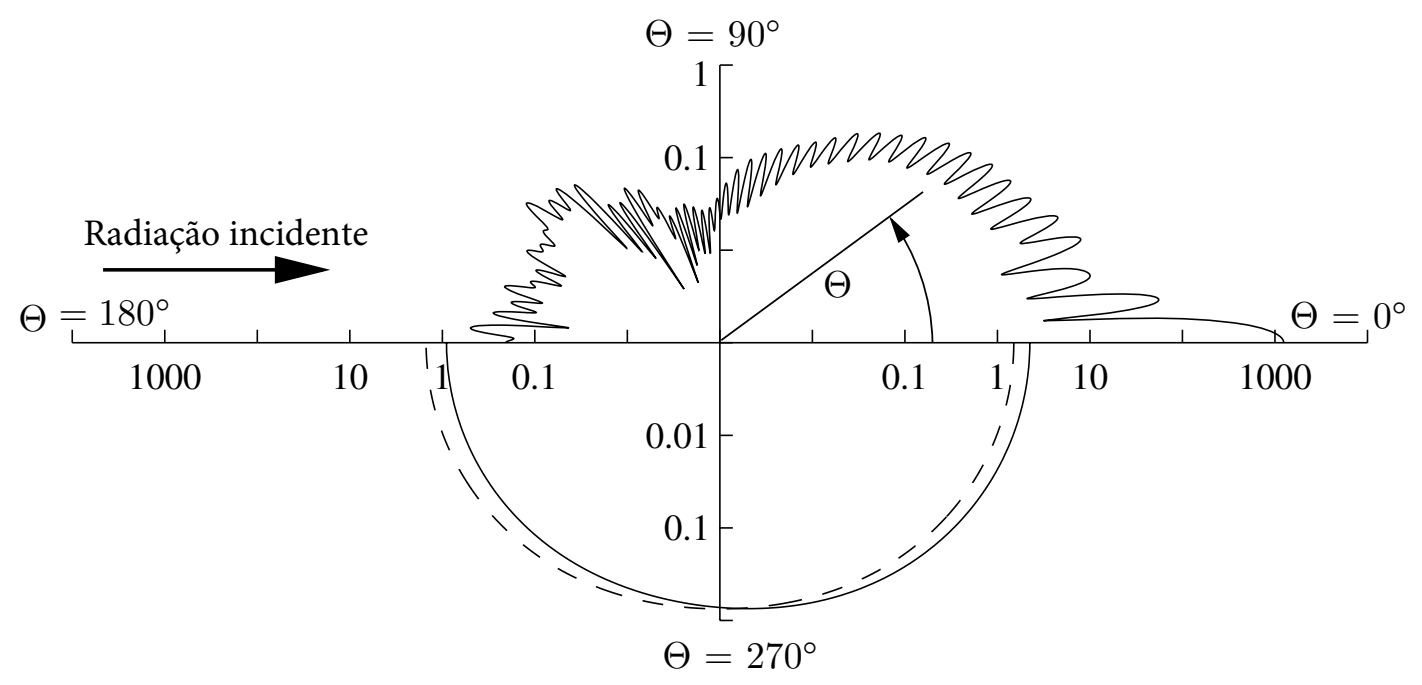

Figura 13 - Função de fase para $\mathrm{m}=1,33+\mathrm{i} 0$; Na linha tracejada $x=0,01$, a linha sólida na parte inferior apresenta $x=1$ e a curva sólida na parte superior $x=50$. (Zdunkowski et al., 2007) 
3.3.2 Lei de Beer-Lambert-Bouguer e Absorção

A radiância espectral incidente $\left(L_{\lambda}(0)\right)$ em um meio homogêneo de espessura $s$, ilustrada na figura 14, poderá sofrer atenuação por absorção ou espalhamento.

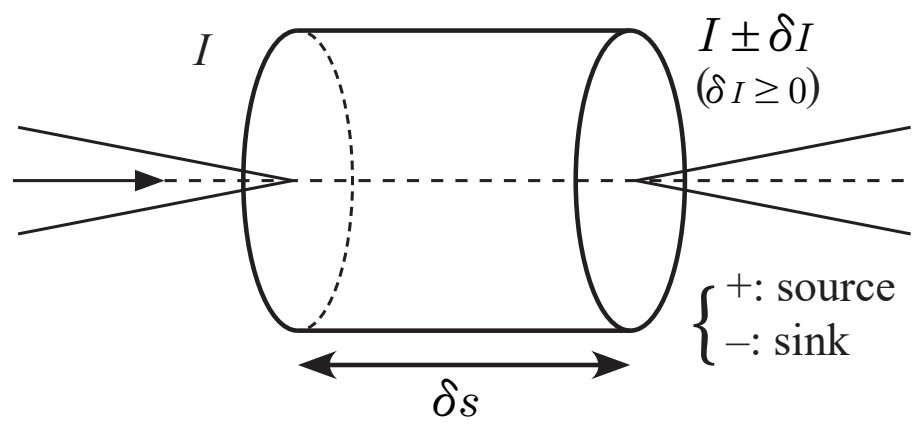

Figura 14 - Representação gráfica para Lei de Beer. (Sena, 2013)

Assim, a radiância espectral emergente $\left(L_{\lambda}(s)\right)$ naquela direção será dada pela Lei de Beer-Lambert-Bouguer (equação (25)), também conhecida como Lei de Beer-Lambert ou apenas Lei de Beer.

$$
L_{\lambda}(s)=L_{\lambda}(0) e^{-\delta_{\lambda}}
$$

em que $\tau$ é a espessura óptica, definida por:

$$
\delta_{\lambda}=\int_{0}^{s} b_{\lambda} d s
$$

sendo $b$ é o coeficiente linear de extinção do meio.

\subsubsection{Espessura e Profundidade Óptica}

A equação (26), que se refere à espessura óptica do meio, está associada ao caminho óptico percorrido pelo feixe de radiação solar, que é maior à medida que o ângulo zenital solar aumenta, conforme figura 15.

Assim, define-se a profundidade óptica como a espessura óptica projetada na direção vertical $\left(\theta_{0}=0^{\circ}\right)$ :

$$
\tau_{\lambda}=\delta_{\lambda} \cdot \cos \left(\theta_{0}\right)
$$




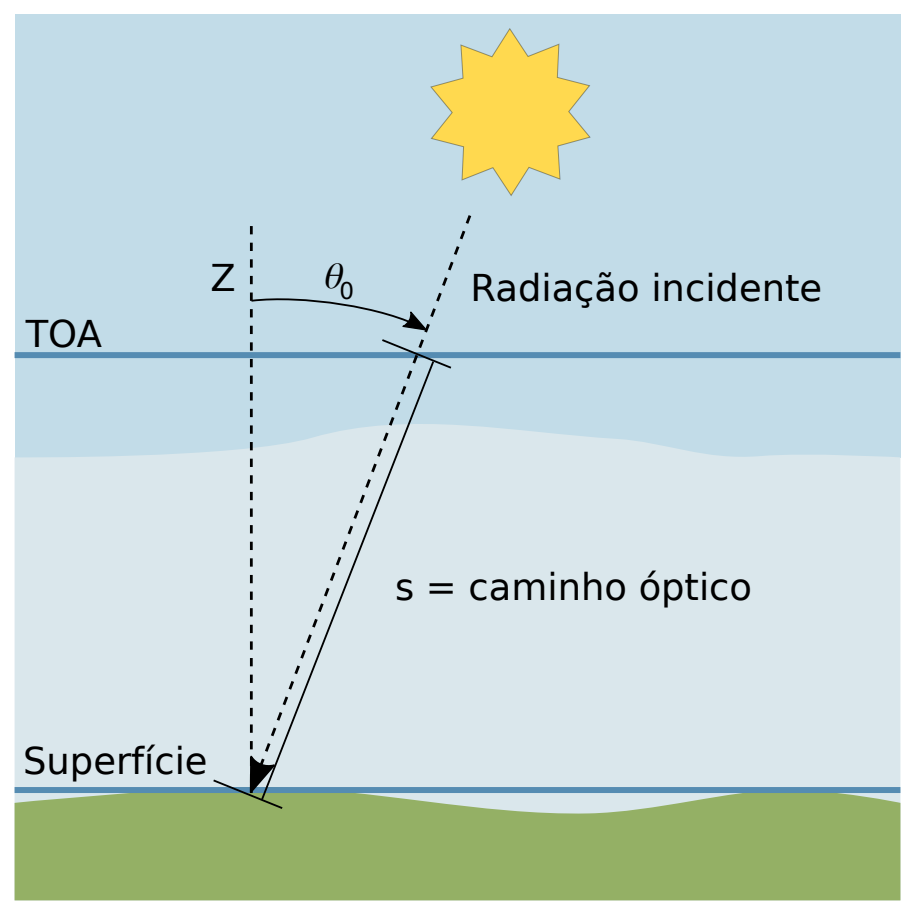

Figura 15 - Representação para interação entre radiação eletromagnética incidente na atmosfera. Adaptado de (Sena, 2013).

A profundidade óptica pode ser decomposta em suas componentes devido à extinção da radiação por moléculas, aerossol e nuvens. No caso de nuvem será amplamente utilizado neste trabalho o termo COD (Cloud Optical Depth), a profundidade óptica associada à uma nuvem para um determinado comprimento de onda.

3.3.4 A Equação de Transferência Radiativa (ETR) para atmosfera plano-paralela

Uma boa aproximação das características e propriedades atmosféricas, muito utilizada na comunidade científica, é a de atmosfera plano-paralela. Para esta aproximação, considera-se que as variações verticais são mais significativas que as horizontais e que a espessura da atmosfera (cerca de $120 \mathrm{~km}$ ) é muito inferior ao raio terrestre (aproximadamente $6300 \mathrm{~km}$ ). Assim, a atmosfera é vista como um conjunto de camadas horizontalmente homogêneas estruturadas verticalmente Yamasoe and Corrêa (2016), caracterizadas por propriedades homogêneas, como por exemplo, temperatura e profundidade óptica.

Nas seções anteriores foram apresentadas, independentemente, algumas interações possíveis entre um feixe incidente e um meio material. Considerando conjuntamente os 
efeitos de adição e remoção de energia por absorção, espalhamento e emissão térmica, um feixe que atravessa uma atmosfera plano-paralela pode ser descrito pela equação (28):

$$
\mu \frac{\mathrm{d} L_{\lambda}\left(\tau_{\lambda}, \mu, \phi\right)}{\mathrm{d} \tau_{\lambda}}=L_{\lambda}\left(\tau_{\lambda}, \mu, \phi\right)-S_{\lambda}\left(\tau_{\lambda}, \mu, \phi\right)
$$

em que $\tau_{\lambda}$ é a profundidade óptica de extinção, $\phi$ representa o ângulo azimutal, $\mu=\cos (\theta)$ e $S_{\lambda}$ representa a radiação adicionada ao feixe incidente.

Incluindo condições de equilíbrio termodinâmico local, no qual os parâmetros intensivos variam tão lentamente que se pode assumir equilíbrio termodinâmico ao redor de um ponto, é possível reescrever a equação (28) como:

$$
\mu \frac{\mathrm{d} L_{\lambda}\left(\tau_{\lambda}, \mu, \phi\right)}{\mathrm{d} \tau_{\lambda}}=L_{\lambda}\left(\tau_{\lambda}, \mu, \phi\right)-\omega_{0}\left(\tau_{\lambda}\right) J_{\lambda}\left(\tau_{\lambda}, \mu, \phi\right)-\left[1-\omega_{0}\left(\tau_{\lambda}\right)\right] B_{\lambda}\left(\tau_{\lambda}, \mu, \phi\right)
$$

em que $B\left(T\left(\tau_{\lambda}\right)\right)$ é a função de Planck de emissão de corpo negro para um corpo à temperatura $T$; $\omega_{0}$ é o albedo de espalhamento simples, que é a razão entre a eficiência de espalhamento e a eficiência total de extinção; e $J$ é a função fonte do espalhamento múltiplo definida pela equação (30).

$$
J_{\lambda}=\frac{1}{4 \pi} \int_{0}^{2 \pi} \int_{-1}^{1} L_{\lambda} P_{\lambda} d \mu d \phi
$$

Essa aproximação de atmosfera plano-paralela, que consiste em avaliar a atmosfera como uma sequência de camadas planas, paralelas e homogêneas, é utilizada no método DISORT Discrete Ordinates Radiative Transfer Program for a Multi-Layered Plane-Parallel Medium) de resolução da ETR (Stamnes et al., 1988), a ser explicado resumidamente no próximo capítulo.

\subsection{Método numérico de solução da ETR}

Considerando a equação de transferência radiativa (equação (29)), nota-se que mesmo utilizando aproximações de atmosfera plano-paralela, são necessários métodos numéricos para sua resolução computacional. 
$\mathrm{Na}$ literatura podem ser encontrados diversos métodos de resolução da ETR, entre eles: método de dois fluxos (Kylling et al., 1995), método zonal (Hottel and Cohen, 1958), método de Monte Carlo (Howell, 1998), entre outros. Neste trabalho serão empregados modelos de transferência radiativa de solução baseada no método de ordenadas discretas, especificamente o DISORT (Stamnes et al., 1988) a ser explicado a seguir.

O DISORT é provavelmente método de resolução da ETR mais aplicado pela comunidade científica(Mayer et al., 2012). Além de versátil e com custo computacional viável para computadores médios, é possível encontrar grande apoio para sua implementação na comunidade científica. O código do DISORT, desenvolvido por Stamnes et al. (1988), em FORTRAN, é utilizado diretamente em diversos modelos de transferência radiativa, como o SBART (Ricchiazzi et al., 1983) e o MODTRAN (Anderson et al., 1999), ou em outras linguagens, como é o caso do libRadtran que usa uma versão em C do DISORT (Mayer et al., 2012).

\subsubsection{DISORT}

O DISORT, DIScrete Ordinate Radiative Transfer, é um método de resolução para a ETR, proposto por Chandrasekhar (1960) e Stamnes et al. (1988), em atmosfera 1-D plano-paralela, utilizando ordenadas discretas.

Expandindo a função de fase $P(\tau, \mu)$ em série, uma soma de $2 \mathrm{~N}$ polinômios de Legendre, e escrevendo $L_{\lambda}\left(\tau_{\lambda}, \mu, \phi\right)$ como uma série de Fourier, tem-se, excluindo o $\lambda$ subescrito por simplicidade de notação:

$$
L(\tau, \mu, \phi)=\sum_{m=0}^{2 N-1} L^{m}(\tau, \mu) \cos ^{m}\left(\phi_{0}-\phi\right)
$$

A ETR (29) pode ser reescrita como:

$$
\mu_{i} \frac{\mathrm{d} L^{m}\left(\tau, \mu_{i}\right)}{\mathrm{d} \tau}=L^{m}\left(\tau, \mu_{i}\right)-\sum_{j=-N j=0}^{N} w_{i} D^{m}\left(\tau, \mu_{i}, \mu_{j}\right) \times L^{m}\left(\tau, \mu_{j}\right)-Q^{m}\left(\tau, \mu_{i}\right)
$$

$\operatorname{com} i= \pm 1, \ldots, \pm N \mathrm{e}$

$$
D^{m}\left(\tau, \mu, \mu^{\prime}\right)=\frac{\omega(\tau)}{2} \sum_{l=m}^{2 N-1}(2 l+1) g_{l}^{m}(\tau) P_{l}^{m}(\mu) P_{l}^{m}\left(\mu^{\prime}\right)
$$




$$
\begin{gathered}
Q^{m}(\tau, \mu)=X_{0}^{m}(\tau, \mu) \exp \left(-\tau / \mu_{0}\right)+\delta_{m 0} Q^{\text {thermal }}(\tau) \\
X_{0}^{m}(\tau, \mu)=\frac{\omega(\tau) L_{0}}{4 \pi}\left(2-\delta_{m 0}\right) \sum_{l=0}^{2 N-1}(-1)^{l+m}(2 l+1) \times g_{l}^{m}(\tau) P_{l}^{m}(\mu) P_{l}^{m}\left(\mu_{0}\right)
\end{gathered}
$$

$P_{l}^{m}$ são os polinômios de Legendre associados, $\theta$ o ângulo entre a direção incidente e a espalhada, $\delta_{m 0}=1$ se $m=0, \delta=0$ caso contrário, $g_{l}(\tau)=\frac{1}{2} \int_{-1}^{1} P_{l}(\cos \theta) P(\tau, \cos \theta) d \cos \theta$ e $g_{l}^{m}(\tau)=g_{l}(\tau) \frac{(l-m) !}{(l+m) !}$.

A equação (32) pode ser vista como um sistema de $2 \mathrm{~N}$ equações diferenciais acopladas com coeficientes não constantes, sem solução analítica. Assim, para que possua solução, é considerado que $\tau$ e a função de fase são constantes em uma camada, e a contribuição térmica pode ser aproximada por um polinômio para cada $\tau$. Essas equações serão então resolvidas empregando a quadratura de Gauss, que aproxima integrais a somas finitas:

$$
\int_{4 \pi} f d \Omega=\sum_{i=1}^{N} \omega_{i} f\left(s_{i}\right)
$$

$\operatorname{com} \omega_{i}$ sendo a ponderação de cada termo da soma. Demais detalhes podem ser vistos em (Stamnes et al., 2000).

O algoritmo do DISORT pode ser resumido conforme o fluxograma apresentado na figura 3.5. O loop interno obtém as soluções homogêneas e particulares para cada camada. Já o externo determina os fluxos em sua primeira execução e, se necessário, as demais execuções calculam as intensidades no azimute específicado pelo usuário.

\subsection{Propriedades de nuvens no contexto de simulações de transferência radiativa}

Ao considerar o sensoriamento remoto, deve-se notar que nuvens apresentam maior complexidade para tratamento considerando a solução da ETR que outros constituintes. Gases atmosféricos, assim como a superfície, apresentam maior estabilidade no tempo. Os aerossóis, por sua vez, são menos espessos e possuem menor interação com a radiação incidente. Assim, a determinação de propriedades ópticas de nuvens é etapa essencial em um contexto de solução de ETR. 


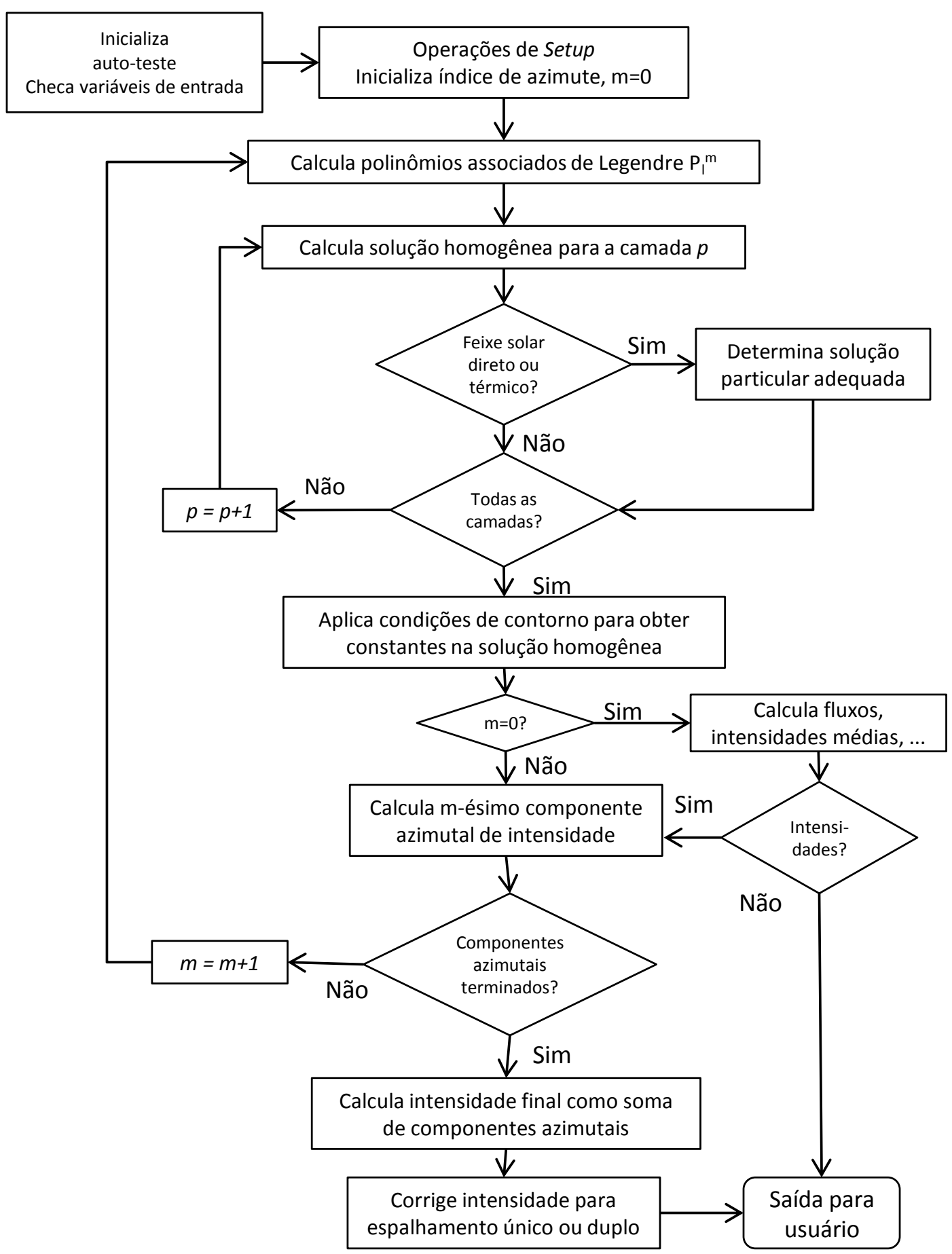

Figura 16 - Fluxograma do algoritmo DISORT, traduzido de (Stamnes et al., 2000).

Dentre essas propriedades, são destacadas a profundidade óptica de nuvem (COD do inglês Cloud Optical Depth) e o raio efetivo das partículas de nuvem. A profundidade óptica da nuvem representa a atenuação da radiação em seu caminho óptico devido às 
partículas de nuvem, conforme representado na equação (27), e é proporcional à espessura geométrica e ao coeficiente de extinção. O raio efetivo é a medida do tamanho médio em uma população de partículas (Wyser, 1998), definido como:

$$
r_{e f f}=\frac{\int_{0}^{\infty} \pi r^{3} n(r) d r}{\int_{0}^{\infty} \pi r^{2} n(r) d r}
$$

em que $n(r)$ é a distribuição de tamanho para $r$, raio da partícula. Assume-se uma distribuição gamma de tamanho, descrita pela equação 38, com parâmetros $m$ e $\Lambda$ frequentemente determinados empiricamente (Morrison et al., 2005; Mayer et al., 2004).

$$
n(r)=n_{0} r^{m} \exp \{-\Lambda r\}
$$

Enquanto gotículas de água podem ser representadas como esferas perfeitas, cristais de gelo apresentam diversos formatos, de forma que a determinação de seu raio efetivo se dá com a utilização do máximo comprimento $L$ ao invés de $r$, com sua distribuição $n(L)$ (Wyser, 1998). A parametrização de $L$ pode variar para diferentes cristais ou técnicas aplicadas. No entanto, para efeito de simplicidade, neste trabalho a dimensão efetiva característica das partículas de nuvem de gelo serão representadas também por $r_{e f f}$.

A interação entre gotículas de nuvem e a radiação pode se dar por espalhamento e, para determinados comprimentos de onda, a teoria Mie é utilizada para descrição dessa interação que é fortemente relacionada com o raio efetivo e a distribuição de tamanho na nuvem.

É possível considerar que o raio efetivo é homogêneo para uma camada horizontal e que o $r_{\text {eff }}$ no topo de uma nuvem é adequadamente similar à mesma característica dentro de uma nuvem na mesma altura, desde que não haja precipitação sobre esse volume (Rosenfeld et al., 2014).

Também é definido o caminho integrado de água líquida (LWP - do inglês Liquid Water Path) como:

$$
L W P=\int_{z_{0}}^{z_{1}} L W C d z
$$

com $L W C$ sendo o conteúdo de água líquida (do inglês Liquid Water Content) em $\mathrm{g} / \mathrm{cm}^{3}$. 
Pode-se notar que, quanto maior o LWP, maior a atenuação na radiação e o albedo da nuvem. Modelos de transferêcia radiativa podem fazer uso de uma relação entre $r_{\text {eff }}$, COD e LWP (Ricchiazzi, 2002; Marshak et al., 2006) como descrita a seguir:

$$
C O D=\frac{3}{4} \frac{Q_{e x t} L W P}{\rho r_{e f f}}
$$

onde $\rho$ é a densidade da água (ou gelo, para caso de nuvens de gelo) e $Q_{e x t}$ o fator de eficiência de extinção (equação (17)). Para nuvens de gelo são considerados IWC (Ice Water Content) e IWP (Ice Water Path), análogos à LWC e LWP definidos anteriormente. 


\section{Materiais e métodos}

\subsection{Modelos de Transferência Radiativa}

\subsubsection{SBDART}

O Santa Barbara DISORT Atmospheric Radiative Transfer, SBDART, é um modelo de transferência radiativa que aplica o DISORT para resolução da ETR. Baseado no LOWTRAN (Kneizys et al., 1988) e no MODTRAN (Berk et al., 1999), o SBDART propõe calcular irradiâncias e radiâncias não só em atmosferas limpas, mas também em atmosfera com nuvens. O código, desenvolvido em FORTRAN 77, é amplamente utilizado pela comunidade científica mesmo tendo atualizações suspensas há aproximadamente dez anos.

\subsubsection{Parametrizações relevantes}

No SBDART, a ETR pode ser resolvida para um comprimento de onda único ou um intervalo, indicados em $\mu m$ (com precisão de até 10nm). É necessário indicar o espectro extraterrestre (solar) que deve ser usado para a simulação que pode ser um dos três padrões disponíveis (LOWTRAN7, 5s e MODTRAN-3) ou através da leitura de um arquivo informado pelo usuário. Além disso, é possível considerar ou não as emissões térmicas na resolução.

No que diz respeito à superfície, têm-se seis superfícies básicas: oceano, lago, água limpa, vegetação, neve e deserto. Essas seis superfícies básicas compõem diferentes combinações para melhor aproximação da refletividade de dada superfície. Caso necessário, também é possível indicar o albedo da superfície diretamente no arquivo de entrada; esse albedo será válido para todos os comprimentos de ondas no intervalo informado para a execução, podendo ser uma função espectral ou um valor constante para todos os comprimentos de onda.

O SBDART possui seis perfis atmosféricos para utilização, além da possibilidade de informar um arquivo com dados específicos para caracterização da atmosfera, ou editar, no arquivo de entrada para execução, a concentração de alguns gases de interesse. No que diz respeito à absorção molecular, o SBDART emprega modelos de baixa resolução 
desenvolvidos para o LOWTRAN 7 (Kneizys et al., 1988), com resolução de cerca de 5nm para o espectro visível e 200nm no infravermelho térmico. Também é possível o emprego de padrões para partículas de aerossol atmosférico ou de definições específicas apresentadas pelo usuário para determinação de espessura óptica de aerossol.

Para resolver a ETR em uma atmosfera com nuvem, é necessário a determinação de algumas grandezas: o coeficiente de eficiência de extinção $\left(Q_{\text {ext }}\right.$ - equação $\left.(17)\right)$, o albedo de espalhamento simples ( $\omega$ - equação (21)), que indica a probabilidade de que a interação com um fóton resulte em espalhamento, e o fator de assimetria (equação (22)), que indica a intensidade do espalhamento frontal. Essas grandezas foram pré-calculadas para gotículas esféricas de raio efetivo entre 2 e $128 \mu \mathrm{m}$ aplicando um código Mie (Stackhouse and Stephens, 1991), que aplica uma distribuição gamma modificada para representação da distribuição de tamanho de gotículas.

Ao inserir uma nuvem na atmosfera a ser considerada, sua espessura é estimada com a determinação da altura de sua base e de topo. Existe a possibilidade de inserção de várias nuvens em diversas camadas.

Para simulações com nuvens de gelo, o SBDART usa parâmetros pré-calculados a partir da teoria Mie para partıculas esféricas de gelo. O código não permite cálculos para particulas de gelo com hábitos diferentes

\subsection{2 libRadtran}

O libRadtran é uma biblioteca de ferramentas para cálculos relativos à transferência radiativa na atmosfera. Assim como o SBDART, radiâncias e irradiâncias podem ser calculadas pelo software para uma dada situação atmosférica com ou sem nuvens e aerossol (Mayer and Kylling, 2005; Emde et al., 2016). Além disso, radiâncias polarizadas, fluxos actínicos, temperatura de brilho e outras grandezas podem ser calculadas através do pacote.

Seu principal programa, o uvspec, resolve a ETR para determinada situação definida pela descrição atmosférica e de propriedades ópticas. Também está presente na biblioteca uma ferramenta para a determinação de propriedades ópticas de partículas líquidas de nuvem com base na teoria Mie (Mie tool). 
Diferentemente do SBDART, sem manutenção há mais de dez anos, aprimoramentos e melhorias ainda estão sendo implementados no libRadtran, que teve sua versão mais recente, a 2.0.1, lançada em Abril de 2016.

\subsubsection{Parametrizações relevantes}

Assim como o SBDART, o libRadtran apresenta seis padrões atmosféricos para as concentrações gasosas: tropical, verão em latitudes médias, inverno em latitudes médias, atmosfera americana padrão, verão subártico, inverno subártico. Para diferentes perfis atmosféricos, é possível indicar arquivo para leitura no uvspec. O mesmo é possível para indicar o albedo de superfície em função do comprimento de onda. Essa grandeza também pode ser definida diretamente no arquivo de entrada, de forma que o albedo será o mesmo para todo comprimento de onda.

O espectro a ser simulado pode ser definido conforme os arquivos disponíveis junto com o pacote do libRadtran para espectro solar e terrestre. O modelo exige rodadas independentes para considerar as emissões térmicas terrestres e o espectro solar.

O libRadtran possui 5 diferentes parametrizações para cálculos referentes à absorção molecular: LOWTRAN, Kato (1 e 2), Fu e Reptran. O LOWTRAN foi inserido no libRadtran devido à questões de compatibilidade e é equivalente ao implementado no SBDART. As parametrizações de Kato (Kato et al., 1999) possuem 575 bandas e apresentam coeficientes de absorção baseados no HITRAN (Fischer et al., 2003). Fu é uma parametrização desenvolvida para modelos climáticos de baixo custo computacional. Finalmente, o REPTRAN (Gasteiger et al., 2014) é uma parametrização inserida no libRadtran que utiliza uma soma com pesos para comprimentos de onda representativos no cálculo de quantidades integradas (por exemplo, irradiâncias). Essa parametrização apresenta três

diferentes resoluções de banda: fine (resolução de $1 \mathrm{~cm}^{-1}$ ), medium (resolução de $5 \mathrm{~cm}^{-1}$ ), coarse $\left(15 \mathrm{~cm}^{-1}\right)$.

Para aerossol atmosférico também é possível escolher opções pré-definidas. Além disso, parâmetros importantes como o albedo de espalhamento simples, o parâmetro de assimetria e espessura óptica, entre outros, podem ser definidos separadamente.

Nuvens de água e gelo são inseridas através de um arquivo informado pelo usuário. Nesse arquivo constam as alturas em relação à superfície, o conteúdo de água líquida ou 
gelo e o raio efetivo de hidrometeoros em cada camada. A conversão destes parâmetros microfísicos em propriedades ópticas se dá através da parametrização escolhida. A opção padrão do uvspec é a parametrização de Hu e Stamnes (Hu and Stamnes, 1993), porém há possibilidade de utilização de propriedades ópticas para nuvens de água obtidas através da aplicação da teoria Mie. Além de possuir uma ferramenta Mie (MIEV0), uma tabela pré-existente pode ser empregada para a obtenção por interpolação das propriedades ópticas considerando as características microfísicas inseridas no arquivo de entrada.

A ferramenta MIEVO calcula as propriedades ópticas utilizando a teoria Mie considerando os raios eftivos, intervalo de comprimento de onda e distribuição de gotas de interesse, indicados pelo usuário. Também é possível indicar a quantidade de termos na expansão de Legendre que deve ser utilizada no cálculo.

Para nuvens de gelo há uma maior quantidade de opções disponíveis. A opção padrão é a proposta por (Fu, 1996) e (Fu et al., 1998), na qual o raio efetivo considerado não segue a definição geral, dada pela equação (37), e é calculada considerando colunas hexagonais. Outras parametrizações estão disponíveis, como a de (Yang et al., 2000), que é similar a de (Key et al., 2002), porém com cálculos de espalhamento mais recentes para comprimentos de onda maiores que 3400nm. Utilizando dados de espalhamento simples e supondo uma distribuição gamma para o tamanho dos cristais, também é possível escolher a parametrização de (Yang et al., 2013). Todas essas parametrizações citadas consideram apenas um hábito na estrutura da nuvem. Apenas duas opções de parametrização apresentam opção para uma mistura pré determinada de hábitos: Hey e Baum (Baum et al., 2005, 2007).

Foi escolhida para a utilização a proposta por (Baum et al., 2007), com a mistura de hábitos descrita em (Baum et al., 2005). Essa escolha foi feita buscando uma concordância frente à tendência da comunidade de sensoriamento remoto que a utiliza para produtos de raio efetivo, como no MODIS (Menzel et al., 2015). Isto não garante que esta seja a representação mais correta a ser utilizada para toda nuvem de gelo, já que a dinâmica na formação de cristais não é necessariamente igual em todas as regiões do mundo. No entanto, esse é um padrão adotado em grande parte dos trabalhos e apresenta melhores resultados que o uso de um único hábito, e por isso escolheu-se essa parametrização.

O libRadtran possui diversas formas de resolução da ETR (solvers), entre outros:

disort versão traduzida para C do DISORT; 
fdisort2 DISORT 2.0 em fortran77;

fdisort1 DISORT 1.3 em fortran77;

sdisort DISORT 1.3 com extensão de resolução pseudoesférica;

twostr resolução da ETR considerando dois fluxos (two streams) para irradiâncias;

polradtran resolução da ETR incluindo polarização 1D;

mystic determinação de radiâncias, com polarização, em 3D através do método de Monte Carlo.

Neste trabalho o método escolhido foi o DISORT, em C.

\subsection{Diagrama de Nakajima-King}

A avaliação da sensibilidade da refletância em relação à profundidade óptica e ao raio efetivo pode ser apresentada em um diagrama, como o da figura 17 (Nakajima and King, 1990). Para construção desse diagrama, a ETR deve ser resolvida em dois comprimentos de onda para diversas combinações de raios efetivos e profundidades ópticas considerando mesma geometria de observação, superfície e atmosfera.

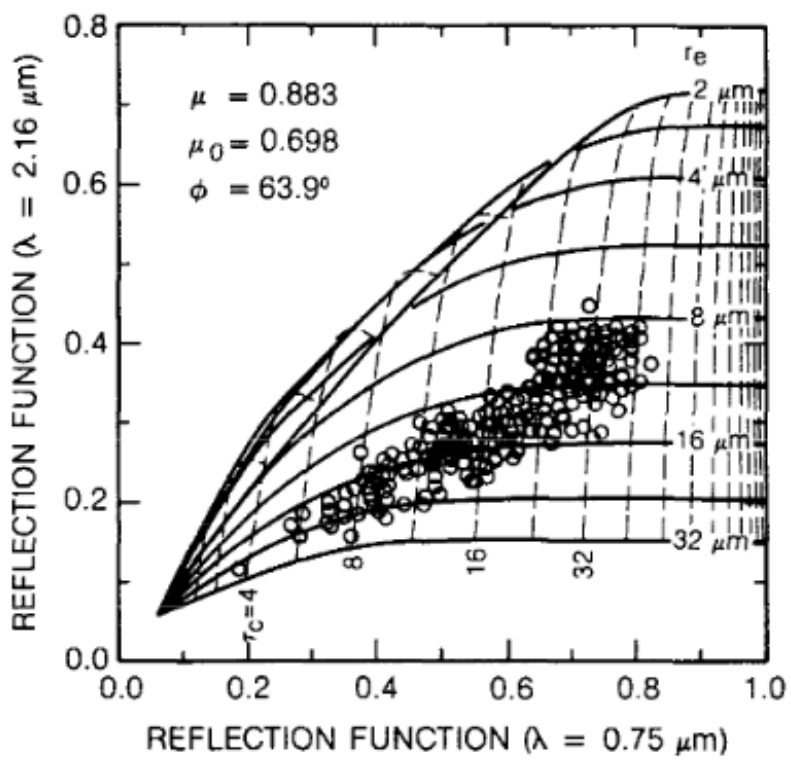

Figura 17 - Diagrama Nakajima-King apresentado em (Nakajima and King, 1990). Refletâncias calculadas para diferentes valores de COD em 0,75 $\mu \mathrm{m}$ e diferentes raios efetivos nos comprimentos de onda $0,75 \mu \mathrm{m}$ e 2,16 $\mu \mathrm{m}$. Alguns dados medidos sobre stratocumulus estão sobrepostos ao diagrama. 
É possível observar que a profundidade óptica apresenta grande relação com a refletância em um comprimento de onda não absorvedor $(0,75 \mu m)$ e pouca dependência no raio efetivo. O comportamento oposto pode ser visto considerando um comprimento de

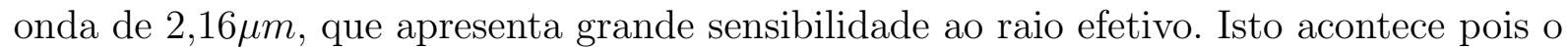
livre caminho médio dos fótons é maior em comprimentos de onda pouco absorvedores. Esses fótons interagem mais com a nuvem antes de serem totalmente absorvidos, sendo, então, mais sensíveis a profundidade óptica da nuvem. Os fótons fortemente absorvidos não penetram ao longo da espessura da nuvem a ponto de serem sensíveis ao COD, sendo mais sensíveis ao tamanho das gotas.

Os comprimentos de onda são escolhidos de forma que não apresentem absorção por vapor d'água e tenham diferentes interações com partículas de nuvem. De fato, outros comprimentos de onda podem ser escolhidos para a construção desse diagrama, como o apresentado na figura 31, de Kaufman and Nakajima (1993).

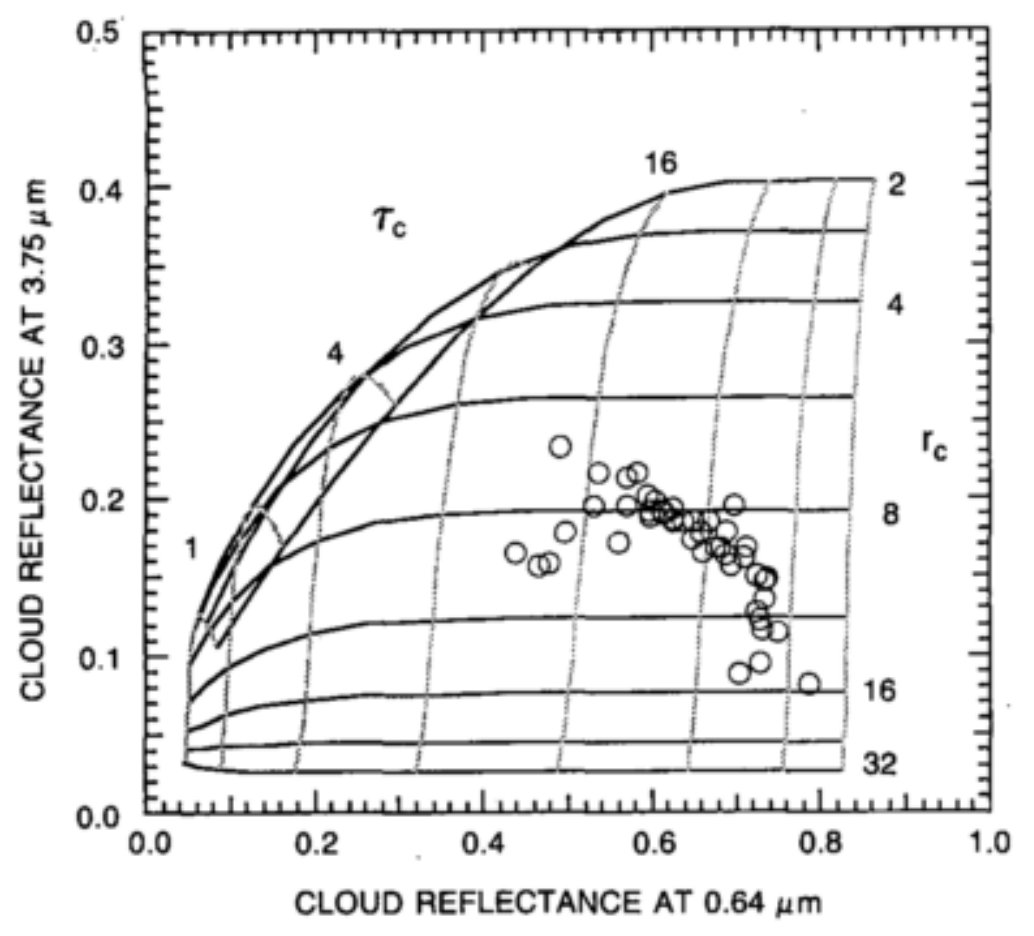

Figura 18 - Diagrama Nakajima-King apresentado em (Kaufman and Nakajima, 1993). Refletância nos comprimentos de onda $0,64 \mu \mathrm{m}$ e 3,75 $\mu \mathrm{m}$ para nuvens em diferentes combinações de profundidade óptica e raio efetivo com ângulo solar zenital de $60^{\circ}$ e ângulo zenital de observação médio de $10^{\circ}$. 
Nos dois diagramas apresentados, nota-se que para profundidades ópticas grandes as tendências são quase ortogonais. Isso evidencia que em um comprimento de onda no visível, por exemplo, a refletância não apresenta grandes variações para diferentes raios efetivos. Dessa forma, para a investigação de propriedades microfísicas, como raio efetivo, em nuvens espessas, as simulações em comprimento de onda no infravermelho próximo se faz mais relevante.

\subsection{GOES-13}

Além de equipamentos de monitoramento espaciais para seu correto funcionamento, o satélite está equipado com um sondador (Sounder) e um gerador de imagens (Imager). O Imager possui cinco canais de medição: 520 a 710 nm, 3753 a 4070 nm, 5800 a 7300 nm, 10,20 a 11,20 $\mu \mathrm{m}$ e 13,00 a 13,70 $\mu \mathrm{m}$. As imagens obtidas da região Amazônica tem ângulo de visada (view zenith angle) entre $10^{\circ}$ e $30^{\circ}$ e resoluções nominais de $1 \mathrm{~km}$ para medidas no canal 1, $4 \mathrm{~km}$ para os canais 2 e 3 e $8 \mathrm{~km}$ para o canal 4 . Para o desenvolvimento de look-up tables são utilizados os dois primeiros canais, com funções espectrais de resposta (funções "filtro") conforme apresentado na figura 19.
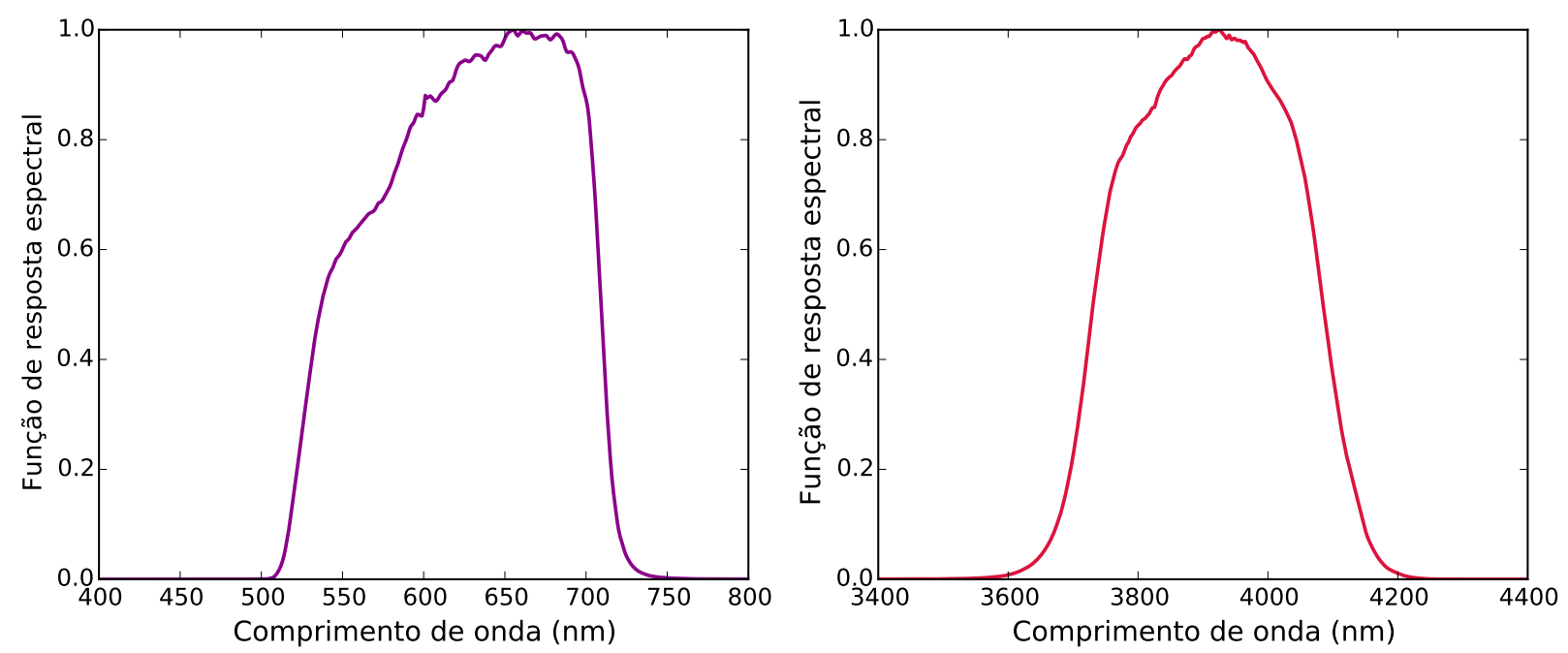

Figura 19 - Funções de resposta para os canais 1 e 2 do Imager do GOES-13 ${ }^{1}$.

0 GOES-8 through GOES-15 Imager Spectral Response Functions, 2011. URL http://www .ospo.noaa. gov/Operations/GOES/goes-imager-srfs.html, acesso em 10/09/201 


\subsection{Análises propostas neste trabalho}

4.4.1 Análise comparativa e validação do libRadtran

Como etapa inicial, foi feita uma análise comparativa dos resultados e das ferramentas disponíveis nos modelos estudados: libRadtran e SBDART. A comparação foi dividida em duas partes:

Superfície e Gases: Avaliação da resposta, em condições equivalentes, para radiância e irradiâncias dadas as variações em albedo de superfície (entre 0 e 1), e variações na quantidade de $\mathrm{H}_{2} \mathrm{O}$ (entre 0 e $80 \mathrm{~mm}$ )e de $\mathrm{O}_{3}$ (entre 250 e $450 \mathrm{DU}$ ) disponíveis na atmosfera;

Nuvens: Comparação dos resultados para nuvens de água fornecidos pelo libRadtran com os obtidos pelo SBDART com parametrização equivalente, para diferentes raios efetivos.

As análises foram feitas considerando dois comprimentos de onda únicos $(\Delta \lambda$ mínimo), 640nm e 3900nm, representativos para os canais 1 e 2 do GOES-13, para minimizar as possíveis diferenças referentes aos métodos de integração utilizados pelos dois modelos. Também foram utilizados intervalos referentes aos comprimentos de onda visíveis (VIS), de 590 a $660 \mathrm{~nm}$, e aos comprimentos de onda na região do infravermelho (IR), de 3850 a 4000 nm. Para a resolução da ETR no libRadtran, escolheu-se o DISORT com sua versão em C, que apresenta melhorias no desempenho, sem diferença significativa no resultado em relação ao DISORT 2.3 em FORTRAN.

\subsubsection{Estudo do libRadtran}

Após a validação do libRadtran como modelo de comportamento similar ao SBDART, outras características deste modelo foram investigadas para que melhores escolhas fossem feitas para o desenvolvimento das look-up tables. No que diz respeito a resolução da ETR, foram analisados os resultados de simulações para diferentes valores de ângulo de visada, $10^{\circ}, 20^{\circ}$ e $30^{\circ}$, com ângulo solar zenital (SZA) de $30^{\circ}$ em atmosfera com nuvens de água e gelo. Os cálculos de radiância efetuados pelo libRadtran neste trabalho tem altura de observação no topo da atmosfera (TOA), que corresponde a $120 \mathrm{~km}$ para o modelo. 
Considerando nuvens de água, foram avaliadas as refletâncias para diferentes combinações de alturas de base e topo de nuvem, com quatro diferentes raios efetivos $(2 \mu m$, $20 \mu m, 40 \mu m$ e $59 \mu m)$. A ferramenta Mie foi escolhida para um cálculo mais preciso das propriedades ópticas em nuvens de água. Avaliando as refletâncias para diferentes alturas de topo de nuvem, foi determinada uma função de correção percentual na refletância em função da altura da nuvem medida.

Analogamente às nuvens de água, a análise para nuvens de gelo consiste na avaliação das refletâncias obtidas para diferentes alturas de base e topo de nuvem. Para esta etapa, considera-se que a nuvem é formada por uma combinação pré-determinada de cristais com hábitos diversos, na parametrização de Baum (Baum et al., 2005), similar à utilizada em inferências de propriedades microfísicas obtidas com o sensor MODIS (Platnick et al., 2003). Também foi encontrada uma correção para as refletâncias de nuvem de gelo análoga à determinada para nuvens de água, isto é, considerando-se várias combinações de altura da base e de topo das nuvens de gelo. Essas funções de correção para nuvens de água e de gelo permitem que os resultados aqui obtidos possam ser aplicados em casos de nuvens com dimensões geometricas diversas das usadas nas simulações realizadas neste trabalho.

\subsubsection{Tabela de referência}

O uso de tabelas de referência, comumente chamadas de look-up tables (LUT), é frequente em estudos de sensoriamento remoto (e.g. (Platnick et al., 2003; Kaufman and Nakajima, 1993; King et al., 1992a; Nakajima and King, 1990) e consiste na determinação de uma vasta tabela de valores chave para consulta futura e inferência de grandezas de interesse. Produtos de nuvem de diversas missões, como o MODIS (Menzel et al., 2015; Heidinger et al., 2015), utilizam essa técnica para a inferência de COD e raios efetivos. Pode-se considerar que os dados simulados para a obtenção de diagramas Nakajima-King, como exposto anteriormente, constituem uma look-up table.

Tabelas de referências apresentam irradiâncias, radiâncias e refletâncias calculadas para todas as combinações possíveis dado um conjunto de valores pertinentes para cada parâmetro de entrada nos modelos de transferência radiativa. Neste trabalho foram simuladas situações considerando 16 valores de ângulo solar zenital $\left(\theta_{0}\right.$ ou simplesmente SZA) entre 0 e $75^{\circ}$, três valores para ângulo zenital de observação ( $\theta$ ou VZA) entre $10^{\circ}$ e 
$30^{\circ}$ e dois valores de ângulo azimutal relativo ( $\phi$ ou PHI), $150^{\circ}$ e $30^{\circ}$, correspondendo a situações da manhã e tarde, respectivamente. Os parâmetros simulados e valores variados para nuvens de água e gelo estão apresentados detalhadamentes no apêndice. Os códigos utilizados para as simulações estão disponíveis para livre acesso e edição na internet ${ }^{2}$.

Com as radiâncias medidas em dois canais diferentes, excluindo convenientemente as emissões térmicas dos constituintes atmosféricos e da superfície terrestre, procura-se na LUT a combinação simulada que melhor se adequa, com interpolações lineares entre dois pontos consecutivos quando necessário.

Neste trabalho foi utilizada uma profundidade óptica única de valor 50, correspondendo a uma nuvem espessa característica, representando nuvem de convecção profunda típica da região tropical. É importante lembrar que um aumento no COD não apresentaria diferenças significativas nas radiâncias calculadas no canal visível, de forma que os resultados com $\mathrm{COD}=50$ apresentariam mínimas diferenças dos obtidos com $\mathrm{COD}=$ 100, 200, etc, como ilustrado na figura 31.

Conforme discutido anteriormente, a sensibilidade na refletância em comprimentos de onda do infravermelho próximo é suficientemente grande para a determinação do raio efetivo de uma nuvem espessa, de forma que as radiâncias medidas em uma nuvem com $\mathrm{COD}=50$ no canal visível não seriam relevantes para este fim. Assim, neste trabalho foram desenvolvidas look-up tables para nuvens de água e gelo para o intervalo espectral referente ao canal 2 do GOES-13.

Também foram desenvolvidas look-up tables para os dois canais (1 e 2) utilizando seu comprimento de onda central, para nuvens de água e gelo. Assim, foi possível produzir diagramas Nakajima-King de dados para determinação de COD e raio efetivo através de medidas feitas pelo GOES-13 em uma determinada posição: $\theta_{0}=60^{\circ}, \phi=150^{\circ}$ e $\theta=30^{\circ}$.

2 Projeto disponível em: http://fap.if.usp.br/ acorreia/lut-libradtran 


\section{Resultados}

\subsection{Análise Comparativa entre SBDART e libRadtran}

Extensamente utilizado na comunidade científica para cálculos de transferência radiativa em diferentes condições atmosféricas, o SBDART é uma ferramenta estável e bem testada. Porém, sem suporte para atualizações há cerca de dez anos, faz-se necessária uma nova escolha para a realização dos cálculos necessários para pesquisas nesta área. O libRadtran se apresenta como opção por ser uma biblioteca de código aberto e livremente distribuído, possui o DISORT como um dos métodos de resolução da ETR, que é provavelmente o método de resolução mais amplamente implementado nos modelos empregados para pesquisa.

O libRadtran apresenta outras facilidades, como um arquivo de entrada de fácil compreensão, diversas parametrizações para aplicação em nuvens de água, de gelo, e em aerossóis, além da possibilidade de ler aquivos com propriedades ópticas para gotas e partículas esféricas. Também há disponibilização de ferramenta para cálculo dessas propriedades pela teoria Mie e é possível um output com diferentes grandezas além das irradiâncias e radiâncias, como refletância e temperatura de brilho.

Para validar essas funcionalidades e quantificar as possíveis diferenças estruturais e potenciais melhorias no libRadtran, foi realizada uma análise comparativa entre libRadtran e SBDART para as mais diversas situações atmosféricas.

Nestas análises, duas regiões do espectro eletromagnético foram consideradas: visível (VIS) e infravermelho (IR). Para cada uma dessas regiões duas abordagens foram utilizadas. Em uma delas o intervalo de comprimentos de onda é de 590 a 660nm para o visível e 3850 e 4000 nm para o infravermelho. Em outra, utiliza-se um único comprimento de onda ou seja, um intervalo com mesmo valor inicial e final. Dessa forma diferenças referentes à integração de um intervalo espectral são reduzidas. As precisões são de 1nm no SBDART e $0.1 \mathrm{~nm}$ no libRadtran.

A atmosfera indicada em ambos os modelos está apresentada no Apêndice A. Por alguma particularidade da versão do SBDART empregada nesta pesquisa, não foi possível indicar valores específicos para o perfil atmosférico, visto que o código não lia o arquivo designado para isto. Sendo assim, a atmosfera padrão Tropical utilizada pelo SBDART foi 
usada diretamente, com as conversões de unidades necessárias, como o perfil atmosférico informado no libRadtran.

As geometrias solar e de observação utilizada para todas as simulações deste capítulo são as indicadas na tabela 2. O espectro extraterrestre empregado nos dois modelos é um dos disponíveis pelo libRadtran (Kurucz, 1994).

Tabela 2 - Parâmetros usados na comparação entre libRadtran e SBDART (atmosfera sem nuvem)

\begin{tabular}{ll}
\hline & Valor \\
\hline Ângulo Solar Zenital (SZA) & $60^{\circ}$ \\
Ângulo Zenital de Observação & $10^{\circ}$ \\
Ângulo Azimutal de Observação & $30^{\circ}$ \\
Altura da observação & $100 \mathrm{~km}$ \\
Albedo de superfície & 0,1 \\
Atmosfera & padrão tropical do SBDART \\
Coluna total de ozônio & 25 DU \\
Vapor de água & $0 \mathrm{~mm}$ \\
Intervalo de comprimento de onda no visível (VIS) & $590-660 \mathrm{~nm}$ \\
Intervalo de comprimento de onda no infravermelho (IR) & $3850-4000 \mathrm{~nm}$ \\
Comprimentos de onda únicos & $640 \mathrm{~nm}$ e 3900nm \\
$\Delta \lambda$ em torno do comprimento de onda & $0,1 \mathrm{~nm}$ \\
\hline
\end{tabular}

Nestas condições básicas realizou-se uma simulação em cada modelo, sem demais especificações sobre os outros constituintes. Os resultados indicam uma mesma irradiância descendente direta a uma mesma altura. Essa compatibilidade nas irradiâncias, apenas com menor precisão de casas decimais no SBDART, se mantém em todas as análises feitas neste capítulo utilizando um comprimento de onda único no input. Nesse caso, é possível avaliar a refletância em cada ponto, como forma indireta de avaliar as diferenças possíveis nas radiâncias.

Já para os intervalos espectrais indicados, nota-se uma diferença entre as irradiâncias diretas descendentes entre SBDART e libRadtran, mesmo utilizando a mesma informação de radiância espectral solar. Os valores obtidos para essas grandezas nos intervalos calculados estão expostos na tabela 3 .

É possível que essa distância nos valores se deva aos diferentes algoritmos e intervalos de integração utilizados nos dois códigos. No entanto, para o intervalo visível o libRadtran apresenta diferença inferior a $0,2 \mathrm{~W} / \mathrm{m}^{2}$ e, para o infravermelho essa diferença não chega a $10^{-4} \mathrm{~W} / \mathrm{m}^{2}$. 
Tabela 3 - Irradiância direta descendente $\left(W / m^{2}\right)$ para cada intervalo espectral nos modelos testados, com coluna de ozônio 250DU e sem água precipitável

\begin{tabular}{lrr}
\hline \multirow{2}{*}{ Modelo } & \multicolumn{2}{c}{ Irradiância direta descendente $\left(\mathrm{W} / \mathrm{m}^{2}\right)$} \\
\cline { 2 - 3 } & VIS: $590-660 \mathrm{~nm}$ & IR: $3850-4000 \mathrm{~nm}$ \\
\hline SBDART(LOWTRAN) & 58,466 & 0,70421 \\
libRadtran (LOWTRAN) & 58,62695 & 0,7041152 \\
libRadtran (REPTRAN Medium) & 58,54229 & 0,7036439 \\
\hline
\end{tabular}

Nota-se que a parametrização escolhida para absorção molecular resulta em diferentes radiâncias calculadas e irradiâncias. A parametrização empregada afeta diretamente a radiância devido sua precisão espectral. Também a irradiância descendente direta a 100 km difere na utilização do REPTRAN, já que uma grade de valores representativos de comprimentos de onda é empregada e possui precisão diferente da indicada pelo espectro extraterrestre.

\subsubsection{Superfície e gases}

Para avaliar a sensibilidade a características de superfície e concentrações gasosas, foram efetuadas simulações para comparação dos resultados de refletâncias de interesse, conforme figura 20 .
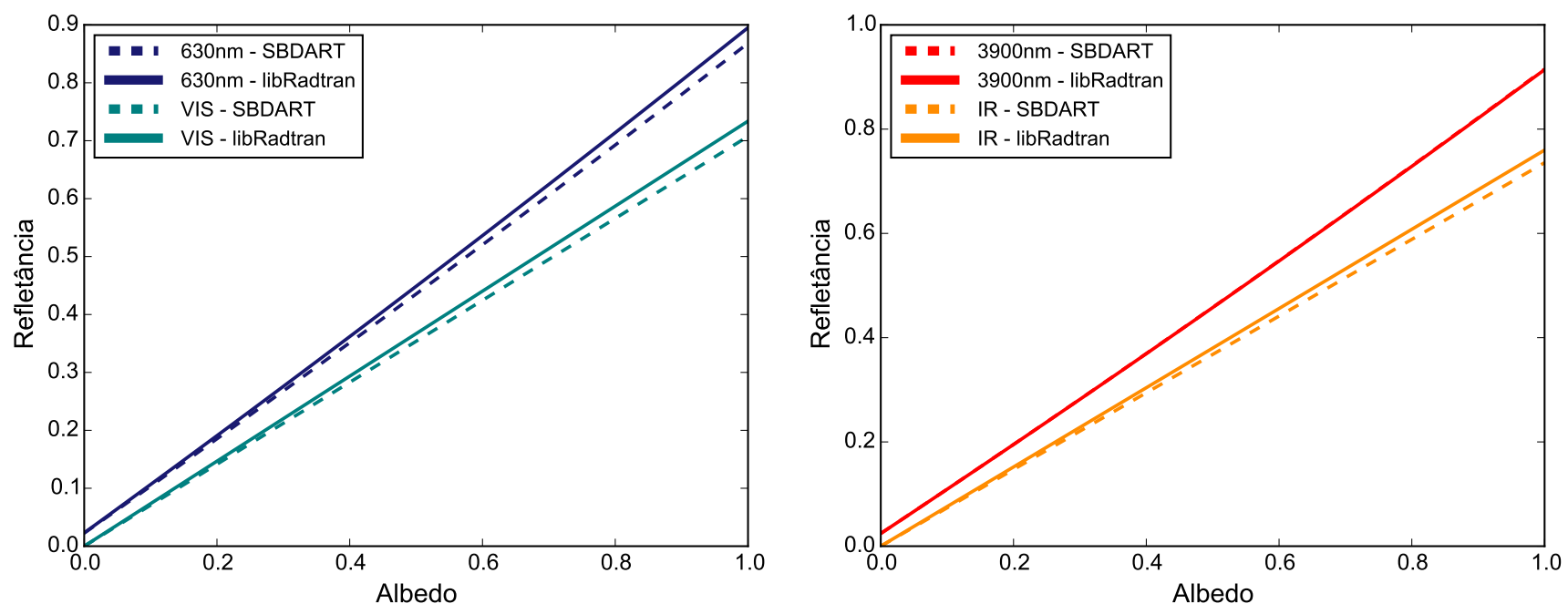

Figura 20 - Refletâncias calculadas pelo libRadtran e SBDART para comprimentos de onda de $630 \mathrm{~nm}$ e intervalo VIS (590 - $660 \mathrm{~nm})$, à esquerda, e para $3900 \mathrm{~nm}$ e IR (3850 - $4000 \mathrm{~nm})$, à direita, para diferentes valores de albedo de superfície. 
Há diferença de até 3,8\% nos resultados do libRadtran em relação ao SBDART considerando variações de albedo de superfície para o comprimento de onda de $630 \mathrm{~nm}$ e os dois intervalos utilizados nesse estudo.

Os cálculos para o comprimento de onda de $3900 \mathrm{~nm}$ apresentam resultados e tendências diversas dos outros intervalos e do comprimento de onda de $630 \mathrm{~nm}$. Isso pode estar relacionado à absorção molecular não expressiva neste específico comprimento de onda, minimizando as diferenças nos resultados dos dois modelos. Ao considerar o intervalo IR as diferenças, potencialmente relacionadas a absorção molecular, ficam mais evidentes.

Outra forma de avaliar os comportamentos do SBDART (sbd) e do libRadtran (lrt) para um mesmo caso é comparar diretamente as refletâncias obtidas em cada modelo. Considerando uma função $\rho_{l r t}=a \cdot \rho_{s b d}+b$ é possível ajustar os pontos simulados para cada albedo nos dois modelos e obter os coeficientes angulares $a$ e lineares $b$ que descrevem as tendências nos resultados das simulações em cada modelo. O conjunto de gráficos obtidos para essa comparação está apresentado na figura 21 enquanto os coeficientes calculados estão presentes na tabela 4 .
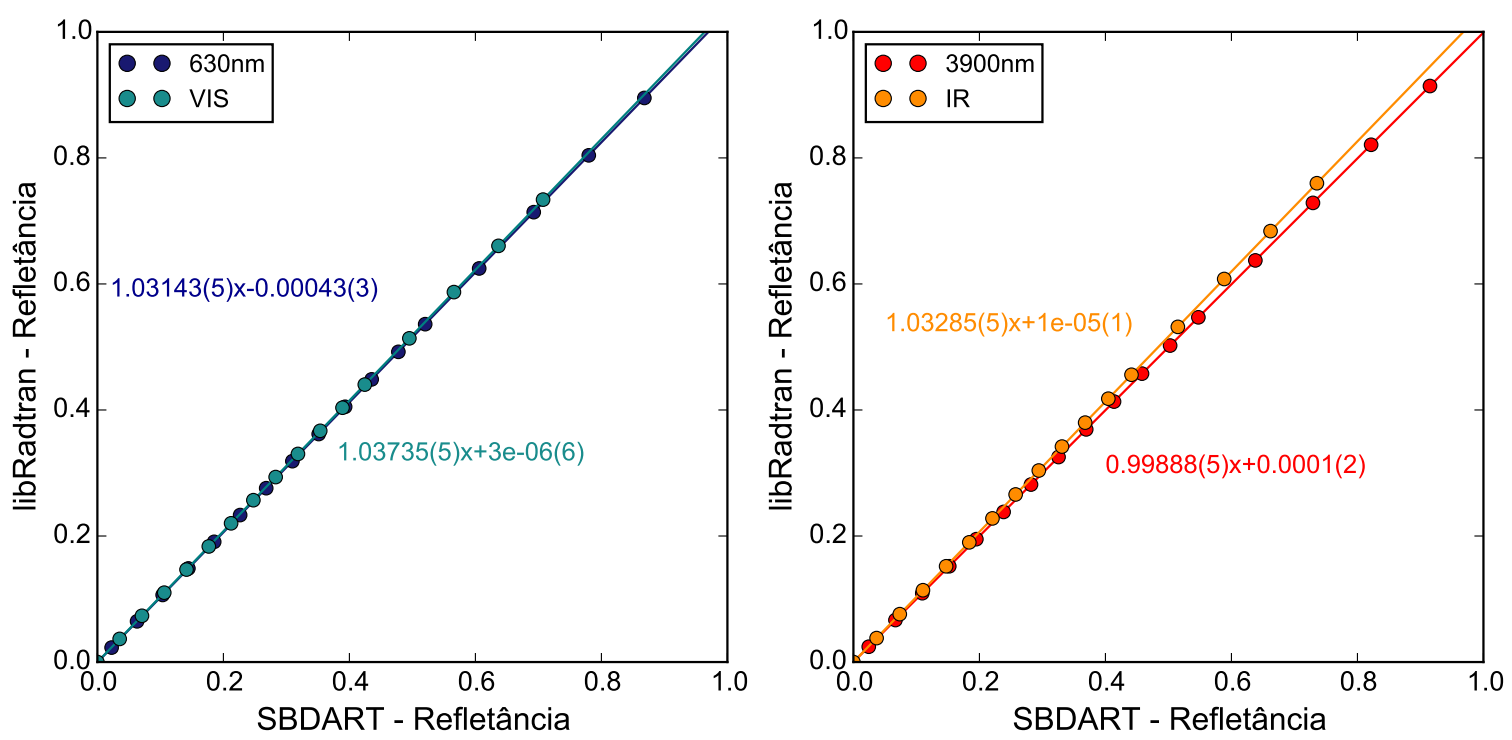

Figura 21 - Refletâncias calculadas pelo libRadtran em função das refletâncias pelo SBDART para diferentes valores de albedo de superfície comprimentos de onda de $630 \mathrm{~nm}$ e intervalo VIS (590 - $660 \mathrm{~nm})$, à esquerda, e para $3900 \mathrm{~nm}$ e IR (3850 - $4000 \mathrm{~nm})$, à direita. 
Tabela 4 - Coeficientes angular e linear para os ajustes de função $\rho_{l r t}=a \cdot \rho_{s b d}+b$ para os intervalos e comprimentos de onda utilizados. $R^{2}>0,99998$ para todos os ajustes

\begin{tabular}{crr}
\hline Intervalo/comprimento de onda & Coeficiente angular & Coeficiente linear \\
\hline $630 \mathrm{~nm}$ & $1,03143(5)$ & $0,00043(3)$ \\
$3900 \mathrm{~nm}$ & $0,99888(5)$ & $0,0001(2)$ \\
VIS & $1,03735(5)$ & $0,000003(6)$ \\
IR & $1,03285(5)$ & $0,00001(1)$ \\
\hline
\end{tabular}

O comportamento diferente já comentado para o comprimento de onda de 3900nm também é visto nesta comparação, como esperado. Desconsiderando esse comprimento de onda, os coeficientes angulares são próximos, apesar de incompatíveis, para todos os casos, apresentando diferença máxima de 0,006 e valor médio de 1,0338, com coeficientes lineares compatíveis com zero. Isto indica que a refletância calculada pelo libRadtran tende a ser maior conforme o crescimento do albedo de superfície, sem que um incremento constante ao modelo possa ser identificado.

Para o estudo da sensibilidade em relação às variações gasosas, o foco será em duas quantidades: coluna total de ozônio e água precipitável na atmosfera (diretamente relacionada à quantidade de vapor atmosférico na atmosfera). As variações na coluna de ozônio foram delimitadas entre 200 e 450 DU e a sensibilidade nas refletâncias podem ser vistas na figura 22 .
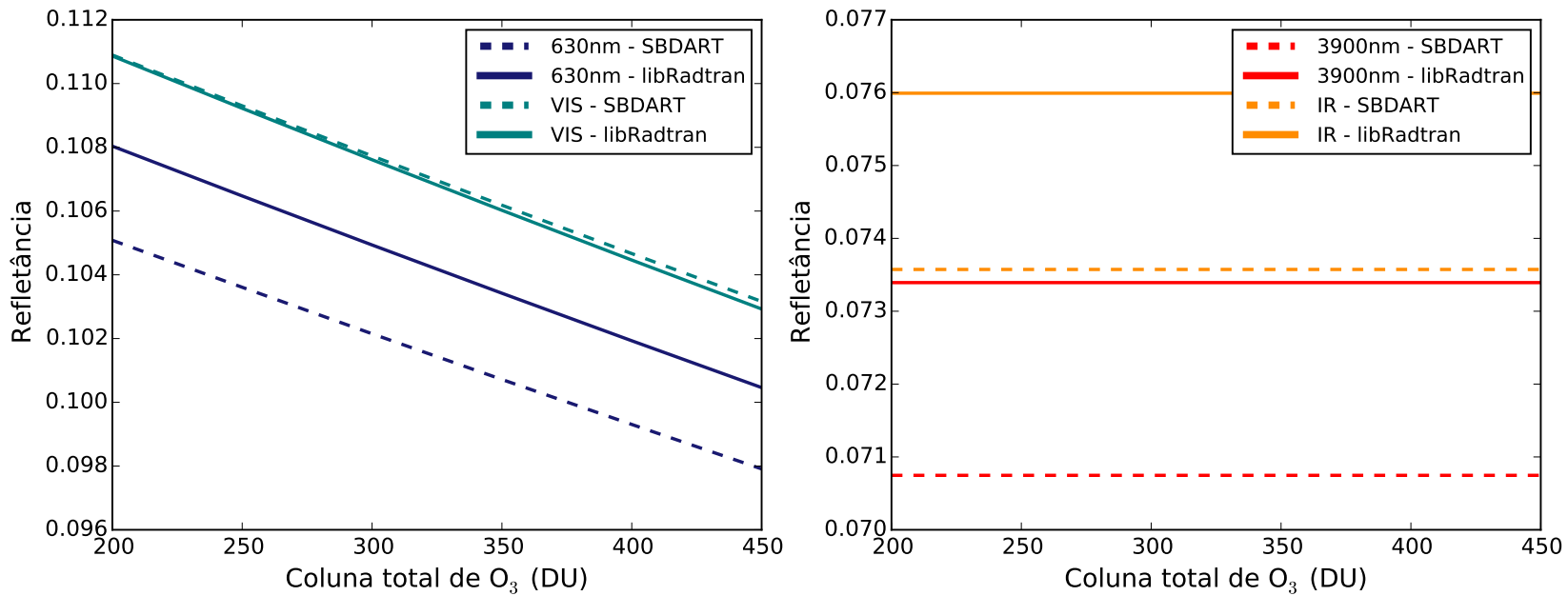

Figura 22 - Refletâncias calculadas pelo libRadtran e SBDART para comprimento de onda de $630 \mathrm{~nm}$ e intervalo VIS (590 - $660 \mathrm{~nm}$ ), à esquerda, e para $3900 \mathrm{~nm}$ e IR (3850 - $4000 \mathrm{~nm})$, à direita, com diferentes valores para coluna de ozônio. 
É importante notar que as variações de ozônio atmosférico no intervalo proposto não impacta na refletância no infravermelho (em 3900nm ou no intervalo IR) calculada em qualquer um dos modelos. Esse comportamento é esperado visto que não há absorção de ozônio na faixa de infravermelho estudada. É possível observar uma diferença relativa ao SBDART constante de 3,7\% para o comprimento de onda de $3900 \mathrm{~nm}$ e de $3,3 \%$ para o intervalo 3850 a $4000 \mathrm{~nm}$.

Com o aumento da coluna de ozônio há uma diminuição nas diferenças entre os modelos para os comprimentos de onda do espectro visível. Para $630 \mathrm{~nm}$ e o intervalo VIS as refletâncias decaem conforme o aumento de $O_{3}$ devido a absorção nos comprimentos de onda do espectro visível.

No intervalo VIS, especificamente, a diferença entre os modelos é muito próxima de zero, como pode ser visto através do ajuste para a função $\rho_{l r t}=a \rho_{s b d}+b$ nos resultados obtidos das simulações (figura 23). Em $630 \mathrm{~nm}$ nota-se uma diferença aproximadamente constante de cerca de $0,3 \%$ na refletância, essa diferença pode estar associada à absorção molecular considerada por cada modelo para o comprimento de onda específico de $630 \mathrm{~nm}$, mesmo com a utilização do LOWTRAN pelos dois códigos.

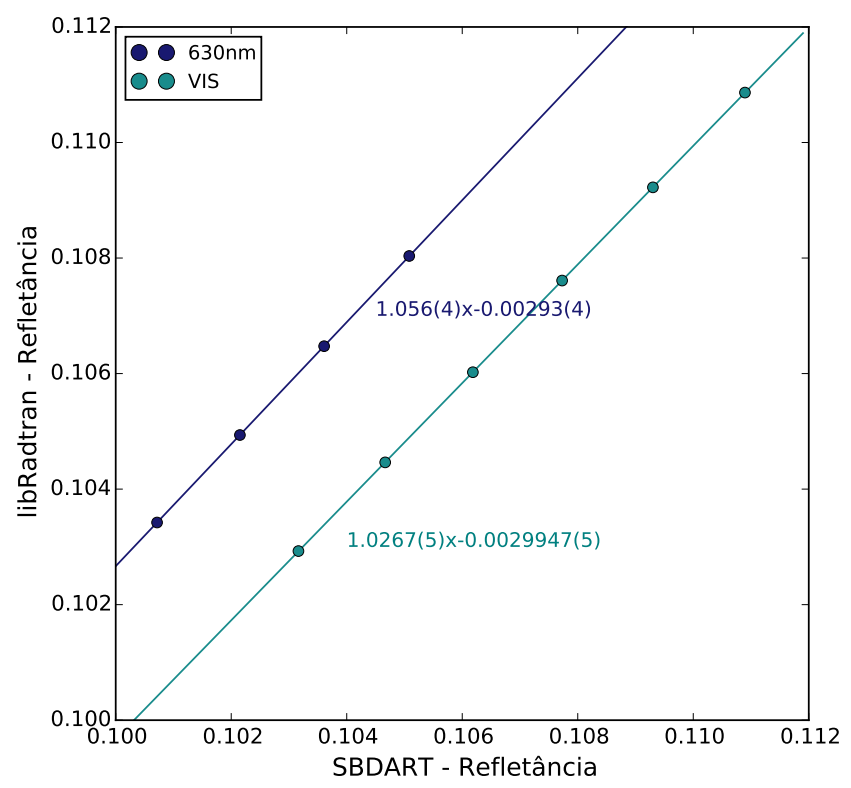

Figura 23 - Refletâncias calculadas pelo libRadtran e SBDART para comprimento de onda de $630 \mathrm{~nm}$ e intervalo VIS, com diferentes valores para coluna de ozônio, com ajuste de função $\rho_{l r t}=a \rho_{s b d}+b$ para cada conjunto de dados. $R^{2}>0.99999$ para os dois ajustes. 
Dessa forma, verifica-se um coeficiente angular 1,0267(5) para o ajuste dos dados obtidos no intervalo VIS, indicando que o libRadtran tende a apresentar dados pouco maiores a medida que a concentração de $\mathrm{O}_{3}$ aumenta. Esse aumento é maior quando utilizado o comprimento de onda $630 \mathrm{~nm}$, o que pode ser visto no coeficiente angular maior para estes resultados: 1,0559(4).

No que diz respeito ao vapor d'água na atmosfera, os resultados apresentam menor concordância (figura 24). Para os comprimentos de onda no espectro visível, único ou intervalo, as diferenças entre os modelos variam em menos de 1\%, porém os valores para $630 \mathrm{~nm}$ se mantém a uma distância relevante dos valores para o intervalo de 590 a 660 nm. Para os comprimentos de onda no intervalo infravermelho e 3900nm nota-se uma diminuição na diferença relativa entre os modelos de cerca de 3,5\% para aproximadamente $-3 \%$ com o aumento do conteúdo de água na atmosfera
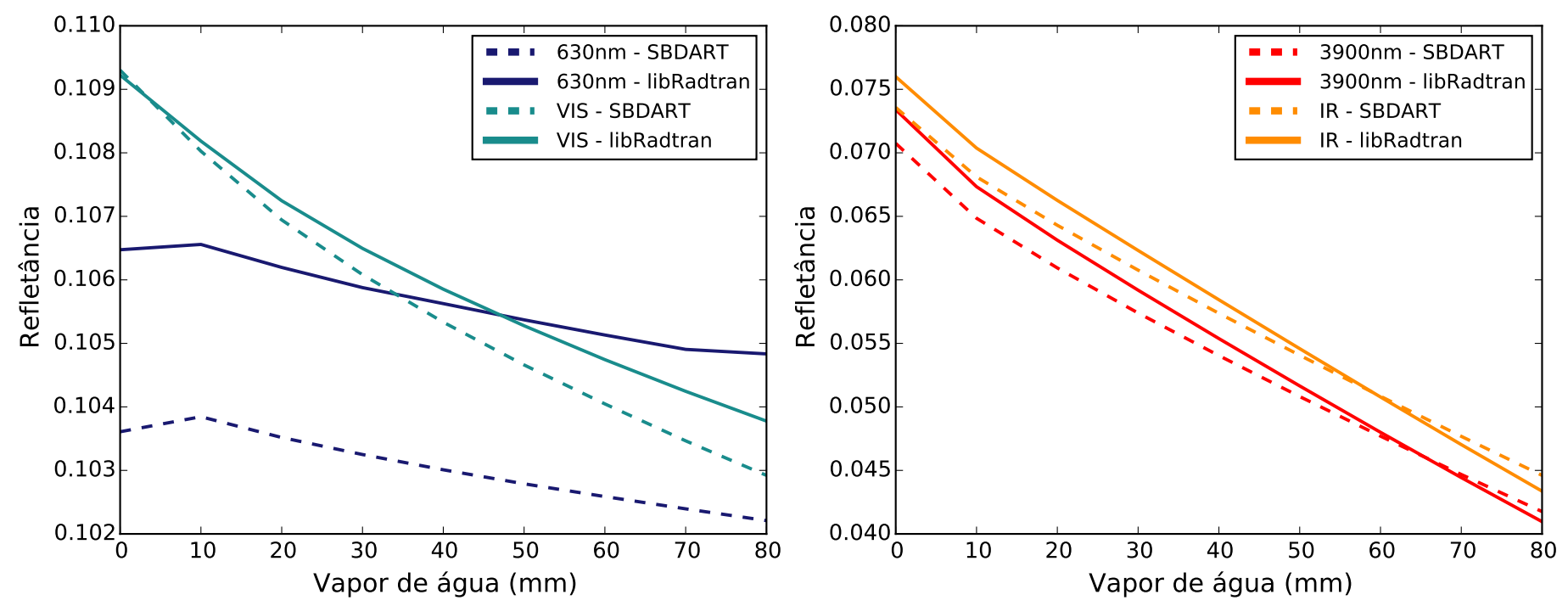

Figura 24 - Refletâncias calculadas pelo libRadtran e SBDART para diferentes valores de $\mathrm{H}_{2} \mathrm{O}$ na atmosfera: à esquerda, comprimento de onda único de $630 \mathrm{~nm}$ e intervalo VIS (590 - $660 \mathrm{~nm}$ ); à direita, comprimento de onda único de 3900nm e IR (3850 - $4000 \mathrm{~nm})$.

Com a análise direta entre os resultados dos dois modelos percebe-se uma diminuição na qualidade do ajuste da função $\rho_{l r t}=a \rho_{s b d}+b$ aos pontos simulados no comprimento de onda $630 \mathrm{~nm}$, com $R^{2}=0,98857$ para o ajuste apresentado na figura 25 . 

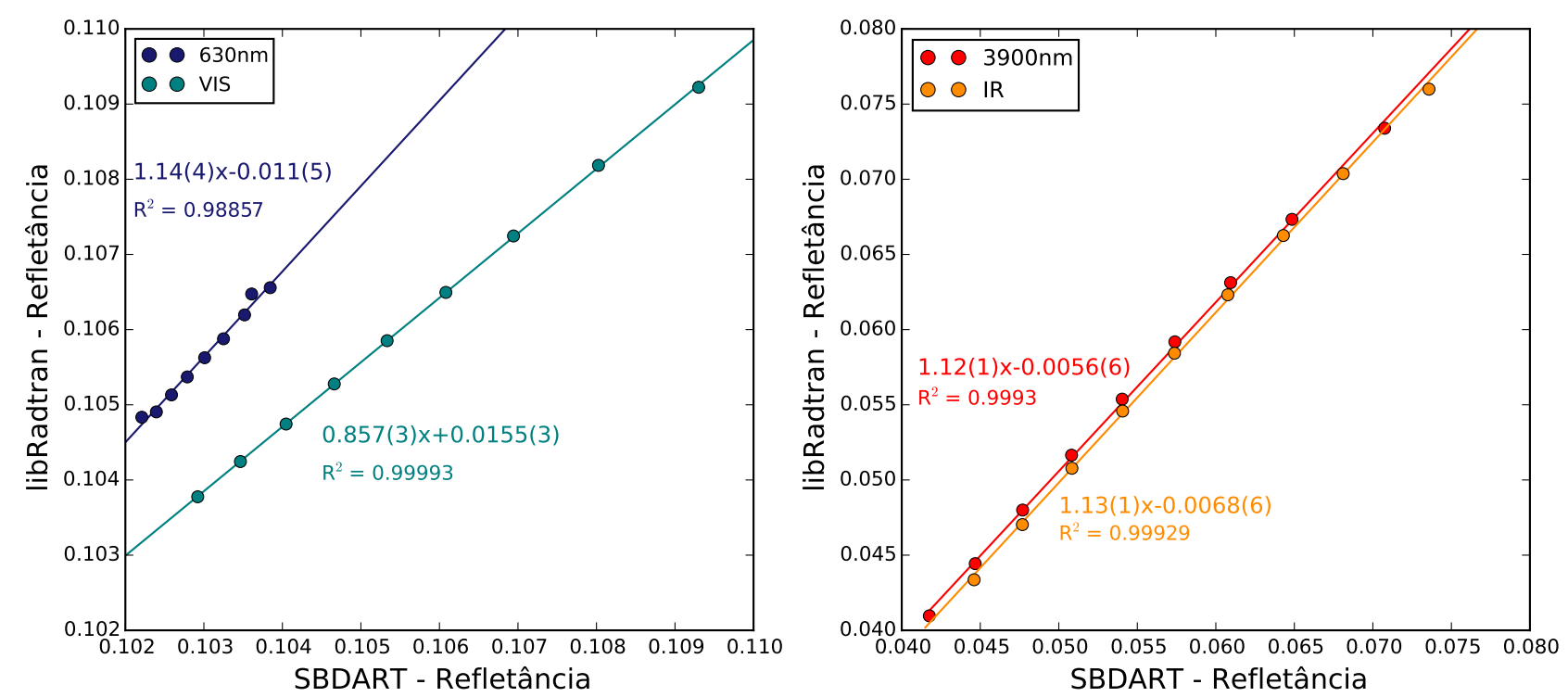

Figura 25 - Refletâncias calculadas pelo libRadtran e SBDART com diferentes valores para vapor d'água para comprimentos de onda de $630 \mathrm{~nm}$ e intervalo VIS, à esquerda, e para 3900nm e intervalo IR, à direita, com ajuste de função $\rho_{\text {lrt }}=a \rho_{s b d}+b$ para cada conjunto de dados. $R^{2}=0.99993$ para todos os ajustes, exceto utilizando o conjunto relativo à $630 \mathrm{~nm}$

Esta diferença encontrada no intervalo visível pode estar relacionada à absorção. De fato, o intervalo visível apresenta bandas de absorção pelo $H_{2} \mathrm{O}$, e o comprimento único de 630nm poderia não apresentar as particularidades dos modelos ao tratar desta absorção. Com um coeficiente angular de 0,85745 entende-se que, com o aumento do vapor d'água, as radiâncias calculadas pelo libRadtran tendem a diminuir em relação às determinadas pelo SBDART, tendência contrária às apresentadas no intervalo IR e nos comprimentos de onda $630 \mathrm{~nm}$ e $3900 \mathrm{~nm}$.

\section{1 .2 Nuvens}

Considerando os parâmetros apresentados na tabela 5 foram calculadas as refletâncias para uma atmosfera com nuvem quente. Também foram considerados dois diferentes raios efetivos $(5 \mu m$ e $25 \mu m)$ para os cálculos.

A parametrização de propriedades ópticas no libRadtran escolhida foi a que utiliza uma tabela pré-calculada de propriedades de acordo com a teoria Mie com interpolações conforme necessidade, para aproximar da parametrização presente no SBDART. 
Tabela 5 - Parâmetros usados na comparação entre libRadtran e SBDART (atmosfera com nuvem de água)

\begin{tabular}{ll}
\hline & Valor \\
\hline Ângulo Solar Zenital (SZA) & $60^{\circ}$ \\
Ângulo Zenital de Observação & $10^{\circ}$ \\
Ângulo Azimutal de Observação & $30^{\circ}$ \\
Altura da observação & $100 \mathrm{~km}$ \\
Albedo de superfície & 0,1 \\
COD & 50 \\
Atmosfera & padrão tropical do SBDART \\
Coluna total de ozônio & 250 DU \\
Vapor de água & $0 \mathrm{~mm}$ \\
Intervalo de comprimento de onda no visível (VIS) & $590-660 \mathrm{~nm}$ \\
Intervalo de comprimento de onda no infravermelho (IR) & $3850-4000 \mathrm{~nm}$ \\
Comprimento de onda únicos & $630 \mathrm{~nm}$ e $3900 \mathrm{~nm}$ \\
$\Delta \lambda$ em torno do comprimento de onda & $0,1 \mathrm{~nm}$ \\
\hline
\end{tabular}

Avaliando o intervalo visível e o comprimento de onda de $630 \mathrm{~nm}$, figura 26, nota-se que à medida que o COD aumenta as diferenças entre os resultados para os diferentes raios efetivos diminuem.
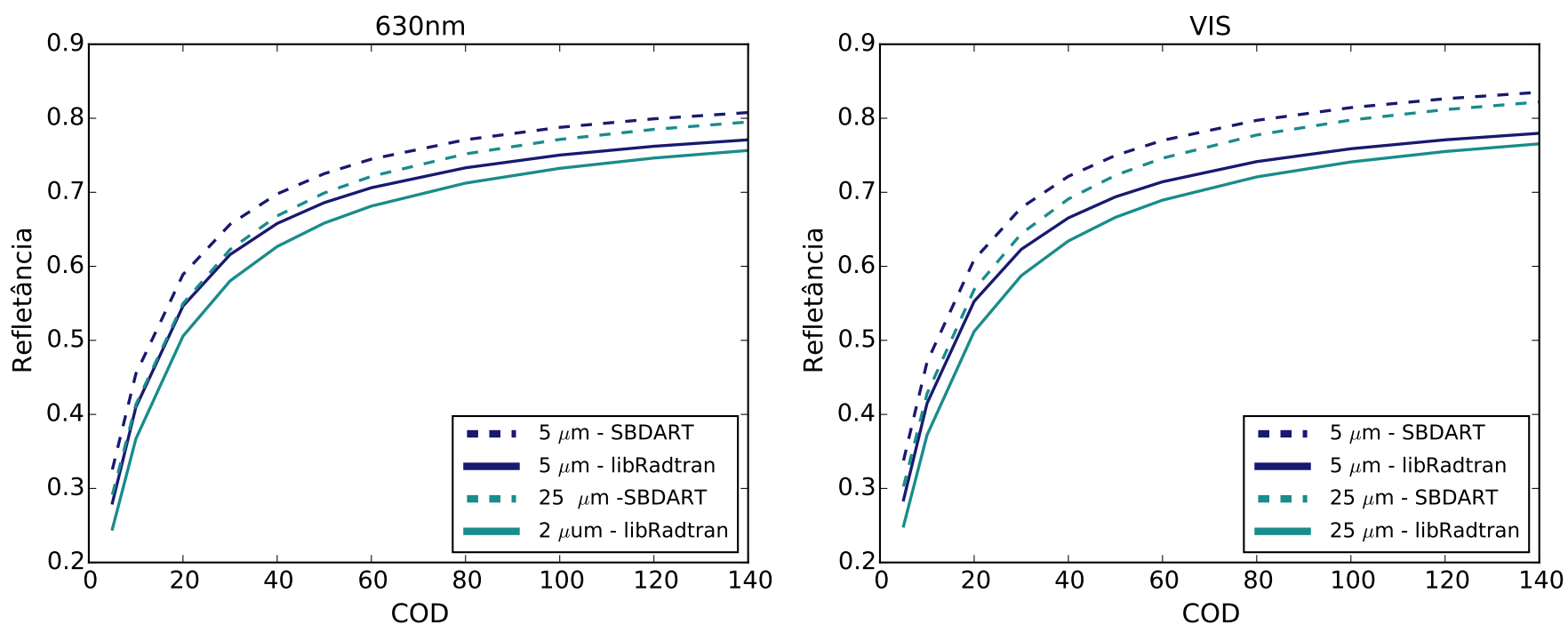

Figura 26 - Refletâncias para 630nm (à esquerda) e no intervalo VIS (590nm a 660 $\mathrm{nm}$ ) (à direita) calculadas pelo SBDART e libRadtran para atmosfera com nuvem, entre 2 e $3 \mathrm{~km}$ da superfície, considerando diferentes profundidades ópticas (COD) para dois raios efetivos $(5 \mu m$ e $25 \mu m)$. 
Mesmo para $C O D \geq 50$ há um aumento sensível na refletância, enquanto a sensibilidade ao raio efetivo é menor. A diferença relativa máxima entre as refletâncias calculadas para $r_{e f f}=5 \mu m$ e $r_{e f f}=25 \mu m$ é de $4,1 \%$ para $C O D=50$ e 1,9\% para $C O D=140$. Isso indica que bandas no espectro visível se mostram adequadas para a determinação de profundidade óptica da nuvem, conforme indica a figura 31, enquanto a inferência de raio efetivo através de dados obtidos através dessas bandas seria pouco precisa.

Conforme já exposto, ao analisar as refletâncias para o infravermelho percebe-se uma maior sensibilidade ao raio efetivo das gotas presentes na nuvem. Dessa forma, são expostas na figura 27 as refletâncias calculadas para os raios de $5 \mu m$ e $25 \mu m$ já que há uma diferença de cerca de $88 \%$ entre elas.
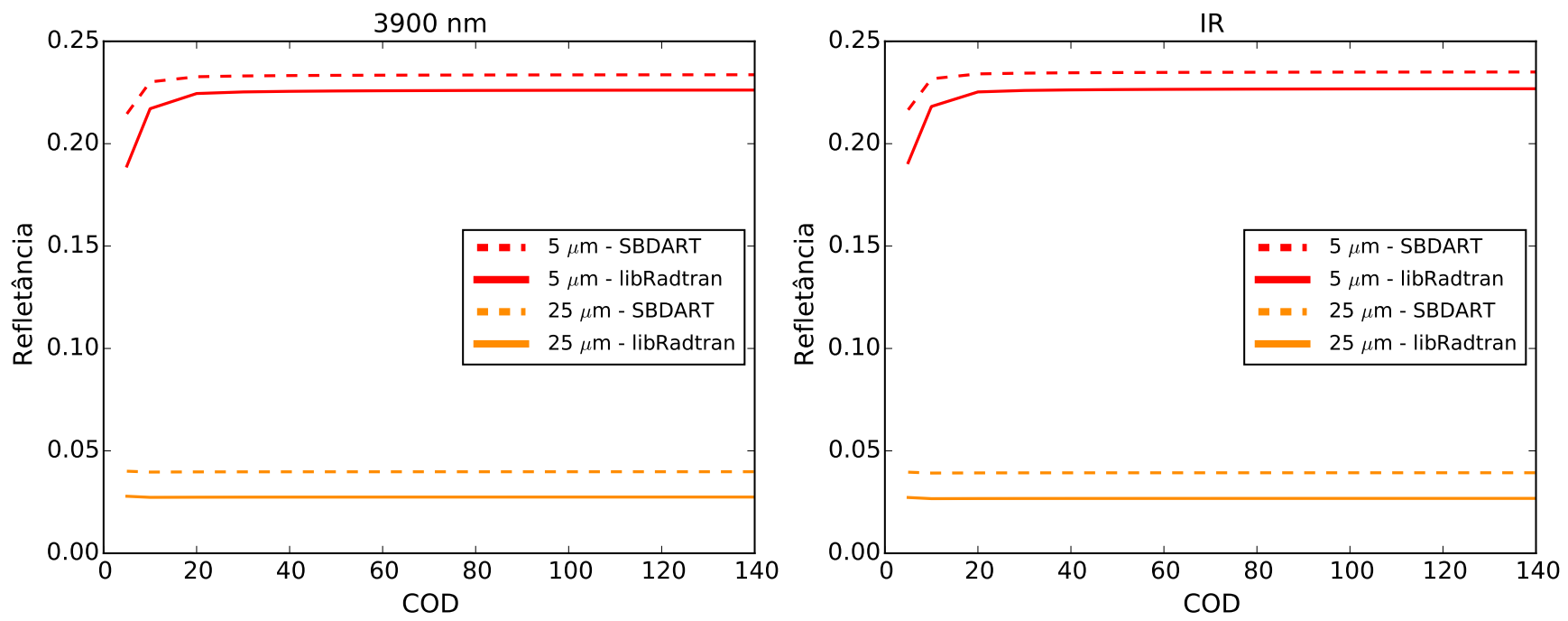

Figura 27 - Refletâncias, considerando dois raios efetivos $(5 \mu m$ e $25 \mu m)$, pelo SBDART e libRadtran para atmosfera com nuvem, entre 2 e 3km da superfície, considerando diferentes profundidades ópticas (COD) para dois comprimentos de onda: $3900 \mathrm{~nm}$, à esquerda, e intervalo IR (3850nm a 4000nm) $5 \mu \mathrm{m}$, à direita.

Nota-se que as refletâncias apresentam resultados praticamente iguais tanto para o intervalo quanto para o comprimento de onda único associado ao infravermelho. Existe uma diferença aproximadamente constante entre os modelos, inferior a 2,5\% na refletância, a partir $\mathrm{COD}=20$, essa diferença pode estar associada à qualidade da interpolação das propriedades ópticas ou até às propriedades em si. 
Para uma comparação direta entre os dois modelos foi ajustada uma equação do tipo $\rho_{l r t}=a \rho_{s b d}+b$, considerando as refletâncias calculadas para nuvens com $C O D \geq 10$, excluindo assim as discrepâncias encontradas em nuvens finas.
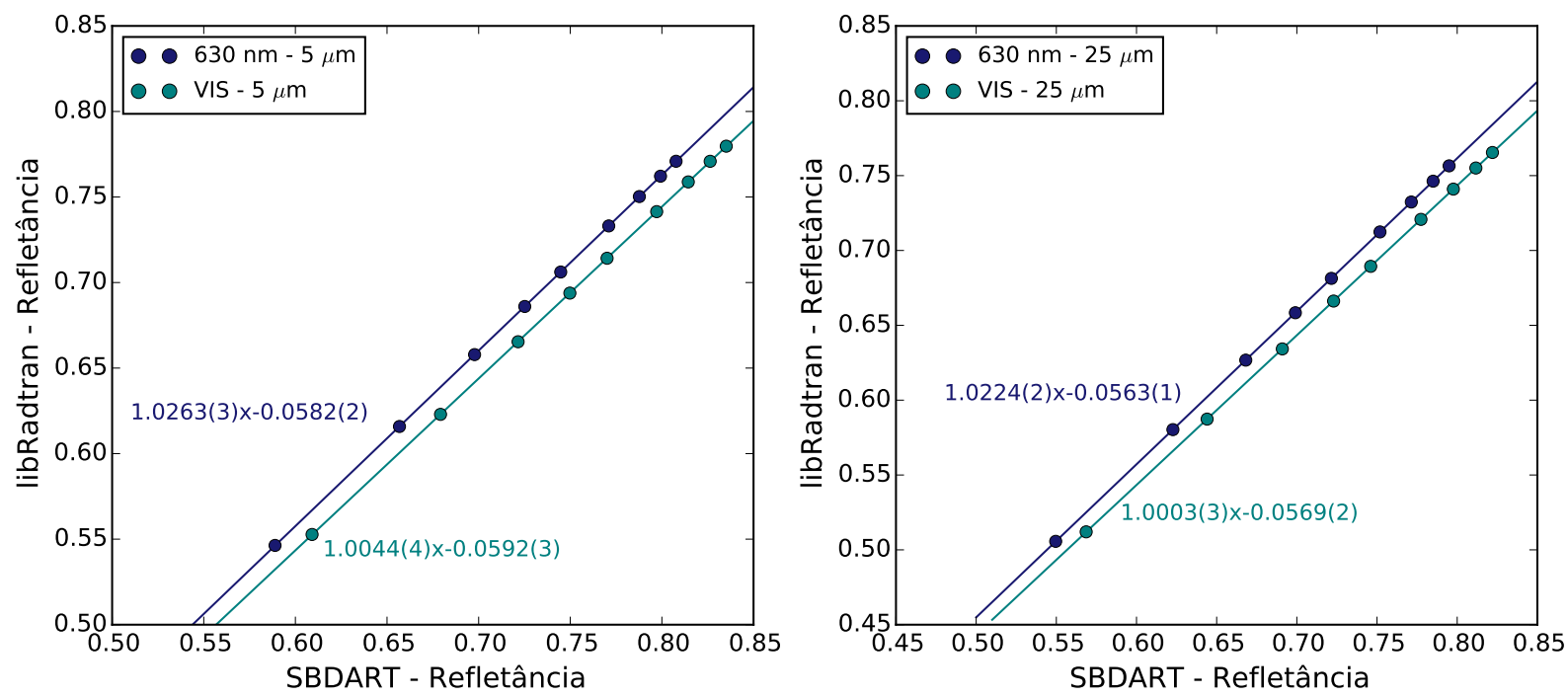

Figura 28 - Refletâncias calculadas pelo libRadtran e SBDART para comprimentos de onda de $630 \mathrm{~nm}$ e intervalo VIS, calculados para diferentes CODs considerando dois raios efetivos, com ajuste de função $\rho_{l r t}=a \rho_{s b d}+b$ para cada conjunto de dados. $R^{2}>0.99998$ para todos os ajustes

Conforme apresentado na figura 28, os resultados obtidos através do libRadtran são sistematicamente maiores que os obtidos pelo SBDART. Para o uso de comprimento de onda simples, as refletâncias crescem com o aumento do COD, obtendo-se coeficientes angulares na ordem de 1,02. É possível, contudo, dizer que há compatibilidade entre os resultados obtidos através dos dois modelos, considerando um acréscimo constante em todos os resultados obtidos pelo libRadtran.

Considerando $r_{\text {eff }}=25 \mu \mathrm{m}$, novamente nota-se a baixa sensibilidade dos comprimentos de onda do infravermelho à profundidade óptica: a variação na refletância entre $\mathrm{COD}=10$ e $\mathrm{COD}=140$ é menor que $5 \times 10^{-4}$. O fato destas variações nas refletâncias para comprimentos de ondas no infravermelho serem menores que $10^{-3}$ implica que, no contexto desse trabalho, para nuvens espessas, medidas em infravermelho são adequadas para a determinação de raio efetivo, de acordo com o esperado pelo diagrama Nakajima-King.

Também foram comparados os resultados de refletância em céu com nuvem de água para variações de albedo de superfície, a fim de avaliar se os dois modelos respondem da mesma maneira para COD $=50$. As refletâncias calculadas para o infravermelho são 

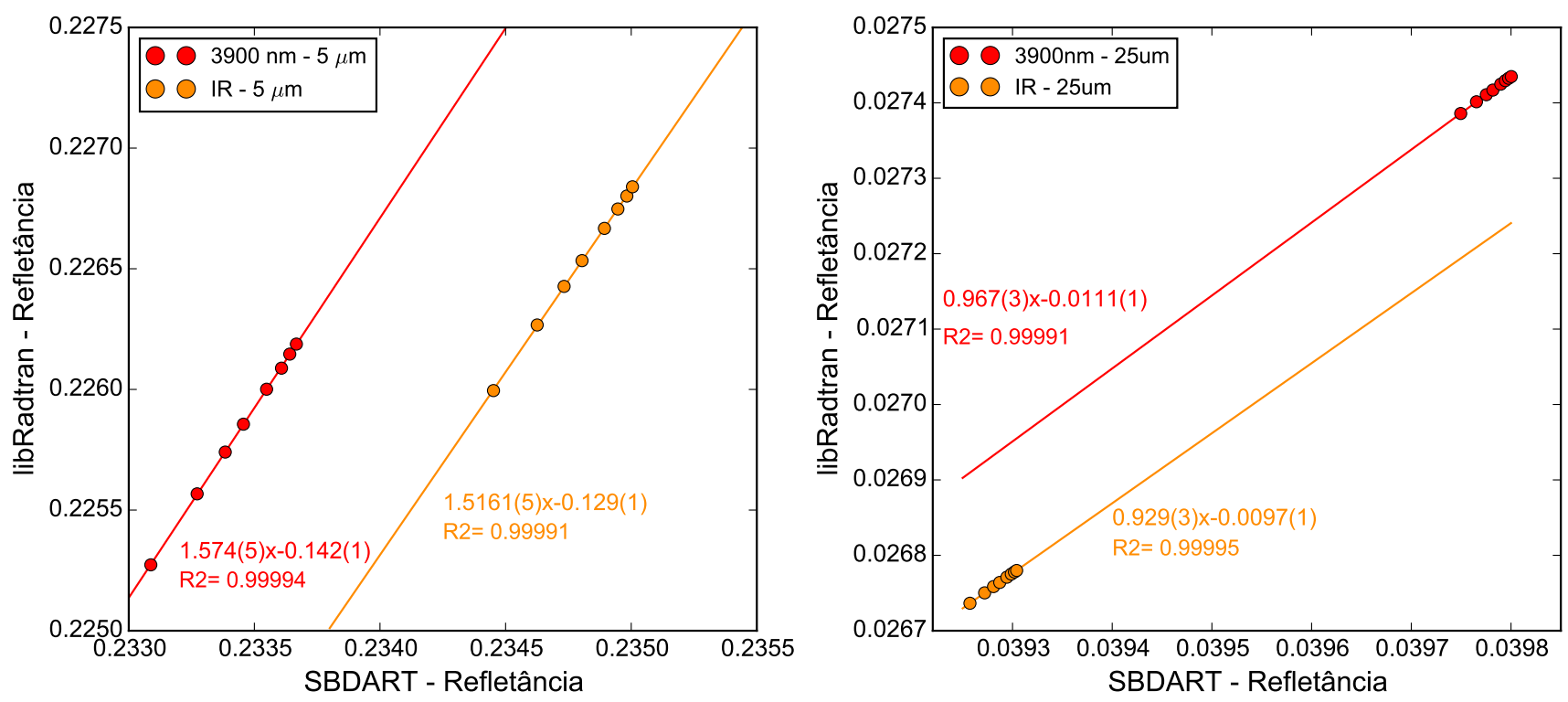

Figura 29 - Refletâncias calculadas pelo libRadtran e SBDART para comprimentos de onda de 3900nm e intervalo IR, calculados para diferentes CODs, com ajuste de função $\rho_{l r t}=a \rho_{s b d}+b$ para cada conjunto de dados. À esquerda resultados considerando $r_{e f f}=5 \mu \mathrm{m}$, à direita $r_{e f f}=25 \mu \mathrm{m} . R^{2}>0,9999$ para todos ajustes.

constantes para o SBDART e para o libRadtran tem alterações da ordem de $10^{-8} \mathrm{Wm}^{-2} s r^{-1}$, que podem ser consideradas desprezíveis, ao variar o albedo de superfície no intervalo entre 0 e 1. A tabela 6 indica os resultados obtidos para o comprimento de onda de 3900nm e para o intervalo IR.

Tabela 6 - Refletâncias calculadas pelo SBDART e libRadtran para o intervalo IR (3850 a $4000 \mathrm{~nm}$ ) e para o comprimento de onda de $3900 \mathrm{~nm}$.

\begin{tabular}{lllll}
\hline & & SBDART & libRadtran & Diferença \\
\hline \multirow{2}{*}{$3900 \mathrm{~nm}$} & $5 \mu \mathrm{m}$ & 0,233384 & 0,225740 & 0,0076437 \\
& $25 \mu \mathrm{m}$ & 0,039775 & 0,027411 & 0,012364 \\
\multirow{2}{*}{$\mathrm{IR}$} & $5 \mu \mathrm{m}$ & 0,234733 & 0,226427 & 0,008305 \\
& $25 \mu \mathrm{m}$ & 0,039281 & 0,026758 & 0,012522 \\
\hline
\end{tabular}

É possível notar que os valores obtidos pelo libRadtran tendem a ser menores do obtido pelo SBDART, e essa diferença aumenta com o raio efetivo. Outras investigações deverão ser feitas para determinação de uma função para essa diferença, o que está fora do escopo atual deste trabalho. 
Para os comprimentos de onda do espectro visível, nota-se alguma sensibilidade ao albedo (figura 30). Porém, para albedos entre 0 e 0,5 , os cinco primeiros pontos na parte inferior esquerda, as refletâncias calculadas apresentam variações absolutas inferiores a $1,6 \%$ para raios efetivos de $5 \mu \mathrm{m}$ e a $2,2 \%$ para $25 \mu \mathrm{m}$, nos dois códigos. Para albedos entre 0 e 0,2 , que podem ser considerados valores típicos para região amazônica, essa variação é da ordem de 1\%. Assim, pode-se concluir que ao aplicar um albedo de superfície fixo em 0,09 para os dois comprimentos de onda não resultará em diferenças significativas para os valores obtidos para confecção da tabela de referência.
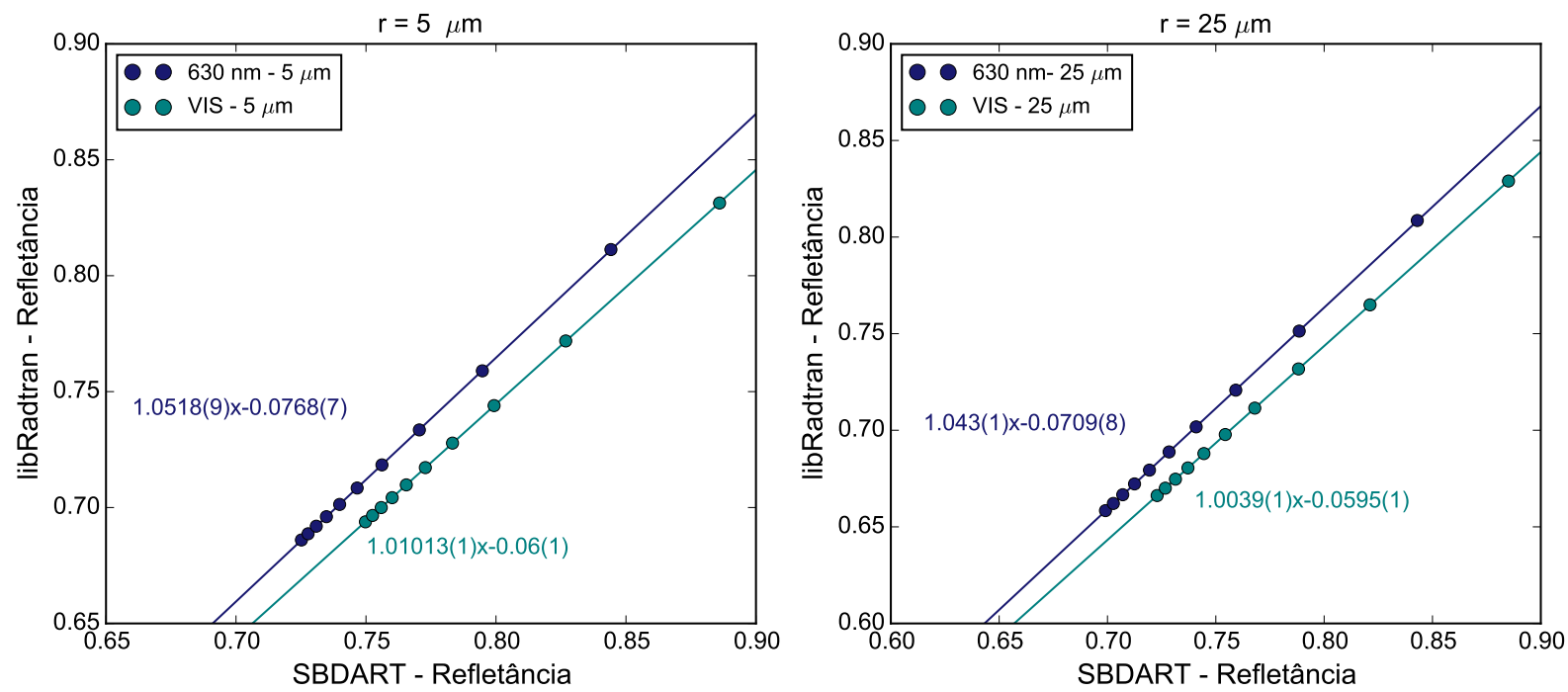

Figura 30 - Refletâncias calculadas pelo libRadtran e SBDART para comprimento de onda de 630nm e intervalo VIS, calculados para diferentes albedos de superfície em atmosfera com nuvem de $\mathrm{COD}=50$, com ajuste de função $\rho_{l r t}=a \rho_{s b d}+b$ para cada conjunto de dados. À esquerda resultados considerando $r_{\text {eff }}=5 \mu \mathrm{m}$, à direita $r_{\text {eff }}=25 \mu \mathrm{m} . R^{2}>0,9999$ para todos ajustes.

Comparando-se os resultados dos dois modelos ao considerar variações de albedo de superfície, pode-se concluir que as refletâncias se comportam de forma compatíveis porém os resultados do SBDART tendem a ser mais elevados com o aumento do parâmetro variável (COD, albedo, água precipitável, coluna total de ozônio). Os coeficientes lineares demonstram um aumento entre 0,05 e 0,1 para os valores calculados pelo libRadtran, o que indica que os modelos apresentam particularidades em alguns cálculos e tratamentos, resultando numa diferente sensibilidade aos parâmetros simulados. Apesar disso, não há diferenças significativas entre os comportamentos dos modelos, de forma que pode-se concluir que o libRadtran é uma ferramenta adequada quando comparada com o SBDART. 


\subsubsection{Comparação com Kaufman-Nakajima}

Conforme explicado no capítulo anterior, o diagrama proposto por Nakajima and King (1990) é uma poderosa representação das interações de duas diferentes bandas do espectro eletromagnético com características de nuvem: COD e raio efetivo.

Em Kaufman and Nakajima (1993) um diagrama foi desenvolvido considerando valores teóricos de refletância para dois canais do AVHRR: $640 \mathrm{~nm}$ e $3750 \mathrm{~nm}$. Os valores foram calculados como média em dois azimutes $\left(30^{\circ}\right.$ e $\left.150^{\circ}\right)$, com SZA de $60^{\circ}$ e VZA de $10^{\circ}$, com albedo de superfície 0,02 . Simulando estas condições nos dois modelos foi possível comparar (figura 31) com alguns pontos extraídos do diagrama presente no estudo citado.

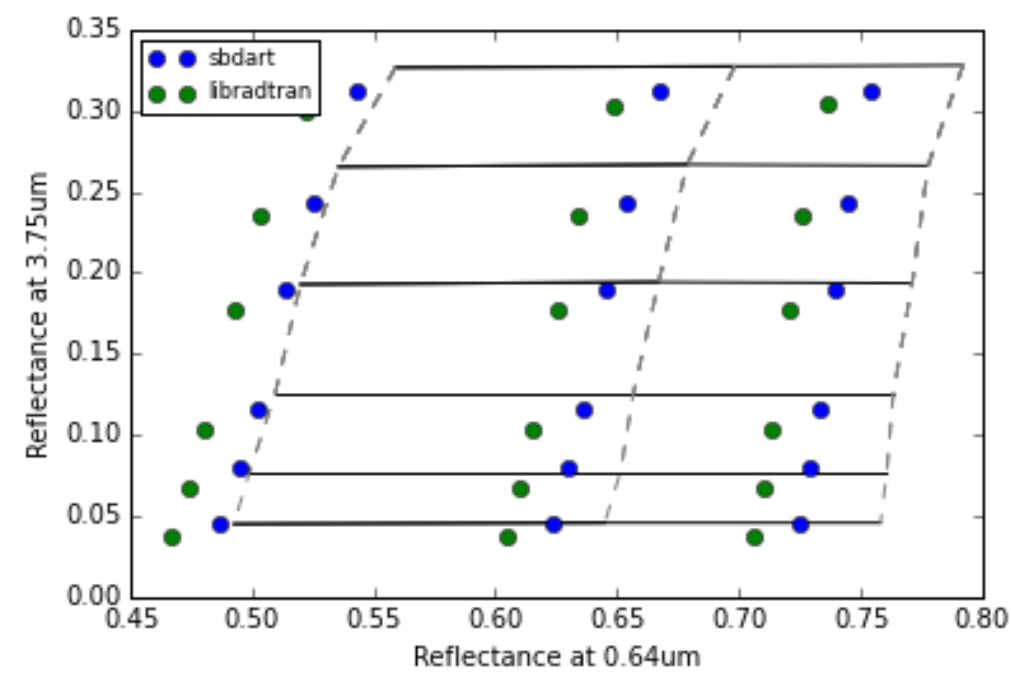

Figura 31 - Diagrama Nakajima-King com valores de referência, retirados de Kaufman and Nakajima (1993), em preto, com valores obtidos através do SBDART em azul e do libRadtran em verde.

O artigo indica que o código de transferência radiativa foi de desenvolvimento próprio, sem mais especificações dele. Assim, a comparação direta entre os resultados apresentados no paper, e os calculados pelo SBDART e libRadtran, não pode ser profundamente discutida devido ao desconhecimento de particularidades do código utilizado no estudo de Kaufman and Nakajima (1993).

As refletâncias obtidas através do libRadtran reforçam a tendência indicada nas análises anteriores, sendo inferiores às calculadas pelo SBDART, que se aproxima mais da referência utilizada. As diferenças nos resultados podem estar associadas aos parâmetros utilizados para propriedades ópticas ou pelo modo como o espalhamento múltiplo é 
considerado em cada modelo. No entanto, os valores simulados pelo libRadtran e pelo SBDART não diferem substancialmente do comportamento apresentado no artigo estudado.

\subsubsection{Discussão}

Além desta comparação entre resultados, é possível encontrar na literatura uma extensa bibliografia de utilização do libRadtran em estudos que envolvem cálculos de transferência radiativas (Bugliaro et al., 2011; Garc et al., 2012; Obregón et al., 2015)

Assim, com a adição dos estudos expostos neste capítulo, que indicam que há boa compatibilidade entre os resultados apresentados pelo SBDART e libRadtran, conclui-se que o libRadtran se demonstra adequado para este trabalho. Além de produzir resultados consistentes, o libRadtran é bem documentado, com input de fácil confecção e entendimento.

Outros estudos que consideram as parametrizações disponíveis no libRadtran, no contexto do desenvolvimento da LUT, são apresentados na seção a seguir.

\subsection{Estudo com o libRadtran}

Visando determinar as parametrizações e opções a serem utilizadas no desenvolvimento das look-up tables, alguns estudos foram desenvolvidos. Estes estudos consistem em avaliação direta das opções apresentadas pelo libRadtran e análises de resultados obtidos considerando diferentes parametrizações e configurações. Foram investigadas as relações entre as refletâncias calculadas no topo da atmosfera e algumas características da nuvem, como altura de sua base e sua espessura.

Todos os cálculos dessa análise utilizam os intervalos de comprimento de onda referentes aos canais 1 e 2 (Ch1 e Ch2, respectivamente) do GOES-13 e também a função espectral de resposta apresentada na figura 19.

\subsubsection{Absorção molecular}

Conforme apresentado no capítulo 3, o libRadtran disponibiliza diferentes parametrizações para absorção molecular. A opção LOWTRAN foi utilizada para as comparações apresentadas no capítulo anterior por ser a mesma empregada pelo SBDART, e foi in- 
serida no libRadtran por questões de compatibilidade visto que o uso do REPTRAN é recomendado (Mayer et al., 2012).

Considerando que no canal 2 do GOES-13 (figura 19) não são encontradas bandas de absorção que necessitem maior definição, a escolha de REPTRAN medium se faz adequada para o desenvolvimento das LUT. No entanto, o uso do REPTRAN fine apresenta melhor resolução de bandas de absorção molecular e por isso foi escolhido para ser utilizado nas simulações para o canal 1 do GOES-13.

Há uma pequena adição no tempo de execução do libRadtran ao optar pelo uso das parametrizações REPTRAN. Porém essa adição é representativa considerando o tempo de execução e outras parametrizações, a serem discutidas nas próximas seções.

\subsubsection{Parametrizações de propriedades ópticas para nuvens}

O libRadtran oferece diferentes parametrizações para as propriedades ópticas de nuvens de água e de gelo. Para nuvem de água, a opção padrão é a apresentada por (Hu and Stamnes, 1993), mas há a opção de utilizar uma tabela de valores pré-calculados utilizando a Teoria Mie, com as interpolações necessárias. Além desta tabela pré-calculada, o usuário pode fornecer diretamente os parâmetros calculados através da ferramenta Mie disponível no pacote do libRadtran.

A ferramenta Mie calcula propriedades ópticas em partículas esféricas através do código de Wiscombe (1980). Para sua utilização, é necessário indicar um arquivo de entrada com características como intervalos de comprimento de onda, e os subintervalos da escala utilizada, raio efetivo da partícula esférica, parâmetros da distribuição de tamanho, quantidade de momentos do polinômio de Legendre que devem ser calculadas, etc. Para este trabalho foi utilizada a opção de saída em arquivo texto (ASCII), a ser lida pelo uvspec.

Para o cálculo através da Teoria Mie, foi usada uma distribuição Gamma de tamanho, conforme a equação (38), e considerados 1000 termos dos polinômios de Legendre, com número máximo de 500 ângulos de espalhamento. Devido às características pedidas para os cálculos, o consumo de máquina é grande, demandando uma boa configuração de memória e processador, levando-se horas para completar uma execução para uma entrada. 
Em nuvens de gelo, a parametrização escolhida para execução do uvspec foi a apresentada em (Baum et al., 2007) na qual é possível utilizar uma mistura de hábitos para composição da nuvem. Essa mistura é apresentada em (Baum et al., 2005) e contém droxtal, colunas sólidas e ocas, planos (plates), rosettes, e agregados.

\subsubsection{Configuração física da nuvem}

Para investigação da sensibilidade à espessura e ao posicionamento da nuvem na atmosfera, foram calculadas as radiâncias para nuvem com COD $=50$ em diversas combinações de altura de topo e de base, que variam entre 1 e $6 \mathrm{~km}$ para nuvens de água e gelo. Assim, foram obtidos resultados para nuvens de água com espessuras entre 1 e 6 $\mathrm{km}$, com bases entre 1 e $4 \mathrm{~km}$. E para nuvens de gelo, bases entre 3 e $5 \mathrm{~km}$ e espessuras entre 1 e $9 \mathrm{~km}$.

Os cálculos para determinação de radiância nesta etapa são para atmosfera com nuvens de água ou de gelo de $\mathrm{COD}=50$ para todos os comprimentos de onda de entrada, com ângulo solar zenital de $30^{\circ}$, ângulo de visada de $10^{\circ}$, azimute de $30^{\circ}$ e albedo de superfície de 0,04 para os dois canais estudados (Ch1 e Ch2), com suas respectivas funções de resposta espectral.

\subsubsection{Nuvens de água}

Com os resultados obtidos através do libRadtran, foi possível organizar as refletâncias obtidas para diferentes alturas de topo de nuvem, para diferentes raios efetivos e altura de base da nuvem. Os cálculos foram feitos considerando raios efetivos iguais à 2 , 20, 40 e $59 \mu \mathrm{m}$.

Através dos gráficos apresentados nas figuras 32 e 33 é possível notar que o topo da nuvem apresenta maior relevância para a variação da refletância que a espessura da nuvem.

Para nuvens de mesma espessura, e portanto mesmo LWP para raios efetivos iguais, nota-se uma variação de até 1,5\% para as refletâncias considerando diferentes alturas de topo. Conforme a figura 32 percebe-se refletâncias maiores para topos mais altos. Uma 
possível explicação pode residir na maior atenuação pela interação com gases atmosféricos até o topo da nuvem, resultando em refletâncias menores para topos mais baixos.
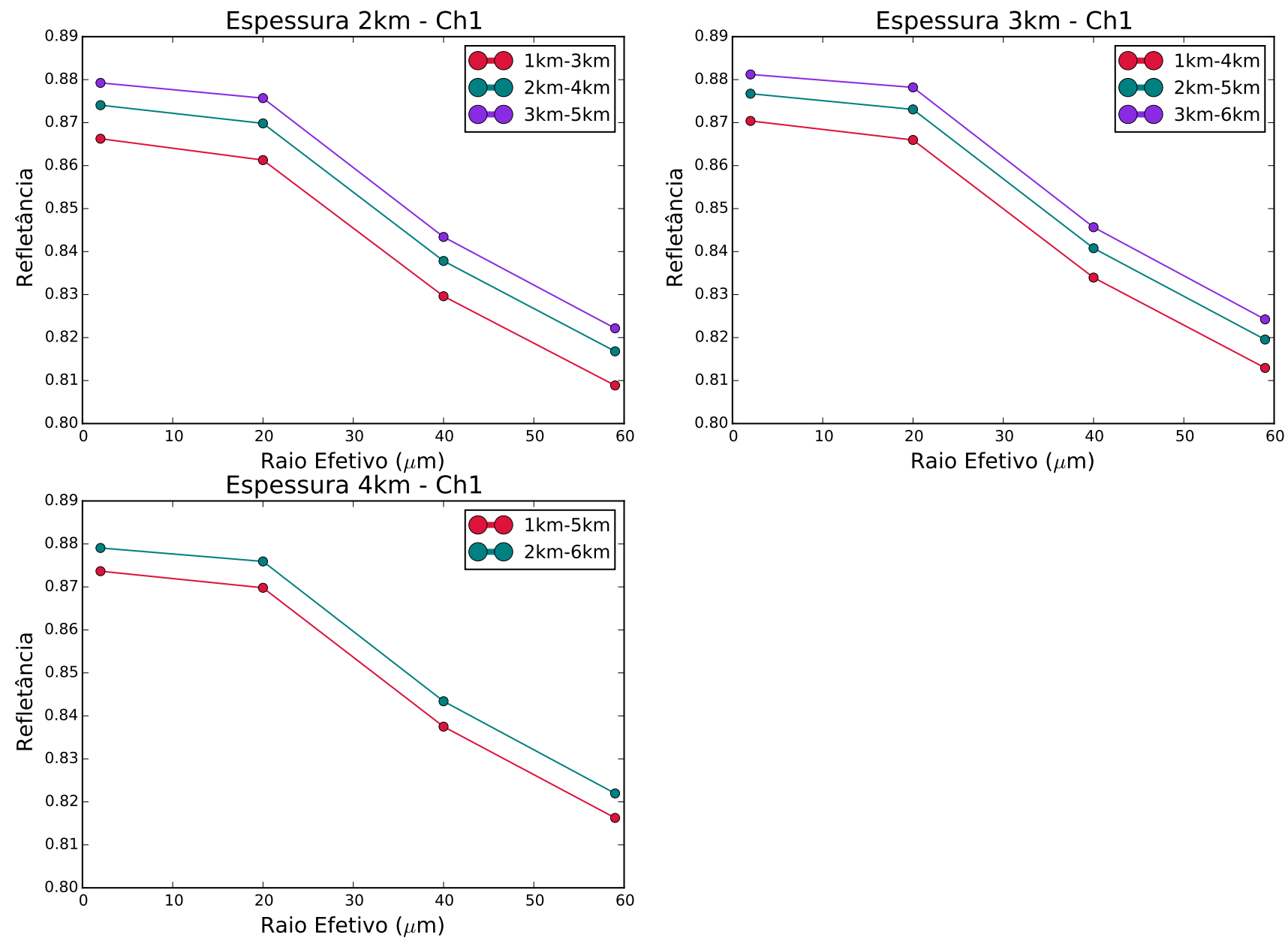

Figura 32 - Refletâncias no topo da atmosfera, para o canal 1, em função do raio efetivo em nuvens de água com espessuras de 2,3 e $4 \mathrm{~km}$.

Apesar da variação absoluta na refletância no canal 1 ser inferior a $8 \%$ para variações de raio efetivo até $60 \mu m$, indicando uma sensibilidade menor quando comparada a variações no COD, é possível notar que o aumento do raio efetivo resulta em refletâncias menores. Ou seja, para nuvens com mesmo conteúdo de água líquida, espessura e profundidade óptica, raios efetivos menores indicam maior albedo da nuvem, devido a um aumento na eficiência do espalhamento nesses comprimentos de onda.

Nota-se, através da figura 33, que para uma mesma posição de topo de nuvem, as variações na refletância são inferiores a $1 \%$ ao considerar outras posições de base de nuvem. E essa variação é reduzida conforme aumenta a altura do topo, ou seja, quanto mais 
alto o topo da nuvem, menor a relevância de sua espessura geométrica para a refletância observada pelo sensor a bordo de um satélite.
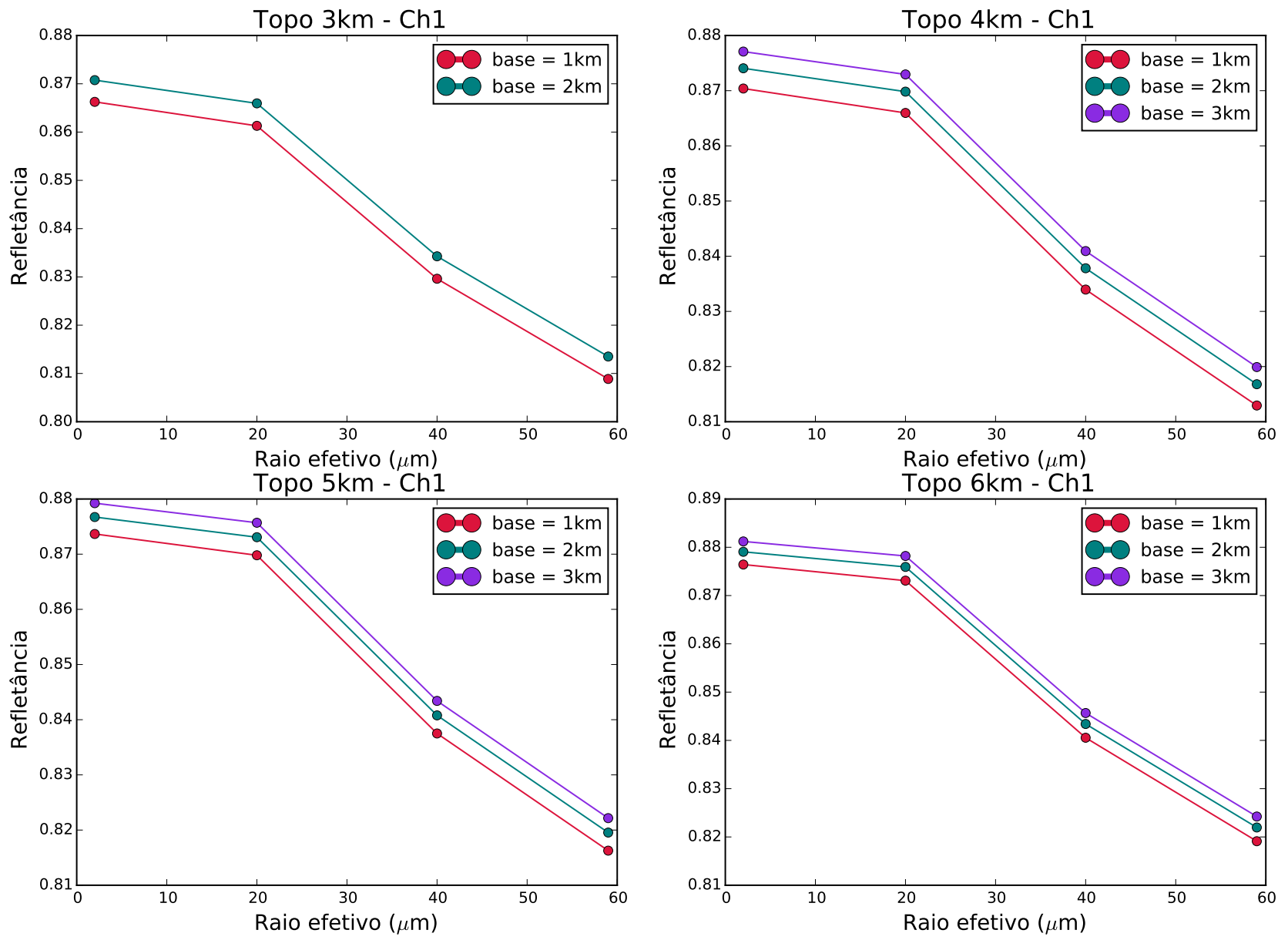

Figura 33 - Refletâncias no topo da atmosfera, para o canal 1, em função do raio efetivo em nuvens de água com topos em 3, 4, 5 e $6 \mathrm{~km}$.

Definindo uma posição de referência $(2 \mathrm{~km}$ - 4km), determina-se uma correção a ser aplicada na refletância correspondente em função do novo topo de nuvem, conforme indica a figura 34. Esta correção é determinada através do ajuste linear dos pontos apresentados. Mesmo aparentemente grosseira, a aproximação a uma função linear pode ser utilizada visto que as correções a serem aplicadas estão entre $-1 \%$ e $1 \%$. Dessa forma, caso a medida de refletância tenha sido feita, por exemplo, em uma nuvem de topo em $5,5 \mathrm{~km}$, a correção a ser feita nesta medida através é $\Delta \rho(\%)=0,38 h-1,56$, com $h=5,5$. Após a correção, é possível utilizar a LUT desenvolvida considerando esta posição de referência para a determinação das características de nuvem. 


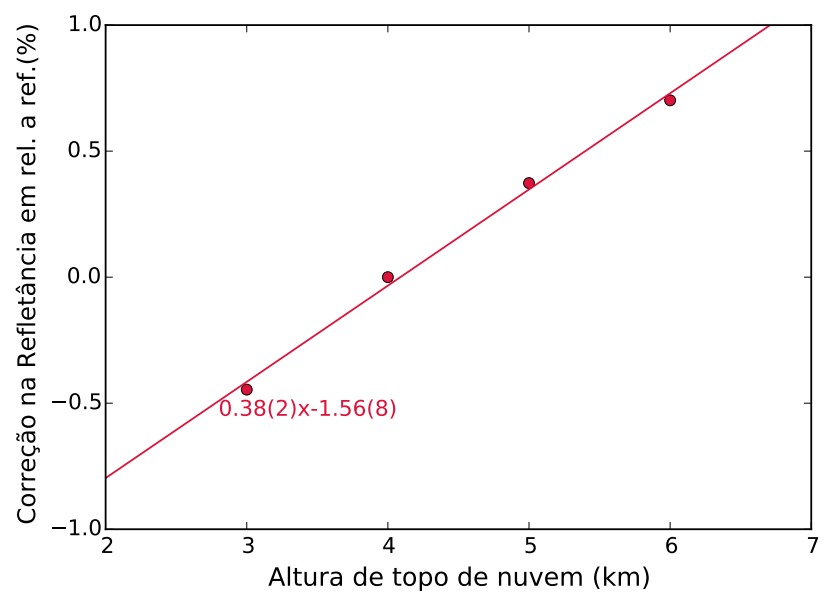

Figura 34 - Correção a ser aplicada na refletância de referência em função do topo de nuvem de água
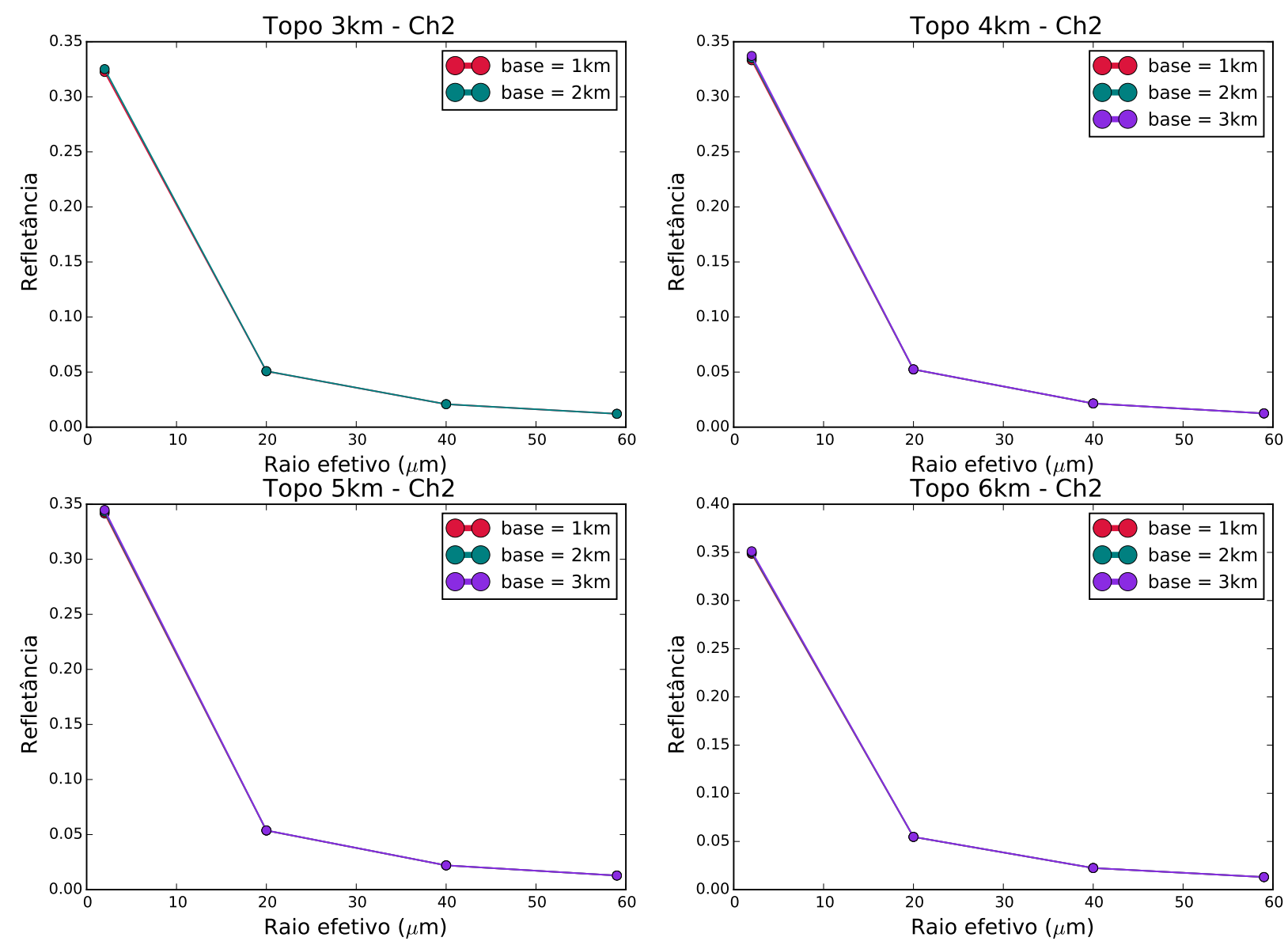

Figura 35 - Refletâncias, para o canal 2, no topo da atmosfera em função do raio efetivo em nuvens de água com topos em $3,4,5$ e $6 \mathrm{~km}$.

Esta correção, no entanto, é apenas necessária para o canal 1 (visível); para o canal 2 é possível notar que as refletâncias pouco diferem ao considerar alturas de base distintas para um valor de topo de nuvem fixado, conforme figura (35). 
Vale ressaltar que ao utilizar a parametrização mie há um aumento de exigência de máquina na execução do uvspec fazendo com que o tempo médio para obter a resposta de uma entrada seja de até 15 minutos, com consumo de memória médio, ainda sendo possível executar mais de um processo paralelamente, conforme a disponibilidade de núcleos no processador.

\subsubsection{Nuvens de gelo}

Em uma análise similar à apresentada para nuvens de água, são consideradas nuvens de gelo com bases entre 4 e $6 \mathrm{~km}$ e topos entre 6 e $9 \mathrm{~km}$. As refletâncias são calculadas para raios efetivos de 5, 20, 40 e $59 \mu \mathrm{m}$. Assim como em nuvens de água, em nuvens de gelo há diferença a ser considerada em relação ao topo da nuvem apenas considerando o canal 1, com variações desprezíveis para o canal 2.
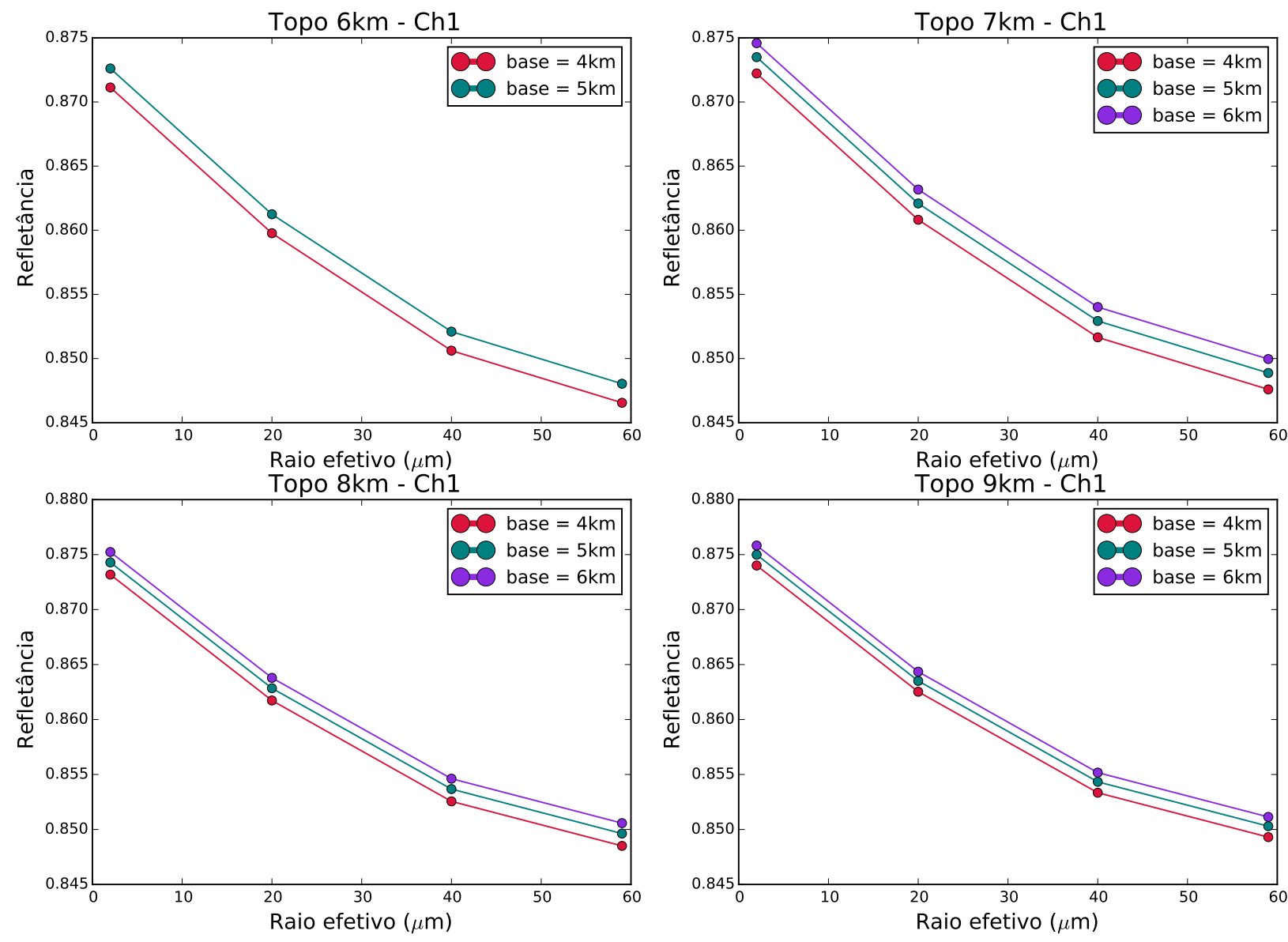

Figura 36 - Refletâncias calculadas para o canal 1 no topo da atmosfera em função do raio efetivo em nuvens de gelo com topos em 6, 7, 8 e $9 \mathrm{~km}$. 
Fixando a nuvem de gelo entre 4 e 6 km como referência, é possível desenvolver uma correção para refletâncias de nuvens com alturas de tipo distintas (figura 37). Também destaca-se que o consumo de máquina cresce consideravelmente ao se calcular radiâncias para nuvens de gelo, exigindo maior quantidade de memória e capacidade do computador.

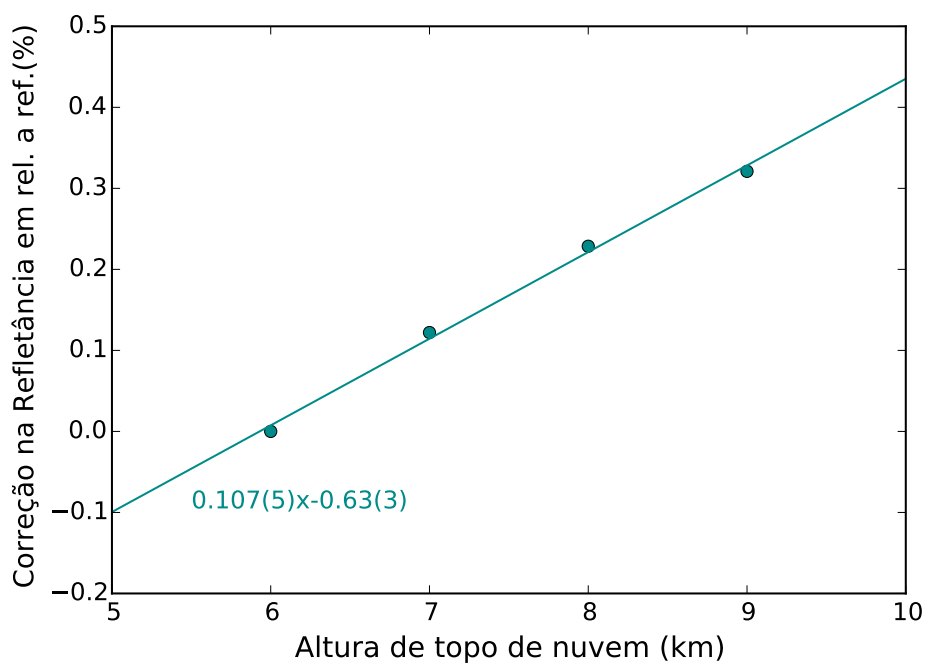

Figura 37 - Correção a ser aplicada na refletância de referência em função do topo de nuvem de gelo.

Avaliando os resultados obtidos para diferentes alturas de topo e base de nuvem nota-se que estas características são relevantes para o resultado na radiância para canal 1 (visível). Neste trabalho será desenvolvida look-up table para nuvens de água localizadas entre 1,5 e $4 \mathrm{~km}$ e nuvens de gelo entre 4 e $6 \mathrm{~km}$. Para nuvens com outras posições de topo, é possível a aplicação das correções nas refletâncias do canal 1: $\Delta \rho(\%)=0,38 h-1,56$ para nuvem de água e $\Delta \rho(\%)=0,107 h-0,63$ para nuvem de gelo, onde $h$ é a altura do topo da nuvem em $\mathrm{km}$.

\subsection{Look-up table para determinação de raio efetivo}

Nesta seção são apresentados os resultados obtidos para a elaboração de uma look-up table para determinação de raios efetivos em nuvens espessas (COD $=50)$ de água e de gelo. Conforme indicado no capítulo 3 e confirmado na seção 5.1, a sensibilidade ao raio efetivo é mais significativa para comprimentos de onda no infravermelho. Desta 
forma, a LUT apresentada neste capítulo foi desenvolvida para o canal 2 do GOES-13, com uso de sua função de resposta espectral.

Os parâmetros utilizados para o desenvolvimento desta LUT estão apresentados em detalhes no apêndice e todos os resultados de associações entre refletância e raio efetivo são dependentes das combinações de valores atribuídos para os ângulos solar zenital (SZA), azimutal (PHI) e de visada (VZA), chamados genericamente de geometria.

Para simplificar a linguagem, diz-se que a refletância calculada para uma determinada geometria é função das três variáveis apresentadas e pode ser escrita na notação $\rho\left(\theta_{0}, \phi, \theta\right)$, onde $\theta_{0}$ é o SZA, $\phi$ o azimute e $\theta$ o VZA.

\subsubsection{Nuvens de água}

Em nuvens de água, os raios efetivos utilizados para o desenvolvimento das LUT variam entre 2 e $59 \mu \mathrm{m}$. Com os resultados, é possível desenhar um gráfico que relacione os raios efetivos dados os resultados para a refletância no canal 2 em diversas condições de geometria.
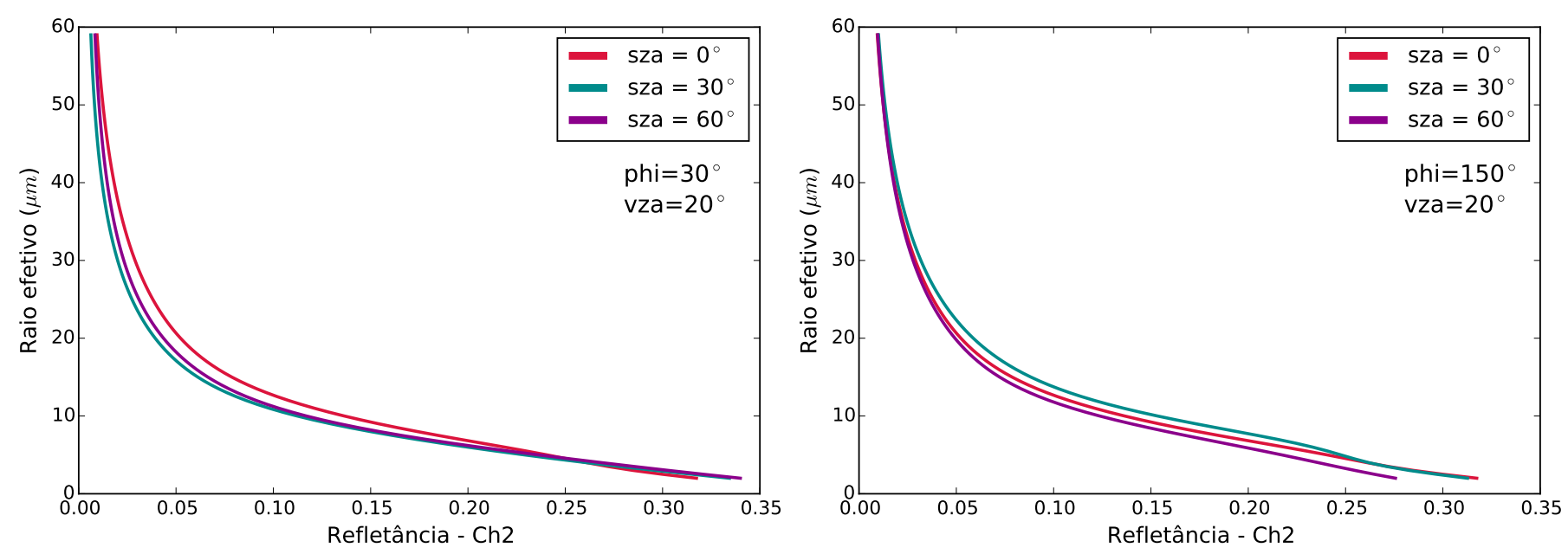

Figura 38 - Raio efetivo em função de refletância no canal 2 para $S Z A=0^{\circ}, 30^{\circ}$ e $60^{\circ}$ com $V Z A=20$ para $P H I=30^{\circ}$ à esquerda e $P H I=150^{\circ}$ à direita.

As figuras 38 e 39 ilustram a grande diferença de comportamento e sensibilidade ao SZA em diferentes combinações de ângulo de visada e azimute. Assim confirma-se que a utilização da LUT depende de conhecer a geometria associada à radiância a ser utilizada para determinar o raio efetivo. 

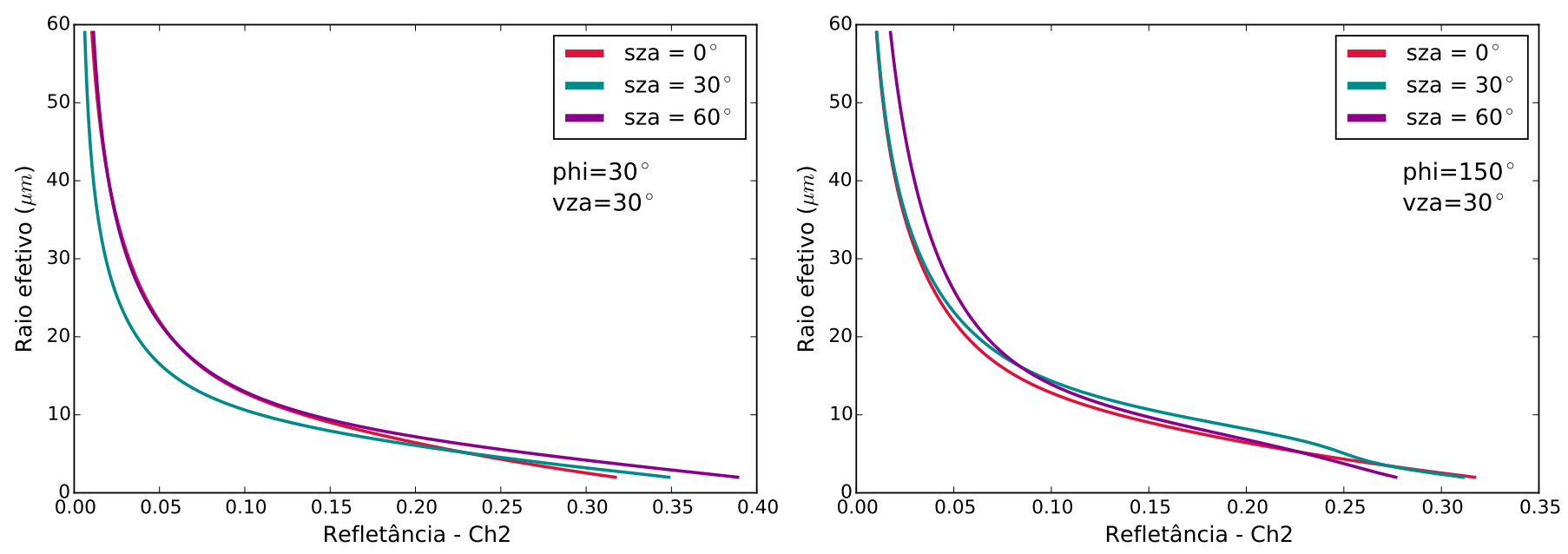

Figura 39 - Raio efetivo em função de refletância no canal 2 para $S Z A=0^{\circ}, 30^{\circ}$ e $60^{\circ}$ com $V Z A=30$ para $P H I=30^{\circ}$ à esquerda e $P H I=150^{\circ}$ à direita.

É possível, dessa forma, estimar geometrias que apresentam maior diferença nas refletâncias medidas e, portanto, diferenças nos raios efetivos. Também pode-se notar o oposto, como os pontos de proximidade ou intersecção de curvas nas figuras 40 e 41 nas quais diferentes geometrias apresentam valores próximos ou idênticos para as refletâncias e, consequentemente, para os raios efetivos.
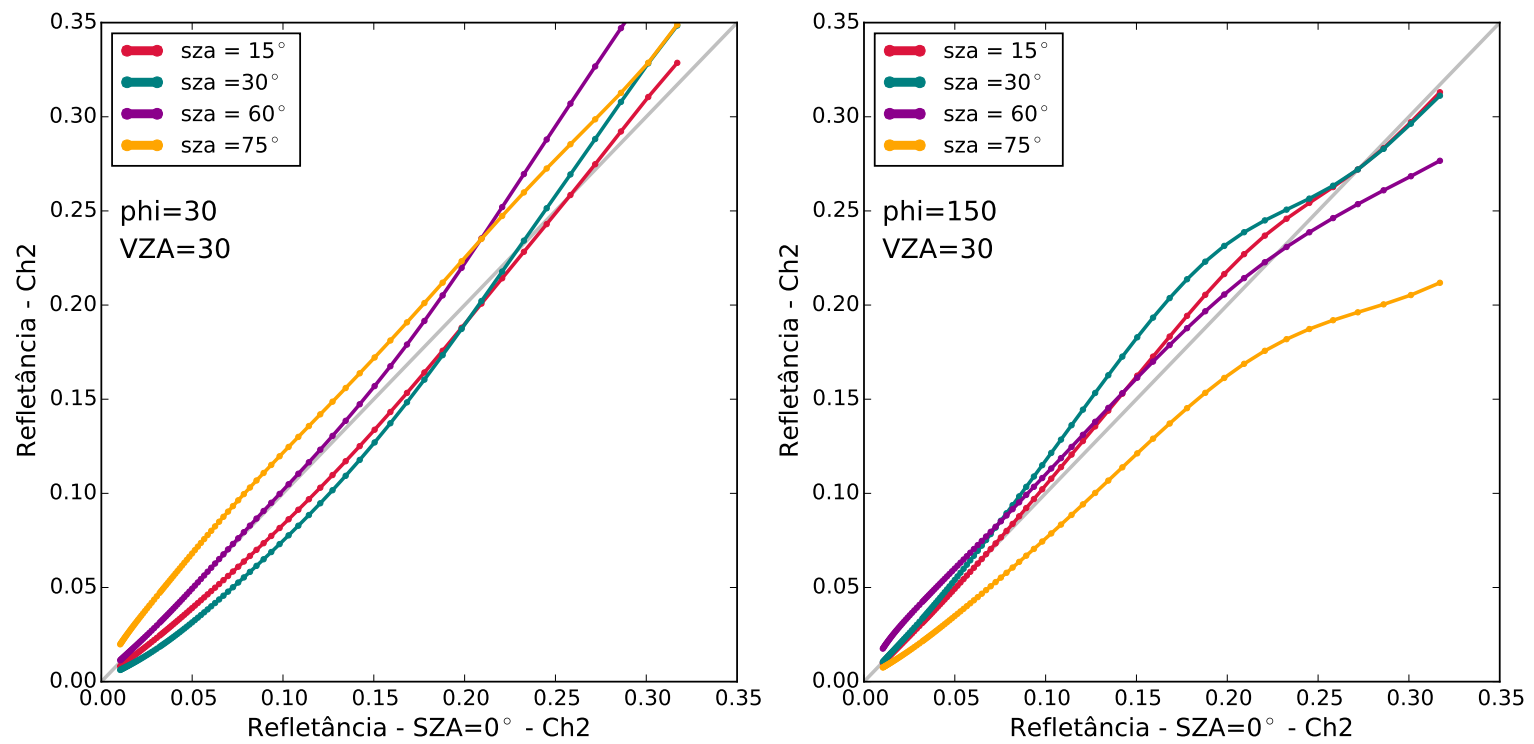

Figura 40 - Refletância obtida para diferentes SZA versus refletância obtida para $\theta_{0}=0^{\circ}$, $\operatorname{com} \theta=30^{\circ}$. Cada ponto representa um raio efetivo calculado. 
Essas curvas possuem diferentes comportamentos para cada combinação de $\left(\theta_{0}, \phi, \theta\right)$, como pode ser visto nas figuras 41 e 42 .
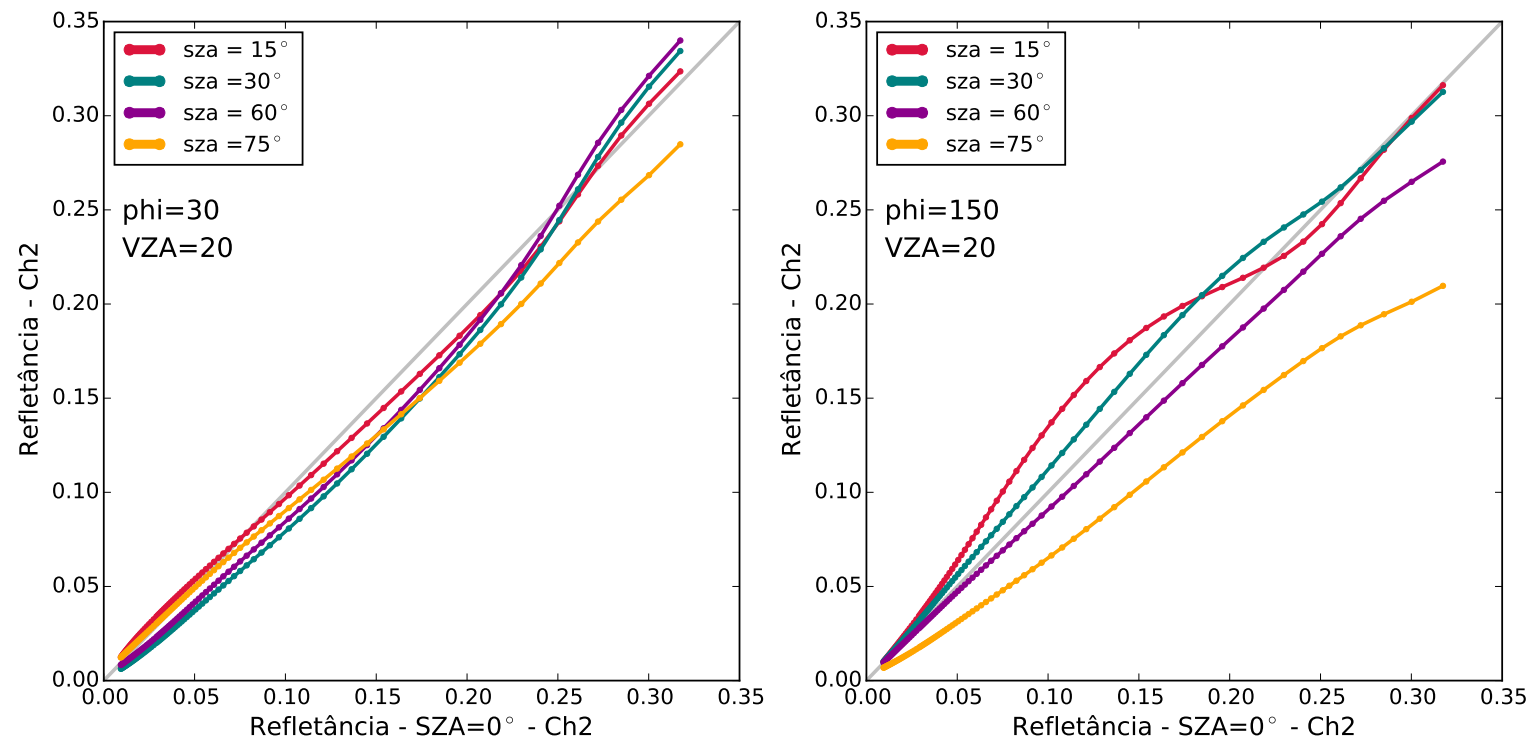

Figura 41 - Refletância obtida para diferentes SZA versus refletância obtida para $\theta_{0}=0^{\circ}$, $\operatorname{com} \theta=20^{\circ}$. Cada ponto representa um raio efetivo calculado.
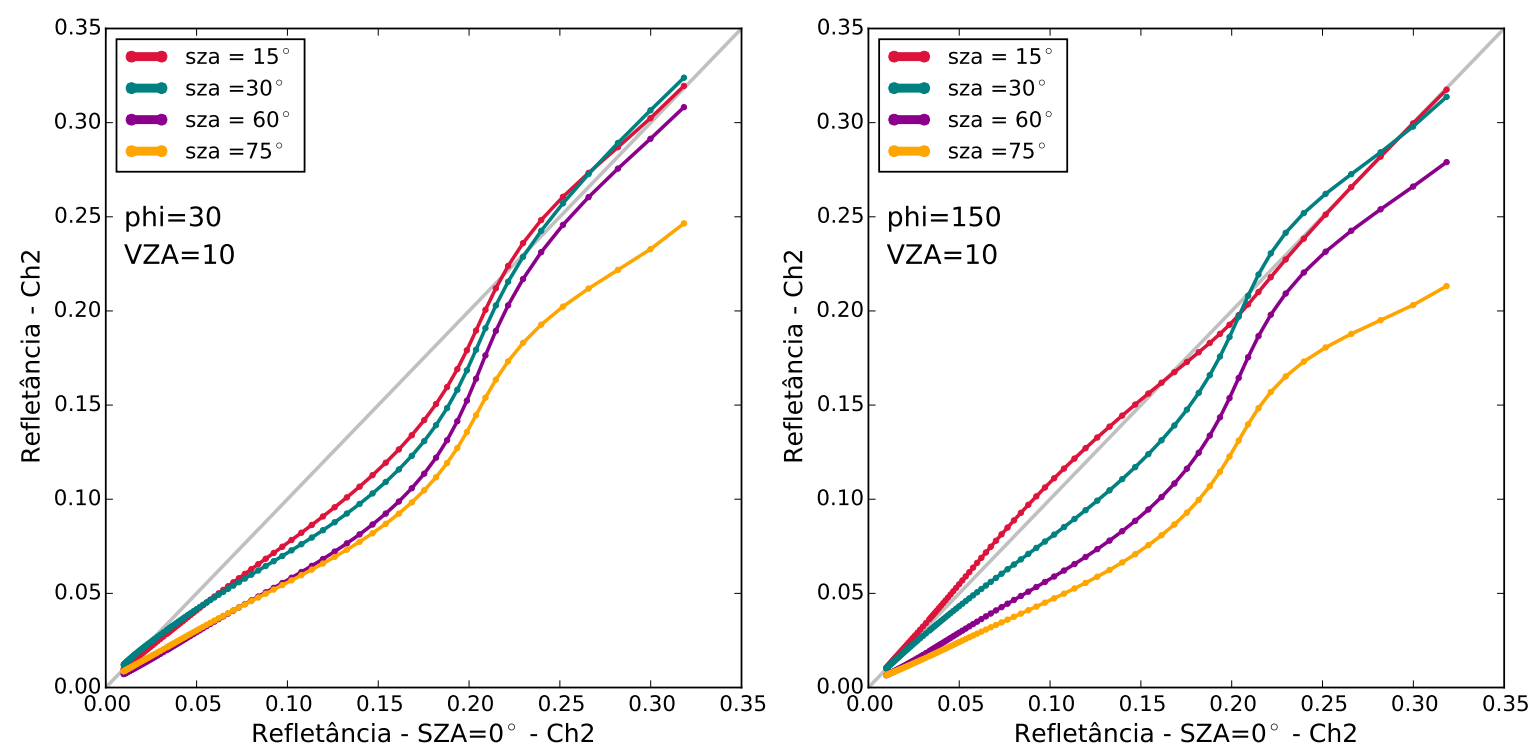

Figura 42 - Refletância obtida para diferentes SZA versus refletância obtida para $\theta_{0}=0^{\circ}$, $\operatorname{com} \theta=10^{\circ}$. Cada ponto representa um raio efetivo calculado.

Pelas figuras 42 e 41 , nota-se que para $\phi=30, \theta=20^{\circ}$ e $\theta_{0} \leq 60^{\circ}$ as refletâncias possuem mesmo comportamento. Tal concordância de comportamento também é vista na 
combinação $\phi=30, \theta=10^{\circ}$. Valores crescentes de $\theta$, para $\phi=150^{\circ}$, tendem a aproximar as refletâncias referentes a raios efetivos mais baixos que $20 \mu \mathrm{m}$.

Outra forma de avaliar estes resultados se dá no agrupamento de refletâncias por raios efetivos, possibilitando a comparação desta grandeza em relação ao SZA, conforme apresentado nas figuras 43, 44 e 45.
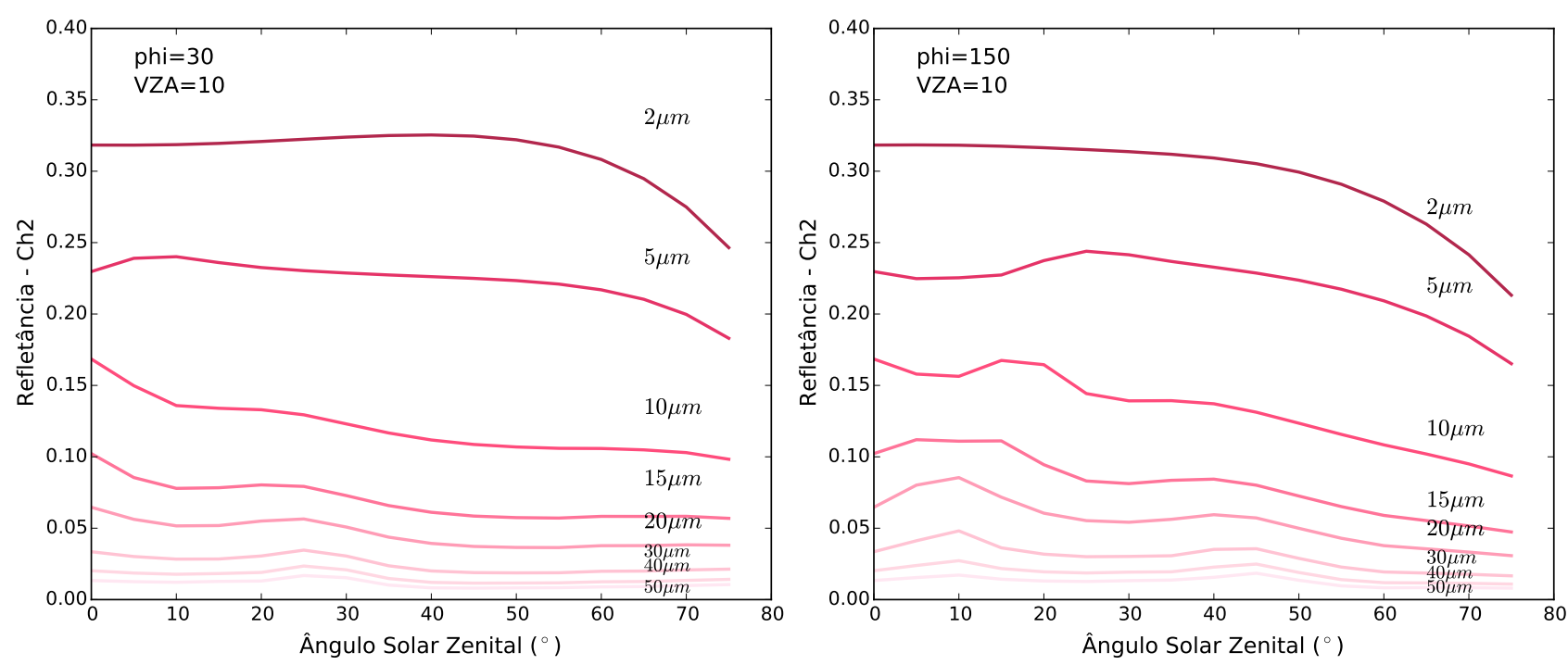

Figura 43 - Refletância obtida para diferentes raios efetivos em função de $\theta_{0}$, com $\theta=10^{\circ}$ e $\phi=30^{\circ}$ à esquerda, e $\phi=150^{\circ}$ à direita. Os valores para os raios efetivos apresentados são $(\mathrm{em} \mu \mathrm{m}): 2,5,10,20,30,40$ e 50. O tom mais escuro inicia em 2, clareando conforme aumenta $r_{e f f}$.
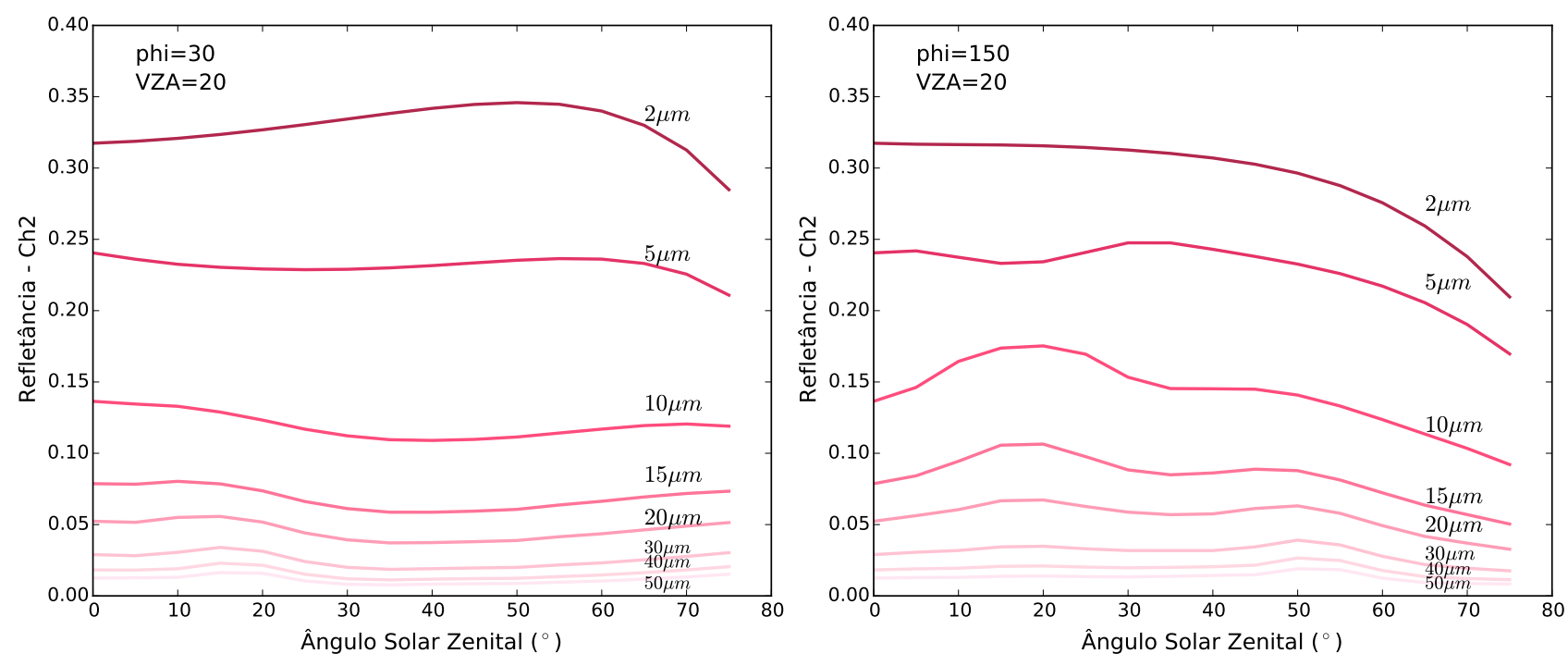

Figura 44 - Refletância obtida para diferentes raios efetivos em função de $\theta_{0}, \operatorname{com} \theta=20^{\circ}$ e $\phi=30^{\circ}$ à esquerda, e $\phi=150^{\circ}$ à direita. Os valores para os raios efetivos apresentados são $(\mathrm{em} \mu \mathrm{m}): 2,5,10,20,30,40$ e 50. O tom mais escuro inicia em 2, clareando conforme aumenta $r_{\text {eff }}$. 

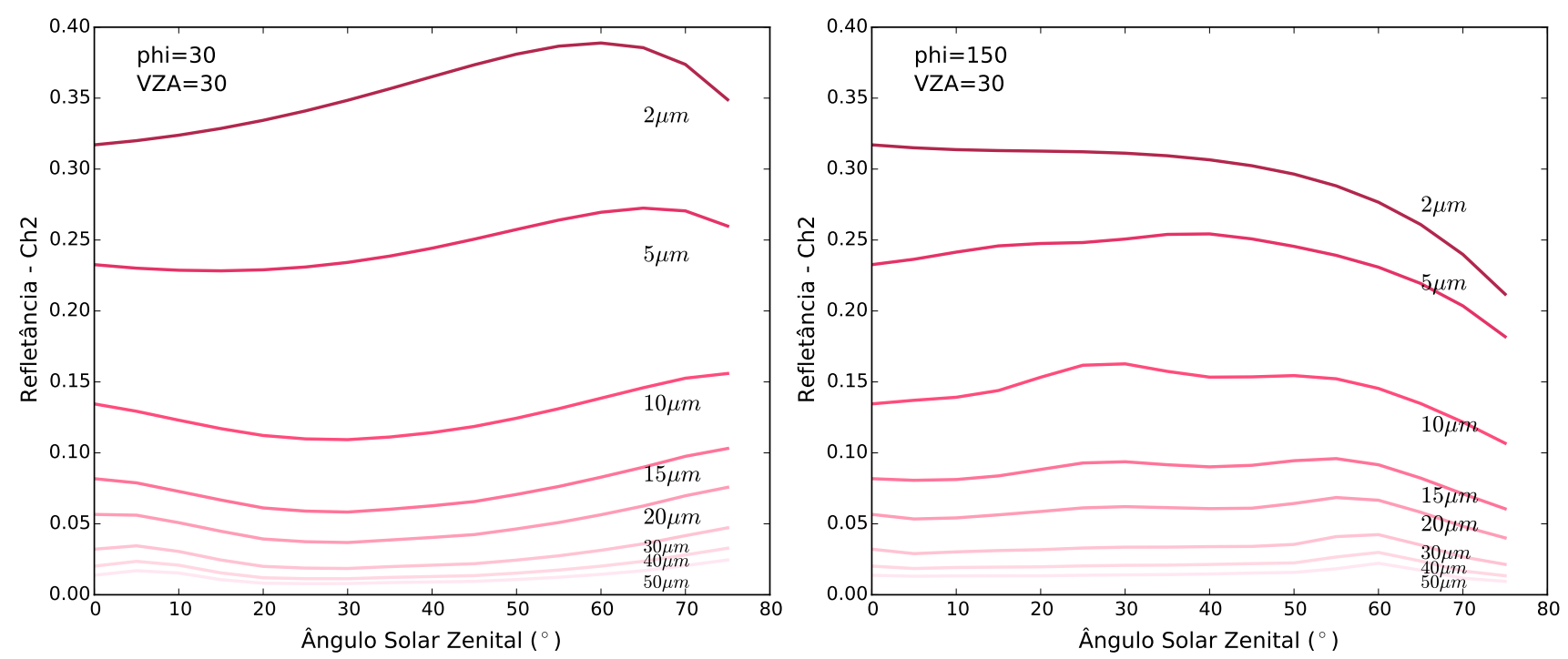

Figura 45 - Refletância obtida para diferentes raios efetivos em função de $\theta_{0}$, $\operatorname{com} \theta=30^{\circ}$ e $\phi=30^{\circ}$ à esquerda, e $\phi=150^{\circ}$ à direita. Os valores para os raios efetivos apresentados são $(\mathrm{em} \mu \mathrm{m}): 2,5,10,20,30,40$ e 50 . O tom mais escuro inicia em 2, clareando conforme aumenta $r_{\text {eff }}$.

Através das figuras 43, 44 e 45, é possível estimar que as inferências de raios efetivos através da LUT tem limite máximo de $r_{\text {eff }} \approx 30 \mu m$, acima disso a refletância seria tão baixa que ficaria sujeita a incertezas nas medidas das radiâncias.

Com esses resultados nota-se que, para ângulo solar zenital maior que 50, observações pela manhã $(\phi=150)$ possuem uma menor amplitude de refletâncias, independentemente do ângulo de visada, de forma que observações na parte da tarde podem apresentar identificação de raios efetivos com maior precisão. Além disso, para raios efetivos maiores, há uma menor variação nas refletâncias calculadas em relação ao $\theta_{0}$. O aumento nos valores de $\theta$ está associado a curvas mais acentuadas nessa mesma relação.

\subsubsection{Nuvens de gelo}

Os raios efetivos utilizados para desenvolvimento da LUT referente à nuvem de gelo variam entre 5 e $60 \mu \mathrm{m}$. E, assim como visto para nuvens de água, gráficos que relacionam as refletâncias calculadas aos raios efetivos correspondentes foram desenvolvidos.

Como visto nas figuras 46 a 48, nuvens de gelo apresentam maior sensibilidade ao $\theta_{0}$ em relação às nuvens de água quando considerados mesmos valores de $\theta$ e com $\phi=30$. 
Nessa geometria, as refletâncias são crescentes para ângulos $\theta_{0}$ crescentes, especialmente para raios efetivos baixos $\theta_{0} \geq 40^{\circ}$. Essa tendência também pode ser observada nas figuras 49, 50 e 51. Já para $\phi=150^{\circ}$ a sensibilidade ao ângulo solar zenital é consideravelmente menor, independentemente do valor atribuído a $\theta$.

Em nuvens de gelo, notam-se algumas irregularidades nas curvas de raio efetivo em função das refletâncias no canal 2 (figuras 46, 47 e 48). É possível que tais "ressonâncias" sejam resultado da mistura de hábitos na parametrização de propriedades ópticas utilizada para confecção da tabela de referência.
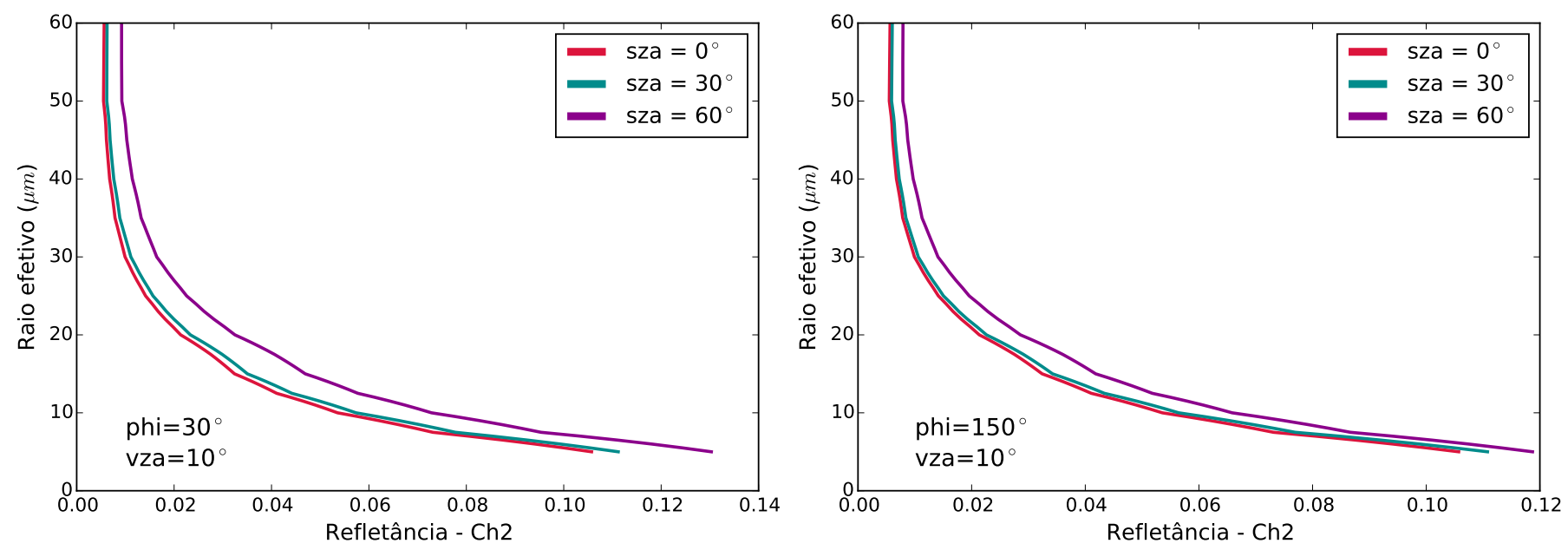

Figura 46 - Raio efetivo em função de refletância no canal 2, para nuvens de gelo, com $\theta_{0}=0^{\circ}, 30^{\circ}$ e $60^{\circ} \operatorname{com} \theta=10^{\circ}$ para $\phi=30^{\circ}$ à esquerda e $\phi=150^{\circ}$ à direita.
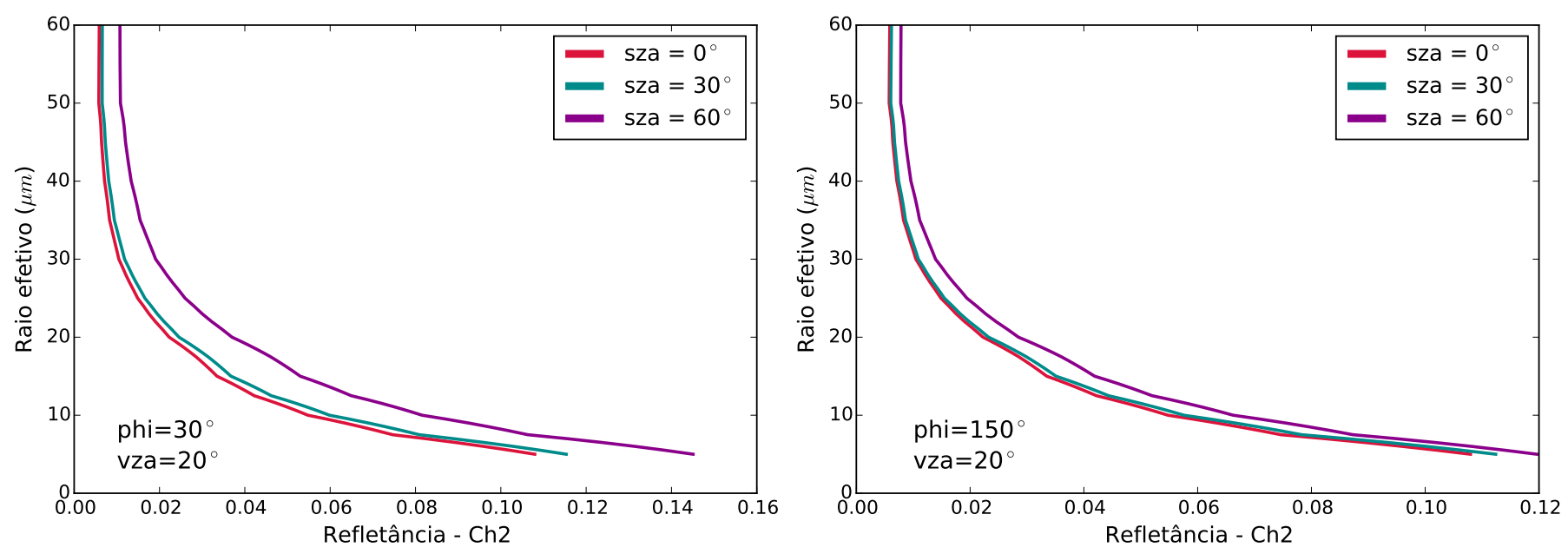

Figura 47 - Raio efetivo em função de refletância no canal 2, para nuvens de gelo, com $\theta_{0}=0^{\circ}, 30^{\circ}$ e $60^{\circ} \operatorname{com} \theta=20^{\circ}$ para $\phi=30^{\circ}$ à esquerda e $\phi=150^{\circ}$ à direita. 

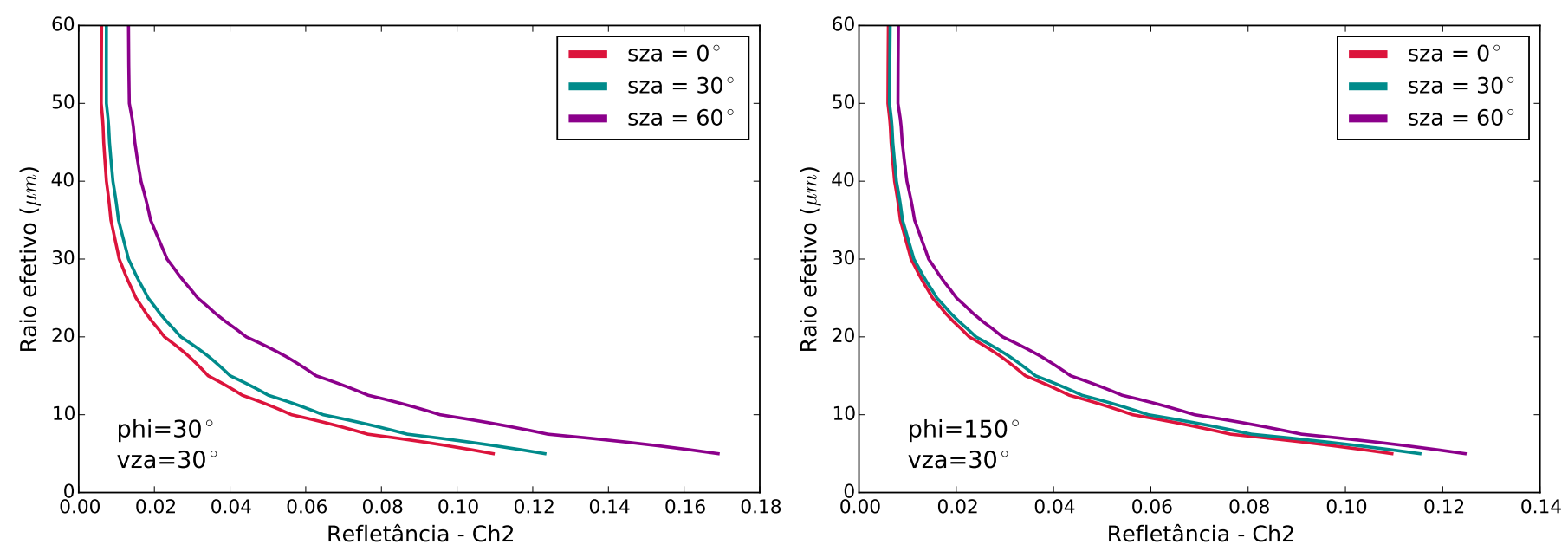

Figura 48 - Raio efetivo em função de refletância no canal 2, para nuvens de gelo, com $\theta_{0}=0^{\circ}, 30^{\circ}$ e $60^{\circ} \operatorname{com} \theta=30^{\circ}$ para $\phi=30^{\circ}$ à esquerda e $\phi=150^{\circ}$ à direita.

Através das fuguras 49, 50 e 51, é possível notar que refletâncias com valores $\rho\left(\theta_{0}, \phi, \theta_{0}\right) \leq 0,02$ são extremamente sensíveis aos raios efetivos associados, neste intervalo encontra-se $30 \mu m \geq r_{\text {eff }} \geq 60 \mu m$.
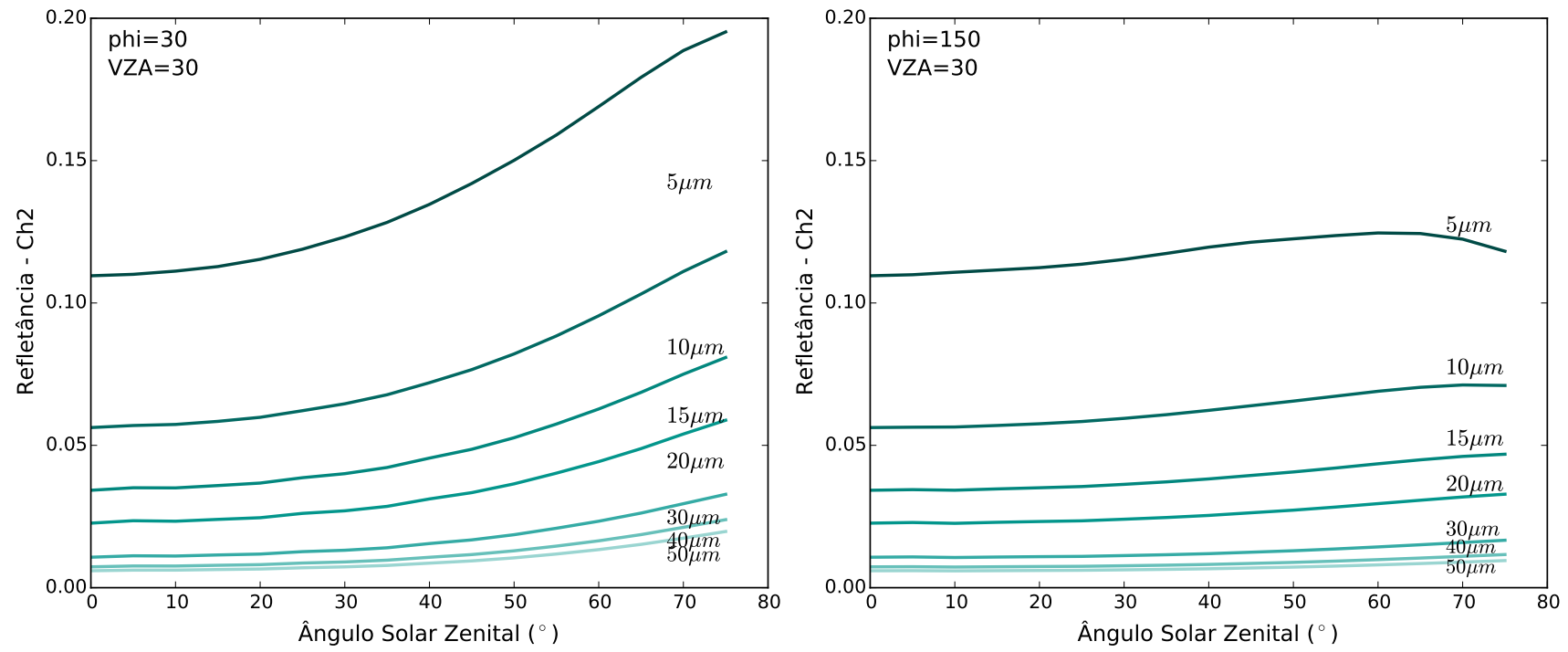

Figura 49 - Refletância obtida para diferentes raios efetivos em função de $\theta_{0}$, com $\theta=30^{\circ}$ e $\phi=30^{\circ}$ à esquerda, e $\phi=150^{\circ}$ à direita. Os valores para os raios efetivos apresentados são $(\mathrm{em} \mu \mathrm{m}): 5,10,20,30,40$ e 50. O tom mais escuro inicia em 2, clareando conforme aumenta $r_{\text {eff }}$. 

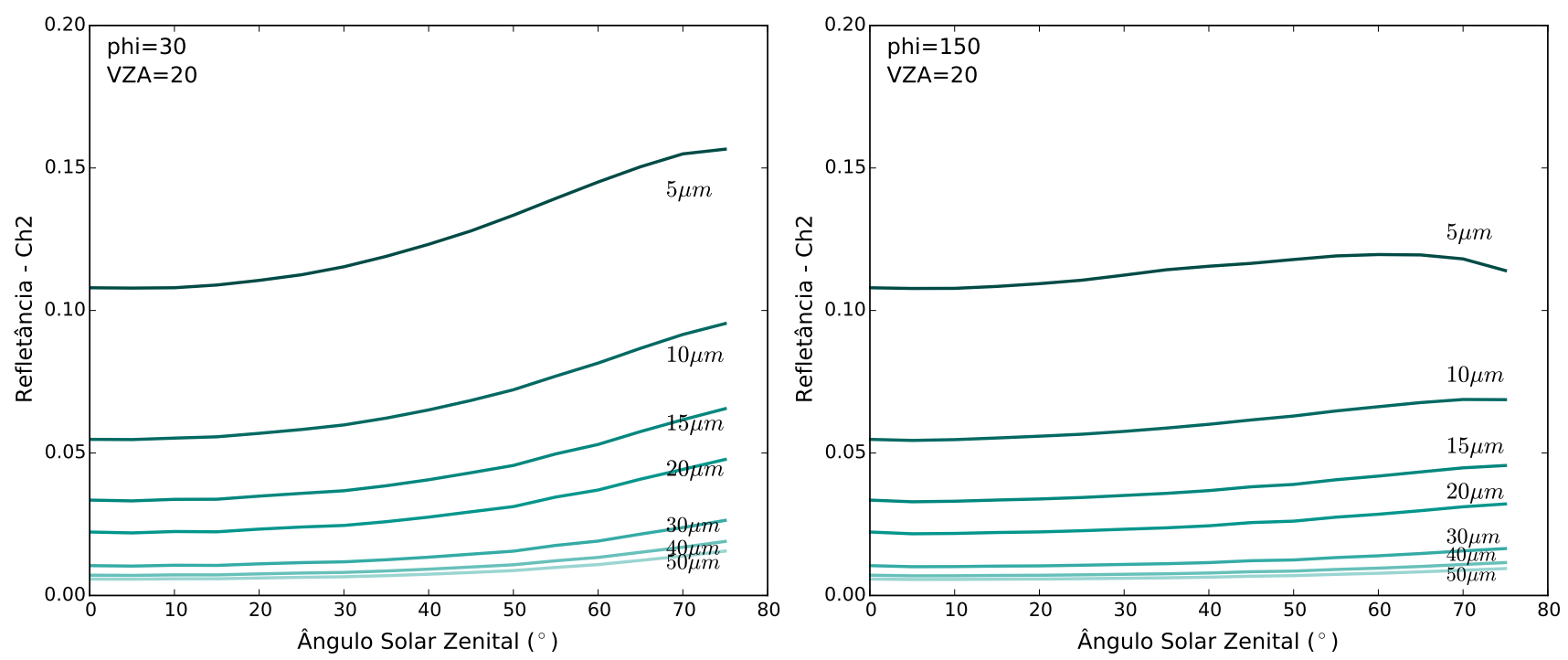

Figura 50 - Refletância obtida para diferentes raios efetivos em função de $\theta_{0}$, com $\theta=20^{\circ}$ e $\phi=30^{\circ}$ à esquerda, e $\phi=150^{\circ}$ à direita. Os valores para os raios efetivos apresentados são (em $\mu \mathrm{m}): 5,10,20,30,40$ e 50. O tom mais escuro inicia em 2, clareando conforme aumenta $r_{\text {eff }}$.
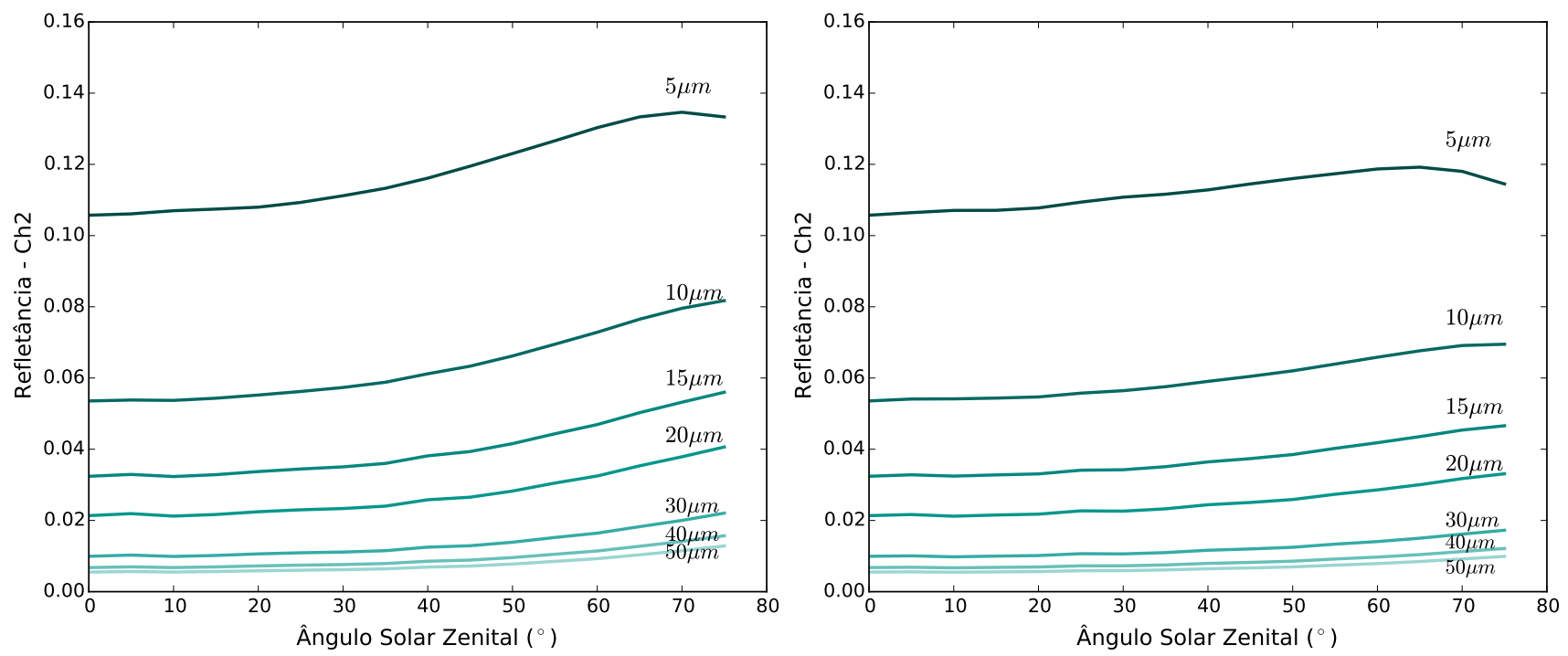

Figura 51 - Refletância obtida para diferentes raios efetivos em função de $\theta_{0}, \operatorname{com} \theta=10^{\circ}$ e $\phi=30^{\circ}$ à esquerda, e $\phi=150^{\circ}$ à direita. Os valores para os raios efetivos apresentados são $(\mathrm{em} \mu \mathrm{m}): 5,10,20,30,40$ e 50. O tom mais escuro inicia em 2, clareando conforme aumenta $r_{\text {eff }}$. 
Refletâncias calculadas em nuvens de gelo possuem maior sensibilidade ao ângulo solar zenital que as calculadas em nuvens de água, porém não apresentam sensibilidade relevante para variações em $\phi$ e em $\theta$.

Considerando os resultados apresentados nesta seção é possível dizer que a tabela de referência desenvolvida tilizando o libRadtran com intervalo referente ao canal 2 do GOES-13 se mostra uma ferramenta consistente para a determinação de raios efetivos em nuvens espessas $(\mathrm{COD}=50)$. Percebe-se um comportamento similar para nuvens de água e gelo, especialmente no que diz respeito à sensibilidade e comportamento das refletâncias em função dos ângulos SZA. Com $\rho\left(\theta_{0}, \phi, \theta\right)<0,05$, a distinção entre raios efetivos de valores $r_{\text {eff }} \geq 30 \mu m$ é dificultada, dada a proximidade dos pontos nesta região.

\subsubsection{Relação entre refletâncias}

Conforme visto na seção anterior, as refletâncias apresentam diferentes comportamentos para cada combinação de valores de $\theta_{0}, \phi$ e $\theta$. Assim, para uma geometria definida, é proposto um estudo para a determinação de uma relação entre as refletâncias calculadas para os canais de interesse e comprimentos de onda centrais destes. Isto porque o tempo comprometido no desenvolvimento da tabela de referência utilizando os intervalos de comprimento de onda e as funções de resposta espectral dos canais (1 e 2) do GOES-13 é muito maior que ao utilizar comprimentos de onda únicos (centrais) correspondentes a cada canal.

Neste estudo é fixado $\theta_{0}=30^{\circ}, \phi=150^{\circ}$ e $\theta=30^{\circ}$ e 0,04 de albedo de superfície. Foram calculadas as refletâncias considerando estes parâmetros para alguns valores de COD e de raios efetivos. Esta etapa consiste na determinação de função que relacione refletâncias na forma apresentada:

$$
\rho_{\lambda}=a * \rho_{c h}+b
$$

sendo $\rho_{c h}$ as refletâncias calculadas utilizando os intervalos referentes aos canais 1 e 2 do GOES-13 e $\rho_{\lambda}$ as refletâncias calculadas utilizando comprimento de onda central, definido como aproximadamente o comprimento de onda médio, considerando as funções de resposta espectral para os dois intervalos. Para o intervalo visível, correspondente ao canal 1, tem-se $\lambda=630 \mathrm{~nm}$ e para o infravermelho, $\lambda=3900 \mathrm{~nm}$, correspondente ao canal 2. 
O libRadtran foi executado para nuvem de água entre 1,5 e $3 \mathrm{~km}$ com raios efetivos variando entre 5, 20, 40 e $59 \mu \mathrm{m}$ para diferentes CODs. Os resultados obtidos para o intervalo visível e para o infravervelho podem ser vistos na figura 52 .
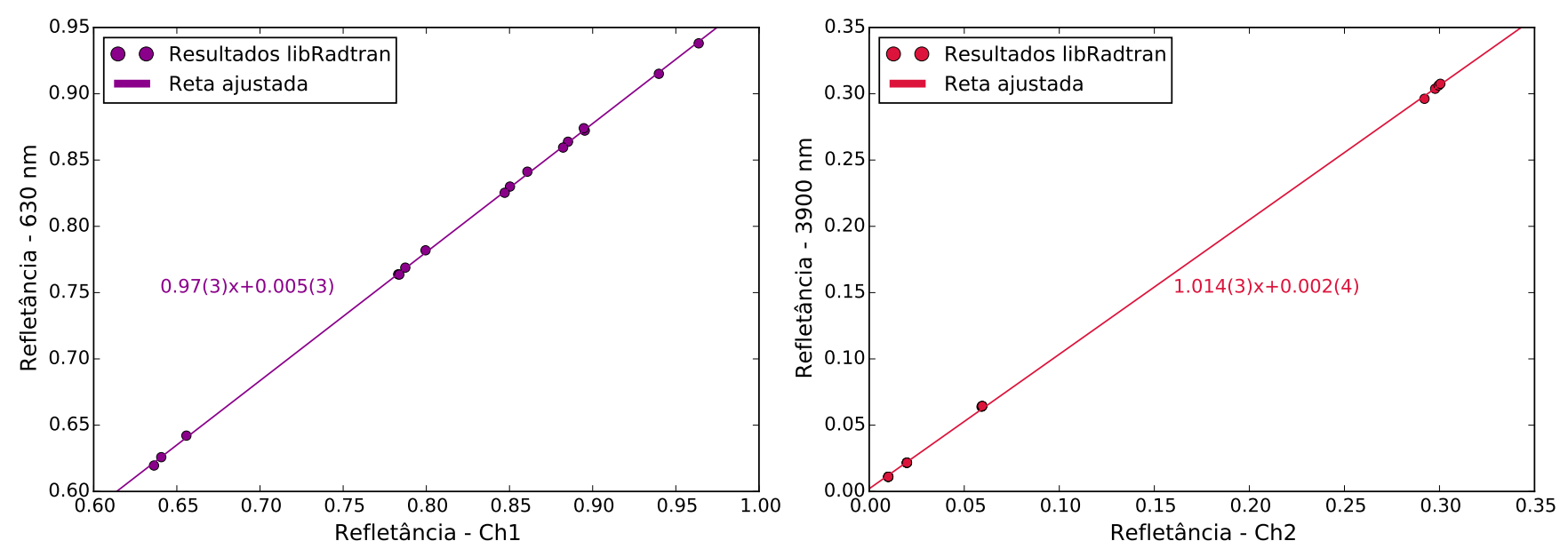

Figura 52 - Refletâncias em comprimento de onda central em função de refletância em canal, para nuvem de água. À esquerda relação para o intervalo visível e à direita para o infravermelho

A nuvem de gelo foi posicionada entre 4 e $5 \mathrm{~km}$, e os raios efetivos tiveram variação entre os valores $r_{\text {eff }}$ de 5, 20, 40 e $59 \mu \mathrm{m}$. A figura 53 apresenta os resultados obtidos para nuvem de gelo.
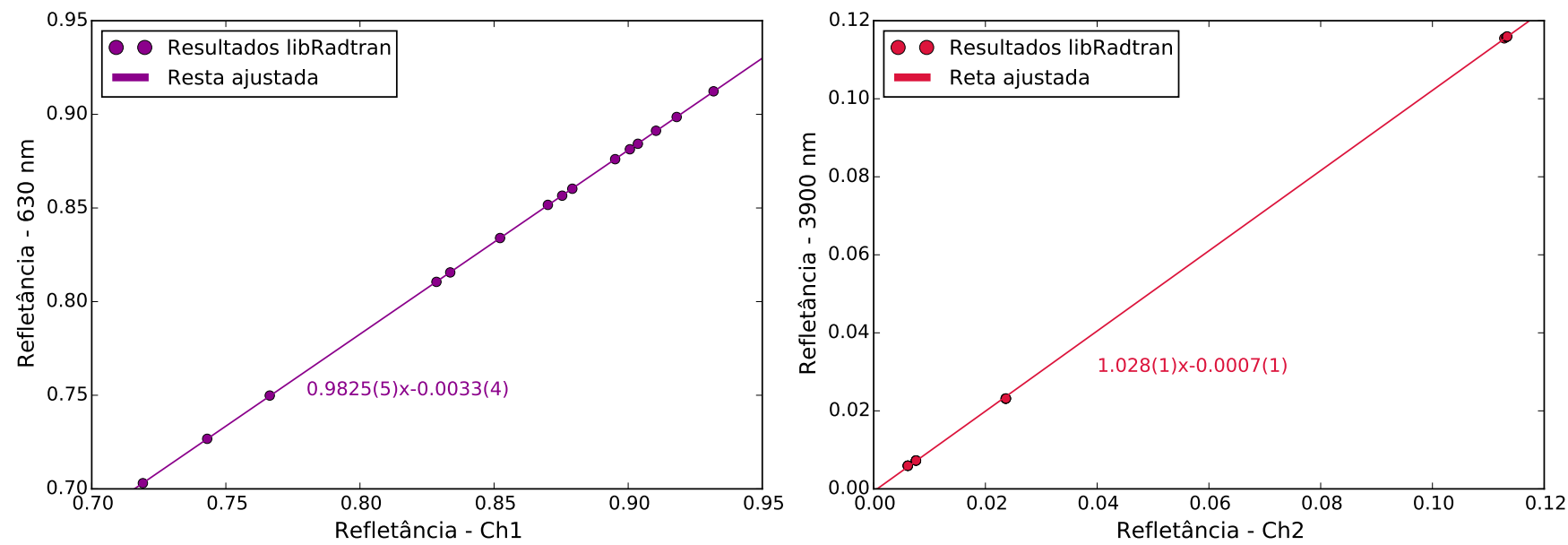

Figura 53 - Refletâncias em comprimento de onda central em função de refletância em canal, para nuvem de gelo. À esquerda relação para o intervalo visível e à direita para o infravermelho 
Considerando as exigências de máquina para execução de uma grande quantidade de chamadas do uvspec, a possibilidade de relacionar refletâncias nos comprimentos de onda centrais às refletâncias para os canais 1 e 2 permite a produção de look-up table completa para nuvens de água e gelo e o desenvolvimento de diagramas Nakajima-King com os resultados.

\subsubsection{Diagrama Nakajima-King}

Foram desenvolvidas LUT completas (parâmetros e características nos Apêndices) para nuvens de água e gelo na geometria fixada. Considera-se que conhecendo as refletâncias medidas nos canais, com as funções expressas na seção anterior, é possível obter as refletâncias com comprimento de onda centrais correspondentes e, então, fazer uso dos diagramas apresentados a seguir (figuras 54 e 55).

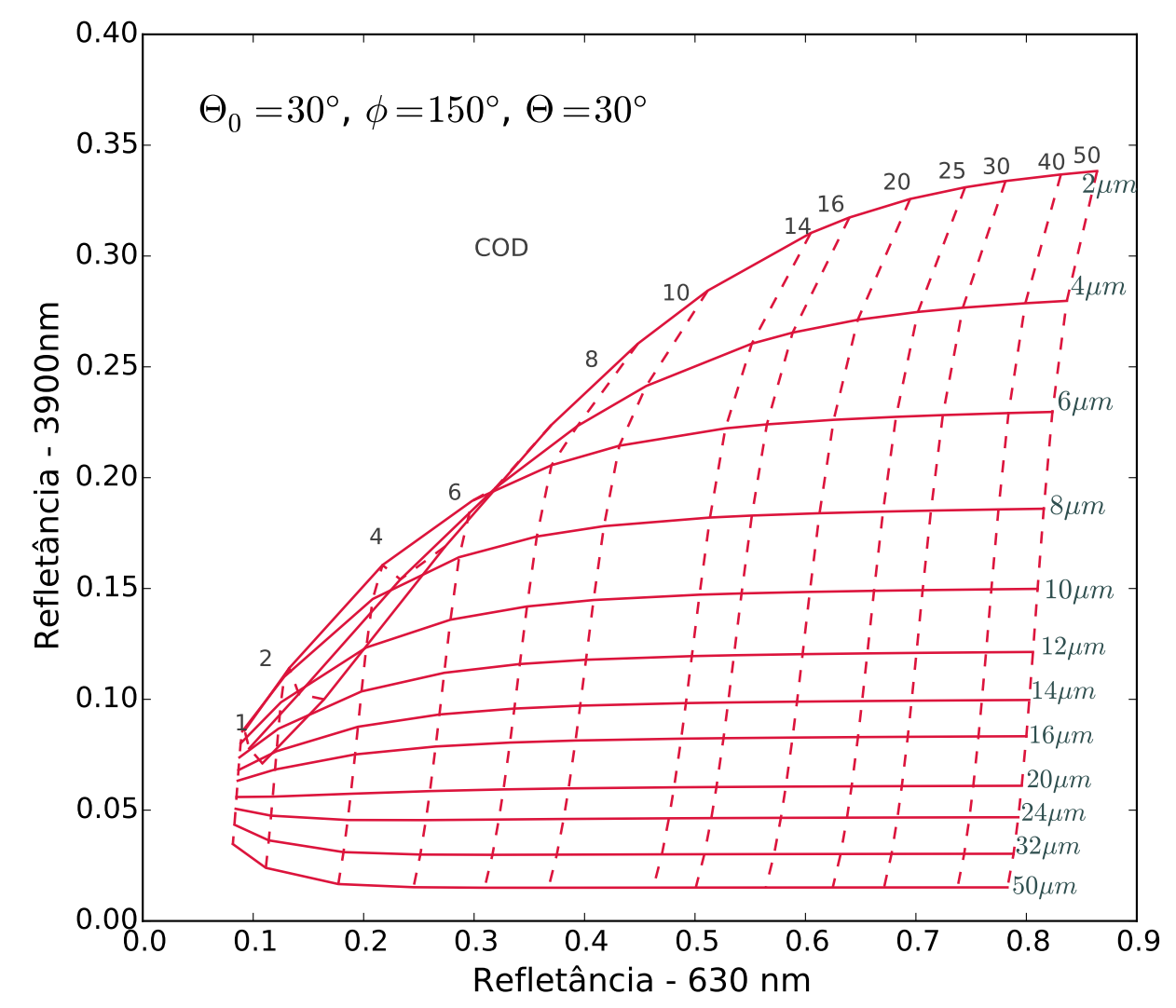

Figura 54 - Diagrama tipo Nakajimka-King para nuvens de água com uso de comprimentos de onda centrais $630 \mathrm{~nm}$ e $3900 \mathrm{~nm}$ 
Através do diagrama desenvolvido para nuvens de água, é possível notar uma tendência quase ortogonal para refletâncias nos dois canais com COD $\geq 10$ e raios efetivos entre 6 e $50 \mu \mathrm{m}$. A proximidade nas refletâncias no infravermelho para raios efetivos maiores que $30 \mu m$ também é evidente.

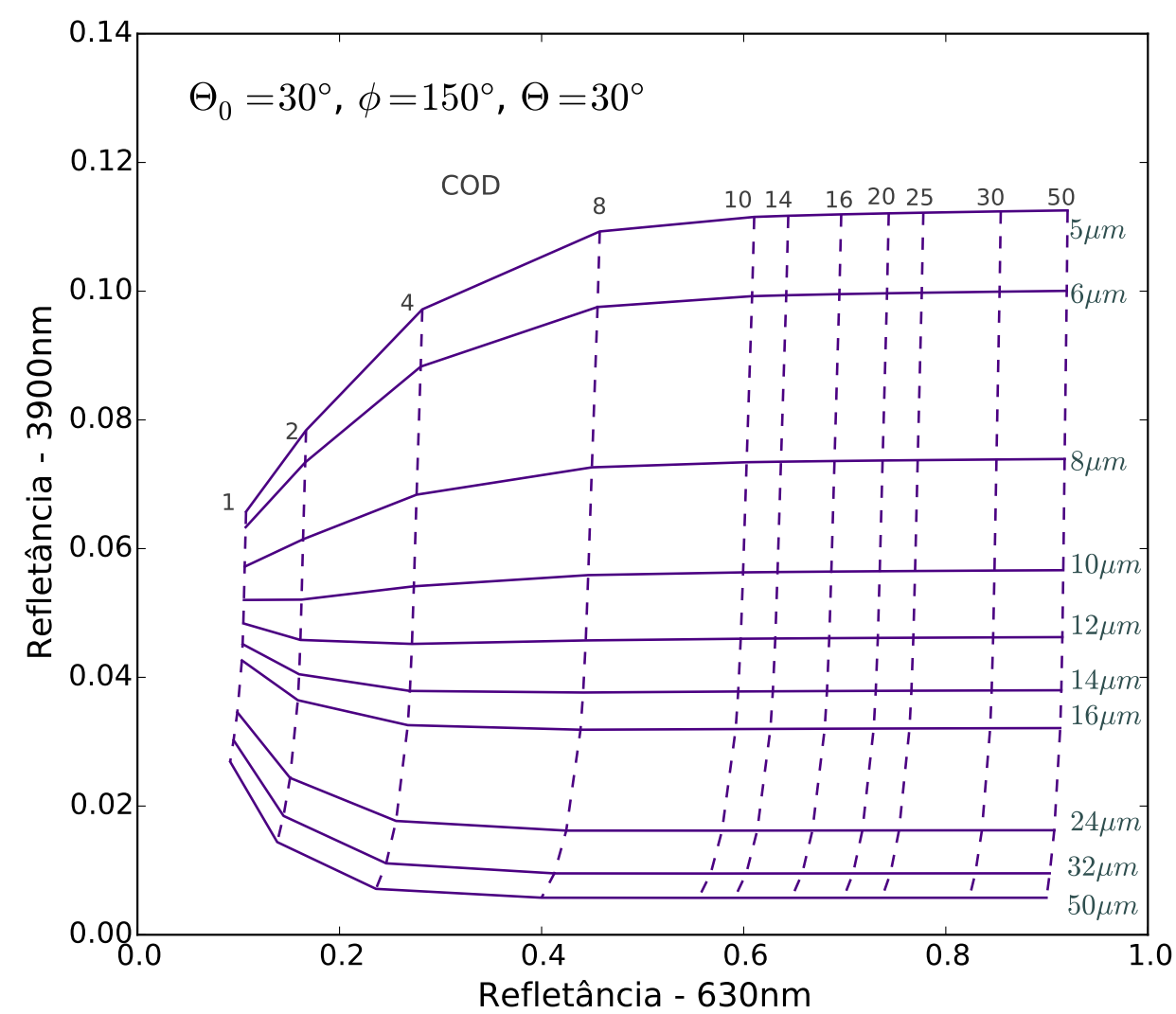

Figura 55 - Diagrama tipo Nakajimka-King para nuvens de gelo com uso de comprimentos de onda centrais $630 \mathrm{~nm}$ e $3900 \mathrm{~nm}$

Percebe-se uma maior ortogonalidade no diagrama de nuvem de gelo que o visto no diagrama desenvolvido para nuvem de água. Isso indica uma menor sensibilidade ao raio efetivo nas refletâncias em $630 \mathrm{~nm}$ e ao COD para as refletâncias calculadas em $3900 \mathrm{~nm}$. Também é importante considerar que a amplitude da variação da refletância em $3900 \mathrm{~nm}$ é inferior a observada em nuvens de água.

\subsection{Aplicação da LUT}

A fim de estudar a evolução diurna de nuvens convectivas profundas, em trabalho desenvolvido pelo grupo de pesquisa (Pugliese Silva et al., 2017) fez-se aplicação direta da 
LUT para determinação de raio efetivo em região delimitada por (coordenadas $2^{\circ} \mathrm{N}, 70^{\circ} \mathrm{W}$, $\left.49^{\circ} \mathrm{W}, 16^{\circ} \mathrm{S}\right)$, conforme apresentada pela figura 56. Dentro desta região foi escolhida uma área menor, com predominância de superfície florestada, para utilização das imagens do GOES-13.

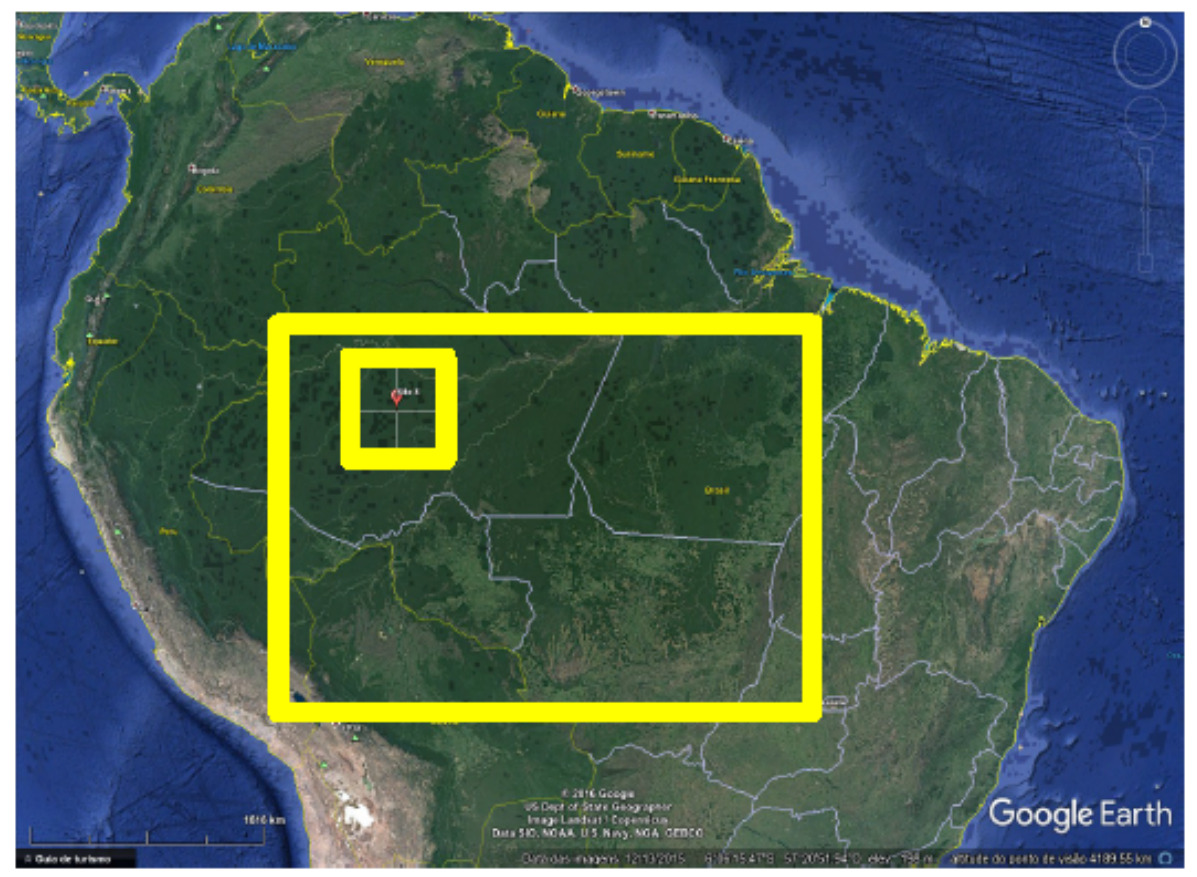

Figura 56 - Região de interesse para determinação de raio efetivo através de dados obtidos pelo GOES-13. O quadrado menor indica a área que possui apenas floresta que foi utilizada. (PugliesiSilva et al., 2017)

A partir de medidas de radiância solar da AERONET, a profundidade óptica do aerossol foi considerada, em função dos meses para o site de Alta Floresta e medidas de coluna de vapor de água em função dos meses foram definidas três estações de interesse: úmida, seca e seca com queima de biomassa (esta última sendo os meses de agosto e setembro, quando há muita fumaça de queimada). Foram selecionadas imagens para um dia representativo em cada estação, dentre uma coleção de dados coletados aproximadamente a cada 30 minutos entre os anos de 2010 e 2014.

A emissão de radiação de Planck, correspondente à temperatura de brilho determinada através do canal 4 (seguindo as recomendações ${ }^{1}$ da NOAA), foi subtraída do sinal bruto medido pelo satélite no canal de 3900 $\mathrm{nm}$. O sinal líquido foi convertido em unidades de refletância e, finalmente, a refletância corrigida do canal 2 foi comparada aos

1 http://www.ospo.noaa.gov/Operations/GOES/calibration/gvar-conversion.html Acessado em 14/Jul/2017 10:00 
valores pré-calculados na LUT para obtenção de uma estimativa de $r_{\text {eff }}$ para o hidrometeoro, empregando-se uma interpolação linear simples entre os valores mais próximos da refletância no visível, infravermelho médio, e a temperatura de brilho de nuvens.

A figura 57 apresenta exemplos dos diagramas de temperatura versus raio efetivo prduzidos por Pugliese Silva et al. (2017). Foi investigado o ciclo de evolução dos tamanhos das gotas para cada estação, através de diagramas horários para os valores das temperaturas de brilho em função dos raios efetivos.

As análises produzidas por Pugliese Silva et al. (2017) possibilitam avaliar o ciclo diurno de nuvens típicas na região Amazônica nas três estações de estudo. Pela manhã, durante a estação úmida, as nuvens apresentam topos mais quentes e gotículas com menores raios efetivos, tendo máximos em aproximadamente $r_{\text {eff }}=18 \mu \mathrm{m}$ entre alturas correspondentes a $-20^{\circ} \mathrm{C}$ e $-40^{\circ} \mathrm{C}$. Com o passar do tempo os raios efetivos aumentam, até 10AM. A partir do fim da manhã nota-se uma redução nos tamanhos de hidrometeoros, associado a um início de maior desenvolvimento vertical visto entre 12:00 e 13:00 (hora local). A partir deste horário é possível notar a ação de convecção profunda, com nuvens atingindo temperaturas até $-80^{\circ} \mathrm{C}$, com raios efetivos máximos por volta de $28 \mu \mathrm{m}$.

Um número menor de nuvens é formado durante a estação seca. Nessa estação é possível notar que as nuvens são, em média, mais quentes e com crescimento no tamanho dos hidrometeoros menos acentuado que o observado na estação úmida, atingindo raios efetivos máximos menores que $20 \mu \mathrm{m}$. O crescimento vertical também é inferior ao que acontece durante a estação de queima de biomassa.

Durante a estação de queimadas, considerando a maior disponibilidade de CCN na atmosfera, nuvens de fase mista (com temperaturas entre $0^{\circ} \mathrm{C}$ e $-40^{\circ} \mathrm{C}$ ) atingem menores temperaturas em média ao longo do dia, e com maiores raios efetivos, de forma mais rápida que a evidenciada na estação seca sem poluição. Em nuvens quentes o raio efetivo médio decresce ao longo do dia. Após 13h (hora local) é possível notar que há maior frequência de nuvens em baixas temperaturas para a estação seca que na estação de queima de biomassa, e o crescimento de nuvens é maior também nesta estação. Com esses dados é possível avaliar que a maior presença de aerossol na atmosfera pode implicar em diferenças no ciclo diurno de nuvens na Amazônia. 

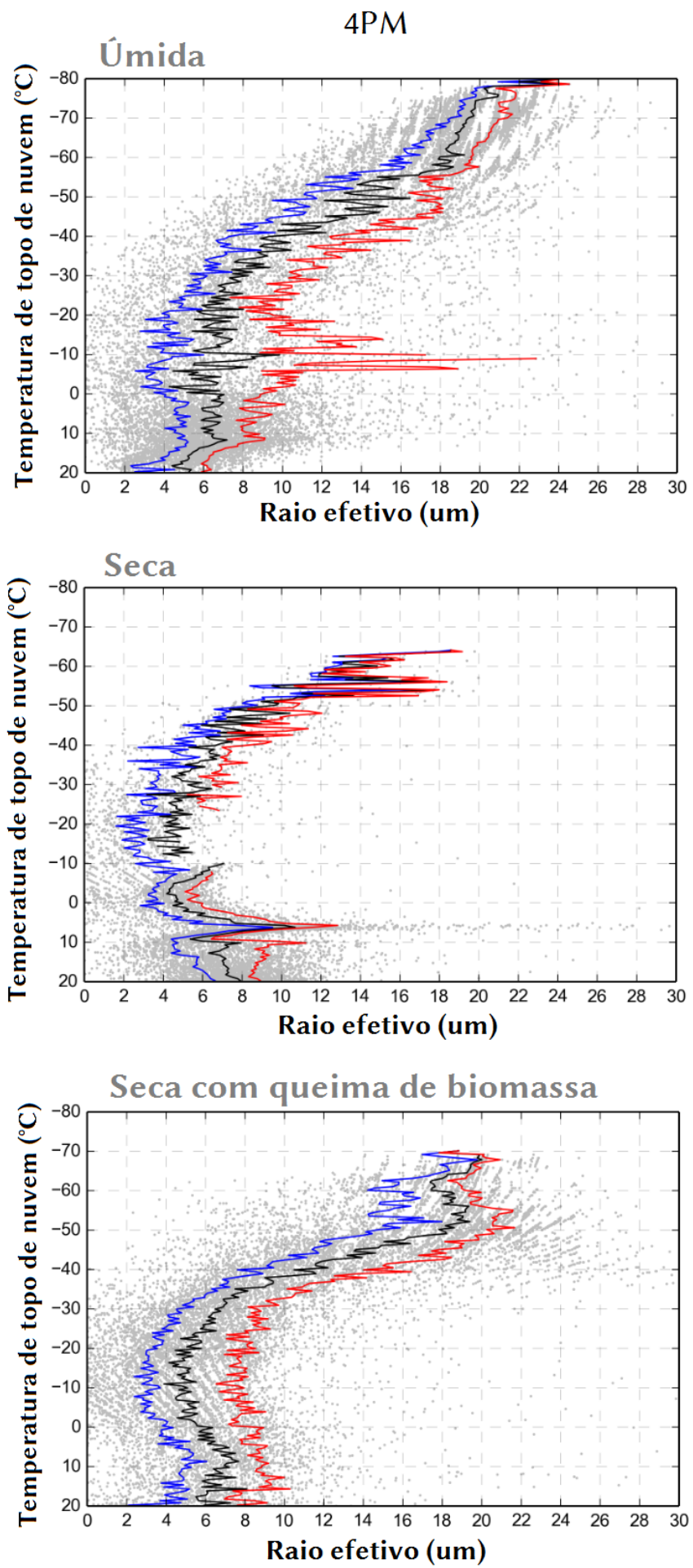

Figura 57 - Exemplos de diagramas produzidos por Pugliese Silva et al. (2017). Temperaturas de topo de nuvem em função dos raios efetivos, às 16:00 (horário local), para as três estações determinadas. As curvas nos gráficos representam os três quartis das distribuições de tamanho. (Pugliese Silva et al., 2017) 



\section{Conclusões}

Considerando medidas de sensores a bordo de satélite, é preciso estudar transferência radiativa e códigos que calculam radiância para dada condição atmosférica. Neste trabalho foi estudado o código de transferência radiativa libRadtran, comparando-o em relação ao SBDART. Foram estudadas características do libRadtran acerca de diferentes configurações de geometria de observação, iluminação e posicionamento de nuvens, além de variações em propriedades atmosféricas e de suuperfície. Por fim, foram desenvolvidas tabelas de referência para determinação de raios efetivos, viabilizando o uso de dados obtidos por sensores a bordo de satélites geoestacionários, auxiliando, desta forma, pesquisas acerca da interação entre partículas de aerossol atmosférico e nuvens.

Em análise comparativa entre os modelos, foram calculadas refletâncias para diferentes albedos de superfície e concentrações de ozônio, em dois comprimentos de onda únicos (630 nm e $3900 \mathrm{~nm}$ ) e em dois intervalos representativos VIS, 590 a $660 \mathrm{~nm}$, e IR, 3850 a $4000 \mathrm{~nm}$. Ao comparar o libRadtran ao SBDART, nota-se que o libRadtran apresenta resultados sistematicamente menores, como indicam as figuras 21, 23, 25 e 28, para atmosfera com ou sem nuvem. Em atmosfera sem nuvens o resultado do libRadtran é cerca de 3,7 \% inferior aos resultados obtidos através do SBDART quando são consideradas variações no albedo de superfície e na coluna total de ozônio. É possivel determinar que a coluna total de ozônio não apresenta variação relevante nas refletâncias, conforme visto nas figuras 22 e 23. A refletância tem crescimento inferior a $5 \%$ considerando variações entre 200 e 400 DU.

Uma hipótese sugerida para explicar os resultados observados entre os modelos, é que as diferenças seriam resultados do uso de parametrizações e codificações mais modernas pelo libRadtran. Pode-se eliminar a hipótese de diferenças meramente devido aos algoritmos de integração, haja visto que resultados menores que do SBDART são vistos tanto para intervalos quanto para comprimento de onda únicos. Corroborando para essa hipótese tem-se as diferenças de comportamento entre refletâncias calculadas pelos dois modelos ao considerar variações de vapor na atmosfera entre 0 e $80 \mathrm{~mm}$ : os resultados do libRadtran chegam a ser $4 \%$ maiores que os calculados pelo SBDART. No entanto a variação é de 0,7 \% na refletância, que pode ser considerada desprezível nos demais desenvolvimentos deste trabalho. 
Ao comparar os dois modelos em atmosfera com nuvem os resultados obtidos para as refletâncias através do libRadtran também são inferiores ao SBDART em aproximadamente 4\%. Na presença de nuvem espessa $(\mathrm{COD}=50)$ o albedo de superfície $(<0,3)$ é responsável por uma variação na ordem de $0,5 \%$ nas refletâncias. Isso indica que é possível a utilização de albedo constante $=0,09$ para a determinação das look-up tables propostas sem prejudicar o resultado. Também nota-se que as refletâncias são constantes nos dois modelos para $C O D>20$ quando considerado o comprimento de onda de $3900 \mathrm{~nm}$ ou o intervalo IR.

Os dois códigos estudados apresentam comportamentos e tendências em geral convergentes, apesar das diferenças observadas. De fato, o libRadtran tem se tornado padrão dentro da comunidade de transferência radiativa e seu uso é adequado para desenvolver look-up tables para a recuperação de características microfísicas de nuvens. Todas as análises desta pesquisa consideraram os dois canais necessários para a determinação de raio efetivo e COD com base em refletâncias calculadas através de medidas do GOES-13. Assim, pode-se concluir que o libRadtran pode ser utilizado nas opções apresentadas, para confecção de look-up tables mais abrangentes, e confecção de diagramas do tipo Nakajima-King de outras situações de interesse.

Em estudo visando entender o impacto da altura da nuvem nas refletâncias calculadas nota-se, como o esperado, que o libRadtran apresenta refletâncias coincidentes para nuvens em posições diferentes quando considerado o canal 2, como na figura 35. Para comprimentos de onda no visível, canal 1, a posição do topo da nuvem altera as refletâncias calculadas. Na aplicação dos resultados obtidos neste trabalho para nuvens com diferentes alturas de topo pode ser utilizada uma correção percentual na refletância, calculada em nuvem de referência, em função da altura de topo. Esta correção pode ser escrita, para nuvens de água, como $\Delta \rho_{\%}(h)=0,38 h-1,56$, onde $\Delta \rho_{\%}$ é o percentual a ser adicionado à refletância a ser corrigida e h é a altura do topo em unidades de km. Para nuvens de gelo a correção pode ser escrita como $\Delta \rho_{\%}(h)=0,107 h-0,63$.

Após esses estudos, foi desenvolvida uma tabela de referência de valores de refletância para diversas situações típicas de observação da atmosfera amazônica pelo GOES-13. Através destes resultados é possível determinar os raios efetivos dos hidrometeoros até aproximadamente $30 \mu \mathrm{m}$ através de medidas de radiância pelo Canal 2 do Imager a bordo do GOES-13. Maiores investigações devem ser feitas para determinar precisamente a incerteza associada aos raios efetivos estimados através desse método, associando adequadamente as 
incertezas presentes tanto nas medidas tomadas quanto nos resultados obtidos através do libRadtran. Entretanto a tabela desenvolvida permite que maiores investigações acerca do tamanho dos hidrometeoros na Amazônia sejam feitas utilizando anos de dados já coletados pelo satélite, que não disponibiliza produtos de nuvens de raio efetivo.

Pugliese Silva et al. (2017) utilizaram os resultados obtidos neste trabalho para caracterizar o ciclo diurno de nuvens na Amazônia em três diferentes estações. É possível notar que nuvens da estação chuvosa possuem maior desenvolvimento vertical com hidrometeoros com maiores raios efetivos que os vistos nas estações secas. Também é possível perceber que a estação caracterizada por queima de biomassa possui nuvens com maior desenvolvimento vertical após 13h (hora local), e possui crescimento de hidrometeoros mais rápido que a estação seca não poluída. Pugliese Silva et al. (2017) indicam que a disponibilidade de aerossol na atmosfera pode alterar o ciclo de nuvens na região Amazônica e que há diferenças substanciais em suas características entre subestações da estação seca. Essa análise, que abrange dados do GOES entre 2010 e 2014, foi possível através da utilização direta das tabelas de referência pré-computadas desenvolvidas ao longo desta pesquisa.

Trabalhos que complementam esta pesquisa podem ser desenvolvidos no futuro abrangendo: comparação entre raios efetivos obtidos através das tabelas de referências desenvolvidas neste trabalho e por outros métodos/plataformas; estimativa da tendenciosidade associada ao uso de plataforma geoestacionária com resolução espacial de cerca de 4 km; uso desta abordagem para satélites geoestacionários da nova geração da série GOES-R, que possui melhores resoluções espaciais, temporais e radiométricas. 



\section{Referências}

G. P. Anderson, A. Berk, P. K. Acharya, M. W. Matthew, L. S. Bernstein, J. H. Chetwynd Jr, H. Dothe, S. M. Adler-Golden, A. J. Ratkowski, G. W. Felde, et al. Modtran4: radiative transfer modeling for remote sensing. In Remote Sensing, pages 2-10. International Society for Optics and Photonics, 1999.

M. Andreae, O. Acevedo, A. Araùjo, P. Artaxo, C. Barbosa, H. Barbosa, J. Brito, S. Carbone, X. Chi, B. Cintra, et al. The amazon tall tower observatory (atto): overview of pilot measurements on ecosystem ecology, meteorology, trace gases, and aerosols. Atmospheric Chemistry and Physics, 15(18):10723-10776, 2015.

P. Artaxo, P. H. Oliveira, L. L. Lara, T. M. Pauliquevis, L. V. Rizzo, C. Pires-Jr, M. A. Paixão, K. M. Longo, S. Freitas, and A. L. Correia. Efeitos climáticos de partículas de aerossóis biogênicos e emitidos em queimadas na amazônia. Revista Brasileira de Meteorologia, 21(3):1-22, 2006.

P. Artaxo, L. V. Rizzo, J. F. Brito, H. M. Barbosa, A. Arana, E. T. Sena, G. G. Cirino, W. Bastos, S. T. Martin, and M. O. Andreae. Atmospheric aerosols in amazonia and land use change: from natural biogenic to biomass burning conditions. Faraday discussions, 165:203-235, 2013.

B. A. Baum, P. Yang, A. J. Heymsfield, S. Platnick, M. D. King, Y. Hu, and S. T. Bedka. Bulk scattering properties for the remote sensing of ice clouds. part ii: Narrowband models. Journal of Applied Meteorology, 44(12):1896-1911, 2005.

B. A. Baum, P. Yang, S. Nasiri, A. K. Heidinger, A. Heymsfield, and J. Li. Bulk scattering properties for the remote sensing of ice clouds. part iii: High-resolution spectral models from 100 to $3250 \mathrm{~cm}-1$. Journal of applied meteorology and climatology, 46(4):423-434, 2007.

P. Beckmann and A. Spizzichino. The scattering of electromagnetic waves from rough surfaces. Norwood, MA, Artech House, Inc., 1987, 511 p., 1987.

A. Berk, G. P. Anderson, L. S. Bernstein, P. K. Acharya, H. Dothe, M. W. Matthew, S. M. Adler-Golden, J. H. Chetwynd Jr, S. C. Richtsmeier, B. Pukall, et al. Modtran 4 
radiative transfer modeling for atmospheric correction. In Proceedings of SPIE- The International Society for Optical Engineering, volume 3756, pages 348-353, 1999.

H. Brumberger. Modern Aspects of Small-Angle Scattering. Nato Science Series C:. Springer Netherlands, 2013. ISBN 9789401584579.

L. Bugliaro, T. Zinner, C. Keil, B. Mayer, R. Hollmann, M. Reuter, and W. Thomas. and Physics Validation of cloud property retrievals with simulated satellite radiances : a case study for SEVIRI. pages 5603-5624, 2011. doi: 10.5194/acp-11-5603-2011.

C. Cao, J. Xiong, S. Blonski, Q. Liu, S. Uprety, X. Shao, Y. Bai, and F. Weng. Suomi npp viirs sensor data record verification, validation, and long-term performance monitoring. Journal of Geophysical Research: Atmospheres, 118(20), 2013.

S. Chandrasekhar. Radiative Transfer. Dover Books on Intermediate and Advanced Mathematics. Dover Publications, 1960. ISBN 9780486605906.

G. Cirino, R. Souza, D. Adams, and P. Artaxo. The effect of atmospheric aerosol particles and clouds on net ecosystem exchange in the amazon. Atmospheric Chemistry and Physics, 14(13):6523, 2014.

A. A. Costa, T. M. P. Júnior, E. P. de Souza, J. A. Martins, M. Yamasoe, and M. d. F. Andrade. Aerossóis Atmosféricos e Nuvens. In Primeiro Relatório de Avaliação Nacional - Vol1, chapter 6, pages 209-236. Painel Brasileiro de Mudanças Climáticas, 2015.

C. Emde, R. Buras-schnell, A. Kylling, B. Mayer, J. Gasteiger, U. Hamann, J. Kylling, B. Richter, C. Pause, T. Dowling, and L. Bugliaro. The libRadtran software package for radiative transfer calculations ( version 2 . 0 . 1 ). pages 1647-1672, 2016. doi: 10.5194/gmd-9-1647-2016.

L. V. Ferreira, S. S. Almeida, A. D. Dário, and P. Parolin. Riqueza e composição de espécies da floresta de igapó e várzea da estação científica Ferreira Penna: subsídios para o plano de manejo da Floresta Nacional de Caxiuanã. Pesquisas, Botânica, 56: 103-116, 2005.

J. Fischer, R. Gamache, A. Goldman, L. Rothman, and A. Perrin. Total internal partition sums for molecular species in the 2000 edition of the hitran database. Journal of Quantitative Spectroscopy and Radiative Transfer, 82(1):401-412, 2003. 
Q. Fu. An accurate parameterization of the solar radiative properties of cirrus clouds for climate models. Journal of Climate, 9(9):2058-2082, 1996.

Q. Fu, P. Yang, and W. Sun. An accurate parameterization of the infrared radiative properties of cirrus clouds for climate models. Journal of climate, 11(9):2223-2237, 1998.

R. D. Garc, V. E. Cachorro, E. Cuevas, A. Redondas, and A. Berj. Comparison of measured and modeled UV spectral irradiance at the Izaña station based on LibRadtran and UVA - GOA models Comparación entre la irradiancia espectral UV medida experimentalmente en la estación de Izaña y simulada con los modelos de transferen. 45(1):11-15, 2012.

J. Gasteiger, C. Emde, B. Mayer, R. Buras, S. Buehler, and O. Lemke. Representative wavelengths absorption parameterization applied to satellite channels and spectral bands. Journal of Quantitative Spectroscopy and Radiative Transfer, 148:99-115, 2014.

M. Goulding, R. Barthem, E. Ferreira, et al. The smithsonian atlas of the amazon. 2003.

D. A. Gouveia. Caracterização de nuvens cirrus na região da Amazônia central utilizando um lidar em solo. PhD thesis, Universidade de São Paulo, 2014.

A. K. Heidinger, Y. Li, B. A. Baum, R. E. Holz, S. Platnick, and P. Yang. Retrieval of Cirrus Cloud Optical Depth under Day and Night Conditions from MODIS Collection 6 Cloud Property Data. (January 2010):7257-7271, 2015. doi: 10.3390/rs70607257.

W. Hergert and T. Wriedt. The Mie Theory: Basics and Applications. Springer Series in Optical Sciences. Springer Berlin Heidelberg, 2012. ISBN 9783642287381.

B. N. Holben. Characteristics of maximum-value composite images from temporal avhrr data. International journal of remote sensing, 7(11):1417-1434, 1986.

H. Hottel and E. Cohen. Radiant heat exchange in a gas-filled enclosure: Allowance for nonuniformity of gas temperature. AIChE Journal, 4(1):3-14, 1958.

J. R. Howell. The monte carlo method in radiative heat transfer. Transactions-American Society of Mechanical Engineers Journal of Heat Transfer, 120:547-560, 1998.

Y. Hu and K. Stamnes. An accurate parameterization of the radiative properties of water clouds suitable for use in climate models. Journal of climate, 6(4):728-742, 1993. 
H. Hulst and H. van de Hulst. Light Scattering by Small Particles. Dover Books on Physics. Dover Publications, 1957. ISBN 9780486642284.

M. Iqbal. An Introduction To Solar Radiation. Elsevier Science, 2012. ISBN 9780323151818.

S. Kato, T. P. Ackerman, J. H. Mather, and E. E. Clothiaux. The k-distribution method and correlated-k approximation for a shortwave radiative transfer model. Journal of Quantitative Spectroscopy and Radiative Transfer, 62(1):109-121, 1999.

Y. J. Kaufman and T. Nakajima. Effect of Amazon smoke on cloud microphysics and albedo - Analysis from Satellite Imagery, 1993. ISSN 0894-8763.

J. R. Key, P. Yang, B. A. Baum, and S. L. Nasiri. Parameterization of shortwave ice cloud optical properties for various particle habits. Journal of Geophysical Research: Atmospheres, 107(D13), 2002.

M. D. King, Y. J. Kaufman, W. P. Menzel, and D. Tanre. Remote sensing of cloud, aerosol, and water vapor properties from the moderate resolution imaging spectrometer (modis). IEEE Transactions on Geoscience and Remote Sensing, 30(1):2-27, 1992a.

M. D. King, Y. J. Kaufman, W. P. Menzel, and D. Tanre. Remote sensing of cloud, aerosol, and water vapor properties from the moderate resolution imaging spectrometer (modis). IEEE Transactions on Geoscience and Remote Sensing, 30(1):2-27, $1992 \mathrm{~b}$.

F. X. Kneizys, E. Shettle, L. Abreu, J. Chetwynd, and G. Anderson. Users guide to lowtran 7. Technical report, AIR FORCE GEOPHYSICS LAB HANSCOM AFB MA, 1988.

R. L. Kurucz. Synthetic infrared spectra. In Infrared solar physics, pages 523-531. Springer, 1994.

A. Kylling, K. Stamnes, and S.-C. Tsay. A reliable and efficient two-stream algorithm for spherical radiative transfer: Documentation of accuracy in realistic layered media. Journal of Atmospheric Chemistry, 21(2):115-150, 1995.

K. Liou. An Introduction to Atmospheric Radiation. International Geophysics. Elsevier Science, 2002. ISBN 9780080491677. 
Z. Liu, M. Vaughan, D. Winker, C. Kittaka, B. Getzewich, R. Kuehn, A. Omar, K. Powell, C. Trepte, and C. Hostetler. The calipso lidar cloud and aerosol discrimination: Version 2 algorithm and initial assessment of performance. Journal of Atmospheric and Oceanic Technology, 26(7):1198-1213, 2009.

A. Marshak, J. V. Martins, V. Zubko, and Y. Kaufman. What does reflection from cloud sides tell us about vertical distribution of cloud droplet sizes? Atmospheric Chemistry and Physics, 6(12):5295-5305, 2006.

B. Mayer and A. Kylling. Technical note : The libRadtran software package for radiative transfer calculations - description and examples of use. Atmospheric Chemistry and Physics, 5:1855-1877, 2005.

B. Mayer, M. Schröder, R. Preusker, and L. Schüller. Remote sensing of water cloud droplet size distributions using the backscatter glory: a case study. Atmospheric Chemistry and Physics Discussions, 4(3):2239-2262, 2004. ISSN 16807375. doi: 10.5194/ acpd-4-2239-2004. URL http://www . atmos-chem-phys-discuss . net/4/2239/2004/.

B. Mayer, A. Kylling, C. Emde, U. Hamann, and R. Buras. libradtran user's guide. Edition for libRadtran version, 1, 2012.

W. P. Menzel, R. A. Frey, and B. A. Baum. Cloud top properties and cloud phase algorithm theoretical basis document. Technical Report May, 2015.

H. Morrison, J. a. Curry, M. D. Shupe, and P. Zuidema. A New Double-Moment Microphysics Parameterization for Application in Cloud and Climate Models. Part I: Description. Journal of the Atmospheric Sciences, 62(May 1998):1678-1693, 2005. ISSN 0022-4928. doi: $10.1175 / J A S 3447.1$.

T. Nakajima and M. D. King. Determination of the Optical Thickness and Effective Particle Radius of Clouds from Reflected Solar Radiation Measurements . Part I : Theory. Journal of the Atmospheric Sciences, 47(15), 1990.

C. A. Nobre, G. Sampaio, and L. Salazar. Climate and land use changes in amazonia: Impacts on the hydrological cycle and on biome distribution. Water and the Environment, $12: 144,2005$. 
M. Obregón, A. Serrano, M. J. Costa, and A. M. Silva. Validation of libradtran and sbdart models under different aerosol conditions. In IOP Conference Series: Earth and Environmental Science, volume 28, page 012010. IOP Publishing, 2015.

T. Pauliquevis, P. Artaxo, P. H. Oliveira, and M. Paixão. O papel das partículas de aerossol no funcionamento do ecossistema amazônico. Ciência e Cultura, 59(3):48-50, 2007.

S. Platnick, M. D. King, S. A. Ackerman, W. P. Menzel, B. A. Baum, J. C. Riédi, and R. A. Frey. The modis cloud products: Algorithms and examples from terra. IEEE Transactions on Geoscience and Remote Sensing, 41(2):459-473, 2003.

A. C. PugliesiSilva, A. L. Correia, and M. M. Mendonca. Study of the diurnal cycle of microphysical properties of clouds in the Amazon Basin using GOES measurements. Poster. 2017.

P. Ricchiazzi. Input documentation for sbdart. University of California, Santa Barbara, 2002.

P. Ricchiazzi, S. Yang, C. Gautier, and D. Sowle. SBDART: A Research and Teaching Software Tool for Plane-Parallel Radiative Transfer in the Earth's Atmosphere. pages 2101-2114, 1983.

D. Rosenfeld and G. Gutman. Retrieving microphysical properties near the tops of potential rain clouds by multispectral analysis of AVHRR data. Atmospheric Research, 34:359-283, 1994.

D. Rosenfeld and I. M. Lensky. (Satellite-based insights into precipitation formation processes in continental and maritime convective clouds. Bulletin of the American Meteorological Society, 79(11):2457-2476, 1998.

D. Rosenfeld, M. O. Andreae, A. Asmi, M. Chin, G. Leeuw, D. P. Donovan, R. Kahn, S. Kinne, N. Kivekäs, M. Kulmala, et al. Global observations of aerosol-cloudprecipitation-climate interactions. Reviews of Geophysics, 52(4):750-808, 2014.

W. B. Rossow. International satellite cloud climatology project (isccp) stage d1 3-hourly cloud product-revised algorithm in hierarchical data format (isccp_d1). 2011. 
L. F. Salazar, C. A. Nobre, and M. D. Oyama. Climate change consequences on the biome distribution in tropical south america. Geophysical Research Letters, 34(9), 2007.

R. Schiffer and W. B. Rossow. The international satellite cloud climatology project(isccp)the first project of the world climate research programme. American Meteorological Society, Bulletin, 64:779-784, 1983.

J. H. Seinfeld and S. N. Pandis. Atmospherc Chemistry and Physics: From Air Pollution to Climate Change, 1998.

E. T. Sena. Variabilidade espacial e temporal da forçante radiativa direta de aerossóis de queimadas e os efeitos da mudança de uso do solo na Amazônia. PhD thesis, Universisdade de São Paulo, 2013.

P. W. Stackhouse and G. L. Stephens. A theoretical and observational study of the radiative properties of cirrus: Results from fire 1986. Journal of the Atmospheric Sciences, 48 (18):2044-2059, 1991.

K. Stamnes, S.-c. Tsay, W. Wiscombe, and K. Jayaweera. Numerically stable algorithm for discrete-ordinate-method radiative transfer in multiple scattering and emitting layered media. (1), 1988.

K. Stamnes, S.-C. Tsay, and I. Laszlo. DISORT , a General-Purpose Fortran Program for Discrete-Ordinate-Method Radiative Transfer in Scattering and Emitting Layered Media : Documentation of Methodology. Technical report, 2000.

G. L. Stephens, D. G. Vane, R. J. Boain, G. G. Mace, K. Sassen, Z. Wang, A. J. Illingworth, E. J. O'Connor, W. B. Rossow, S. L. Durden, et al. The cloudsat mission and the a-train: A new dimension of space-based observations of clouds and precipitation. Bulletin of the American Meteorological Society, 83(12):1771-1790, 2002.

S. Twomey. The Composition of Cloud Nuclei. Journal of the Atmospheric Sciences, 28: 377-380, 1971.

S. Twomey. The Influence of Pollution on the Shotwave Albedo of Clouds. Journal of Atmospheric Sciences, 34:1549 - 1552, 1977.

J. Wallace and P. Hobbs. Atmospheric Science: An Introductory Survey. International Geophysics. Elsevier Science, 2006. ISBN 9780080499536. 
J. Wang, G. Bisht, R. Knox, and R. L. Bras. Impact of deforestation in the Amazon basin on cloud climatology. Proceedings of the National Academy of Sciences, 106(10): 3670-3674, 2009.

B. A. Wielicki, B. R. Barkstrom, E. F. Harrison, R. B. Lee III, G. Louis Smith, and J. E. Cooper. Clouds and the earth's radiant energy system (ceres): An earth observing system experiment. Bulletin of the American Meteorological Society, 77(5):853-868, 1996.

W. J. Wiscombe. Improved mie scattering algorithms. Applied optics, 19(9):1505-1509, 1980

T. Wriedt. Mie theory: a review. In The Mie Theory, pages 53-71. Springer, 2012.

K. Wyser. The Effective Radius in Ice Clouds. Journal of Climate, II:1793-1802, 1998.

M. Yamasoe and M. P. Corrêa. Processos radiativos na atmosfera - Fundamentos. OFICINA DE TEXTOS, 2016. ISBN 9788579752292.

P. Yang, K. Liou, K. Wyser, and D. Mitchell. Parameterization of the scattering and absorption properties of individual ice crystals. Journal of Geophysical Research: Atmospheres, 105(D4):4699-4718, 2000.

P. Yang, L. Bi, B. A. Baum, K.-N. Liou, G. W. Kattawar, M. I. Mishchenko, and B. Cole. Spectrally consistent scattering, absorption, and polarization properties of atmospheric ice crystals at wavelengths from 0.2 to $100 \mu \mathrm{m}$. Journal of the Atmospheric Sciences, 70(1):330-347, 2013.

W. Zdunkowski, T. Trautmann, and A. Bott. Radiation in the atmosphere: a course in theoretical meteorology. Cambridge University Press, 2007. 
Apêndices 



\section{Parâmetros para produção de tabela de referência - Canal 2}

\begin{tabular}{|c|c|c|}
\hline Parâmetro & Valores & Observações \\
\hline VZA & $10^{\circ}, 20^{\circ}$ e $30^{\circ}$ & \\
\hline PHI & $30^{\circ}$ e $150^{\circ}$ & $($ PHI_0 = 0) \\
\hline SZA & $0,5,10,15, \ldots, 75^{\circ}$ & \\
\hline Albedo de superfície & 0,09 & \\
\hline Intervalo de comprimento de onda & $3700 \mathrm{~nm}$ a $4200 \mathrm{~nm}$ & $\begin{array}{l}\text { Com uso de filter } \\
\text { function } \\
\text { correspondente ao } \\
\text { canal } 2\end{array}$ \\
\hline Perfil atmosférico & Tropical & $\begin{array}{l}\text { (disponível no } \\
\text { libRadtran) }\end{array}$ \\
\hline Vapor d'água & $6.0 \mathrm{~cm}$ & \\
\hline COD & 50 & \\
\hline Cobertura de nuvem & $100 \%$ & \\
\hline Hábitos & general habit mix & $\begin{array}{l}\text { “ic_habit ghm” no } \\
\text { libRadtran }\end{array}$ \\
\hline Parametrização de gelo & Baum et al. 2005 & $\begin{array}{l}\text { “ic_properties } \\
\text { baum_v36” no } \\
\text { libRadtran }\end{array}$ \\
\hline Posição de nuvem & Entre 4 e 6 km & \\
\hline Raios efetivos (um) & $\begin{array}{l}\text { 2.0, 2.5, 3.0, 3.5, 4.0, 4.5, 5.0, 5.5, 6.0, 6.5, } \\
\text { 7.0, 7.5, 8.0, 8.5, 9.0, 9.5, 10.0, 10.5, 11.0, } \\
\text { 11.5, 12.0, 12.5, 13.0, 13.5, 14.0, 14.5, } \\
\text { 15.0, 15.5, 16.0, 16.5, 17.0, 17.5, 18.0, } \\
\text { 18.5, 19.0, 19.5, 20.0, 20.5, 21.0, 21.5, } \\
\text { 22.0, 22.5, 23.0, 23.5, 24.0, 24.5, 25.0, } \\
\text { 25.5, 26.0, 26.5, 27.0, 27.5, 28.0, 28.5, } \\
\text { 29.0, 29.5, 30.0, 31.0, 32.0, 33.0, 34.0, } \\
\text { 35.0, 36.0, 37.0, 38.0, 39.0, 40.0, 41.0, } \\
\text { 42.0, 43.0, 44.0, 45.0, 46.0, 47.0, 48.0, } \\
\text { 49.0, 50.0, 51.0, 52.0, 53.0, 54.0, 55.0, } \\
56.0,57.0,58.0,59.0\end{array}$ & \\
\hline
\end{tabular}




\section{Parâmetros para produção de tabela de referência - Comprimento de onda central}

\begin{tabular}{|c|c|c|}
\hline Parâmetro & Valores & Observações \\
\hline VZA & $10^{\circ}, 20^{\circ}$ e $30^{\circ}$ & \\
\hline PHI & $30^{\circ}$ e $150^{\circ}$ & $($ PHI_0 = 0) \\
\hline SZA & $0,5,10,15, \ldots, 75^{\circ}$ & \\
\hline Albedo de superfície & 0.09 & \\
\hline Comprimentos de onda & $630 \mathrm{~nm}$ e $3900 \mathrm{~nm}$ & \\
\hline Perfil atmosférico & Tropical & $\begin{array}{l}\text { (disponível no } \\
\text { libRadtran) }\end{array}$ \\
\hline Vapor d'água & $6.0 \mathrm{~cm}$ & \\
\hline CODs & $\begin{array}{l}\text { 1.0, 2.0, 4.0, 6.0, 8.0, 10.0, 14.0, 16.0, 20.0, } \\
25.0,30.0,40.0,50.0\end{array}$ & \\
\hline Cobertura de nuvem & $100 \%$ & \\
\hline Hábitos & general habit mix & $\begin{array}{l}\text { "ic_habit ghm” no } \\
\text { libRadtran }\end{array}$ \\
\hline Parametrização de gelo & Baum et al. 2005 & $\begin{array}{l}\text { “ic_properties } \\
\text { baum_v36” no } \\
\text { libRadtran }\end{array}$ \\
\hline Posição de nuvem & Entre 4 e 6 km & \\
\hline Raios efetivos (um) & $\begin{array}{l}\text { 2.0, 2.5, 3.0, 3.5, 4.0, 4.5, 5.0, 5.5, 6.0, 6.5, } \\
\text { 7.0, 7.5, 8.0, 8.5, 9.0, 9.5, 10.0, 10.5, 11.0, } \\
\text { 11.5, 12.0, 12.5, 13.0, 13.5, 14.0, 14.5, } \\
\text { 15.0, 15.5, 16.0, 16.5, 17.0, 17.5, 18.0, } \\
\text { 18.5, 19.0, 19.5, 20.0, 20.5, 21.0, 21.5, } \\
\text { 22.0, 22.5, 23.0, 23.5, 24.0, 24.5, 25.0, } \\
\text { 25.5, 26.0, 26.5, 27.0, 27.5, 28.0, 28.5, } \\
\text { 29.0, 29.5, 30.0, 31.0, 32.0, 33.0, 34.0, } \\
\text { 35.0, 36.0, 37.0, 38.0, 39.0, 40.0, 41.0, } \\
\text { 42.0, 43.0, 44.0, 45.0, 46.0, 47.0, 48.0, } \\
\text { 49.0, 50.0, 51.0, 52.0, 53.0, 54.0, 55.0, } \\
\text { 56.0, 57.0, 58.0, 59.0 }\end{array}$ & \\
\hline
\end{tabular}


